\title{
Reconstructing Deglacial Ocean Ventilation Using Radiocarbon: Data and Inverse Modeling
}

\author{
By \\ Ning Zhao \\ B.S., Nanjing University, 2011 \\ Submitted in partial fulfillment of the requirements for the degree of \\ Doctor of Philosophy \\ at the \\ MASSACHUSETTS INSTITUTE OF TECHNOLOGY \\ and the \\ WOODS HOLE OCEANOGRAPHIC INSTITUTION
}

February 2017

(C) 2017 Ning Zhao

All rights reserved.

The author hereby grants to MIT and WHOI permission to reproduce and to distribute publicly paper and electronic copies of this thesis document in whole or in part in any medium now known or hereafter created.

Signature of Author

Joint Program in Oceanography/Applied Ocean Science and Engineering Massachusetts Institute of Technology and Woods Hole Oceanographic Institution January 9, 2017

Certified by

Lloyd D. Keigwin

Senior Scientist, Department of Geology and Geophysics, WHOI

Thesis Supervisor

Accepted by

Timothy L. Grove Professor, Department of Earth, Atmospheric, and Planetary Sciences, MIT Chair, Joint Committee for Marine Geology and Geophysics 


\title{
Reconstructing Deglacial Ocean Ventilation Using Radiocarbon: Data and Inverse Modeling
}

\begin{abstract}
By
Ning Zhao

Submitted to the MIT/WHOI Joint Program in Oceanography/Applied Ocean Science and Engineering on Jan 9, 2017 in partial fulfillment of the requirements for the degree of Doctor of Philosophy

ABSTRACT

Significant changes occurred during the last deglaciation (roughly 10-20 thousand years (ka) before present) throughout the climate system. The ocean is a large reservoir of carbon and heat, however, its role during the deglaciation is still not well understood. In this thesis, I rely on radiocarbon measurements on fossil biogenic carbonates sampled from the seafloor to constrain deglacial ocean ventilation rates, using new data, an extensive data compilation, and inverse modeling. First, based on a sediment core that is absolutely dated from wooden remains, I argue that the deglacial ${ }^{14} \mathrm{C}$ reservoir age of the upper East Equatorial Pacific was not very different from today. Combined with stable carbon isotope data, the results suggest that the deglacial atmospheric $\mathrm{CO}_{2}$ rise was probably due to $\mathrm{CO}_{2}$ released directly from the ocean (e.g., in the Southern Ocean) to the atmosphere rather than first mixed through the upper ocean. Then using a high-deposition-rate sediment core located close to deep water formation regions in the western North Atlantic, I show that compared to today, the mid-depth water production in the North Atlantic was probably stronger during the Younger Dryas cold episode, and weaker during other intervals of the late deglaciation. However, the change was not as large as suggested by previous studies. Finally, I compile published and unpublished deep ocean ${ }^{14} \mathrm{C}$ data, and find that the ${ }^{14} \mathrm{C}$ activity of the deep ocean mirrors that of the atmosphere during the past $25 \mathrm{ka}$. A box model of modern ocean circulation is fit to the compiled data using an inverse method. I find that the residuals of the fit can generally be explained by the data uncertainties, implying that the compiled data jointly do not provide strong evidence for basin-scale ventilation changes. Overall, this thesis suggests that, although deep ocean ventilation may have varied at some locations during the last deglaciation, the occurrence of basin-scale ventilation changes are much more difficult to be put on a firm footing. An imbalance between cosmogenic production and radioactive decay appears as the most natural explanation for the deglacial ${ }^{14} \mathrm{C}$ activity decline observed in both the atmosphere and the deep ocean.
\end{abstract}

Thesis Supervisor: Dr. Lloyd D. Keigwin (Senior Scientist, Department of Geology and Geophysics, WHOI) 


\section{Acknowledgements}

First, I would like to thank my advisor Lloyd Keigwin. Lloyd is always supportive, encouraging and enthusiastic about my research. He afforded me lots of freedom in my thesis work. What's more, he always has interesting stories to share! I also want to thank Oliver Marchal, who is in my thesis committee and also supervises Chapter 4 of this thesis, for his generosity with his time and help in the past two years. Thanks also to the other members of my thesis committee Delia Oppo, Ed Boyle and David McGee for their guidance during different stages of my PhD study in the MITWHOI Joint Program.

Many people have helped me in various aspects during my $\mathrm{PhD}$ study. I would like to thank Mary Carman for her help with lab work and the care she gave to me, a foreign student in the US. Ann McNichol, Al Gagnon, Li Xu and all other members in the National Ocean Science Accelerator Mass Spectrometry Facility (NOSAMS) prep lab has been extremely helpful for the production of the data used in my thesis. This thesis would not be possible without their help. Dan Amrhein and Jake Gebbie helped me with Chapter 4, from coding to better understanding of inverse modeling. Jake also kindly took the time to chair my defense. I also want to express my gratitude to all the people in the Academic Program Office and Eilean Kozak in McLean Lab who made my life in the Joint Program easier. A great thing about the Joint Program is that you can find experts to talk to in various fields. Discussions with David Thornalley, Weifu Guo, Denner Huang, Liviu Giosan among many other scientists have always been very helpful.

It has been a great experience to meet so many nice and smart JP students, with whom I had lots of insightful conversations. I am also grateful for the time that I spent together with other Chinese students in EAPS at MIT and the Chinese community at WHOI. Thanks to Jingyu for the company in Boston. At last, I want to give my biggest thanks to my parents for their persistent love and support.

This research was supported by NSF-OCE grants 0822854 to Lloyd Keigwin, 1031224 to Lloyd Keigwin, 1204045 to Lloyd Keigwin, 1301907 to Olivier Marchal, Geoffrey Gebbie and Lloyd Keigwin, and 1405160 to Lloyd Keigwin, WHOI Academic Programs Endowed Funds, the Ocean Ventures Fund from WHOI, and a graduate student internship from NOSAMS. 


\section{Table of Contents}

Chapter 1. Introduction ..........................................................................................................

Chapter 2. An atmospheric chronology for Panama Basin and deglacial Pacific thermocline ventilation.................................................................................................... 14

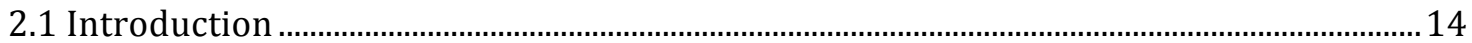

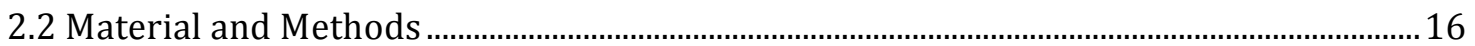

2.3 Results and Discussion .....................................................................................................................19

2.4 Summary

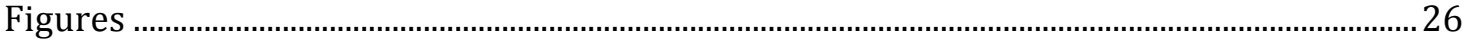

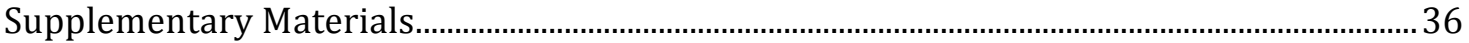

Chapter 3. Strong mid-depth water production in the subpolar North Atlantic during

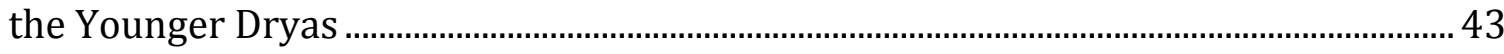

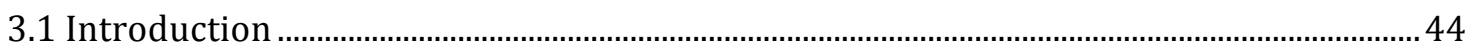

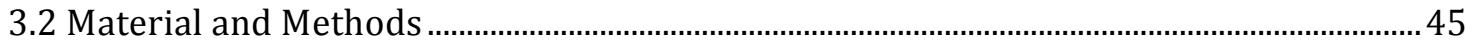

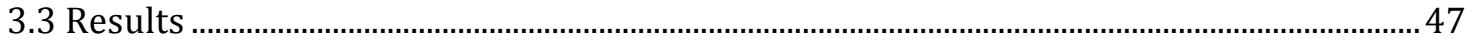

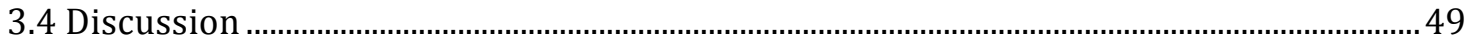

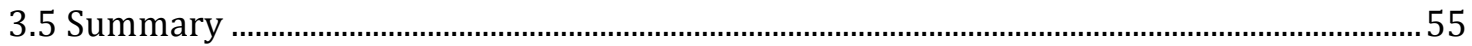

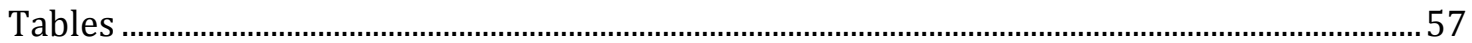

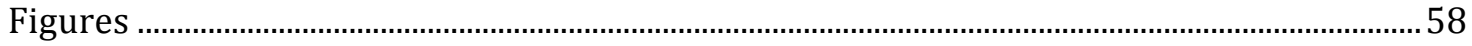

Chapter 4. A synthesis of deglacial deep-sea radiocarbon records and a test of their

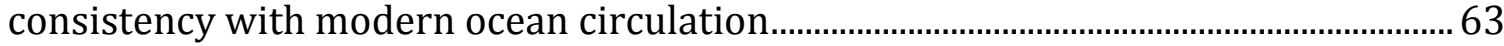

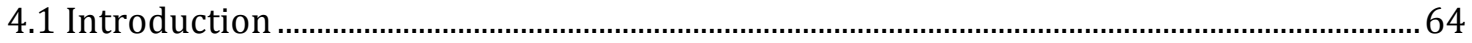

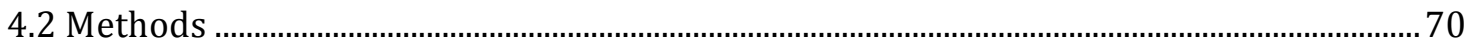

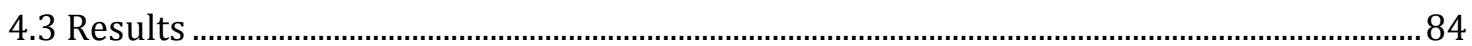

4.4 Discussion .................................................................................................................... 92

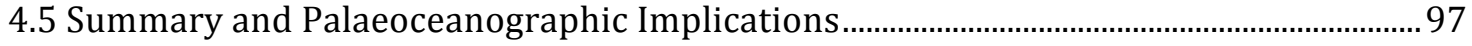

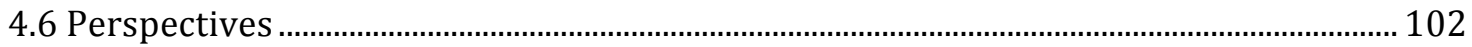

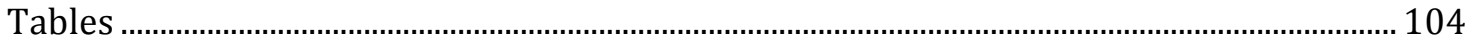

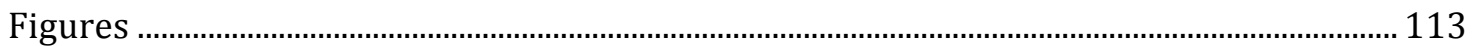

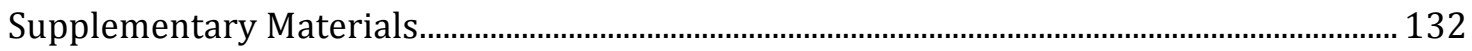

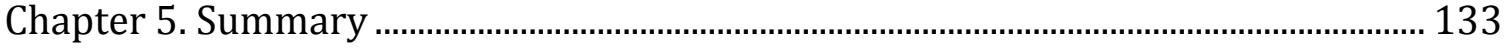

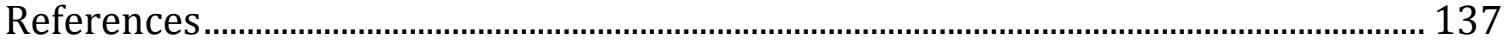




\section{Chapter 1. Introduction}

Today we live in an interglacial world, with sizeable ice sheets confined to Antarctica and Greenland. However, about 20 thousand years before present (ka BP), some other continental regions were also covered with ice sheets (e.g., Clark et al., 2009), the most significant one being the Laurentide Ice Sheet over North America (Fig. 1.1, Dyke, 2004). Associated with the large volume of ice on land was a global sea level drop estimated to $\sim 120-130$ m (Clark et al., 2009). The transition from the glacial period to the Holocene, our current warm interglacial period, is named the last deglaciation or the last termination, and lasted roughly from 20 to 10 ka BP. Significant changes of the global climate took place during this transition as shown by many paleoclimatic records. For instance, the $\mathrm{CO}_{2}$ concentration in the atmosphere increased by $\sim 80$ ppmv (Monnin et al., 2001; Fig. 1.2) and the global mean temperature increased by more than $3^{\circ} \mathrm{C}$ (Shakun et al., 2012; Fig. 1.2).

Since the ocean is an important reservoir of carbon and heat, its evolution during the deglaciation has been the focus of many studies (for recent studies, see, e.g., Jaccard et al., 2016; Martínez-Botí et al., 2015; Skinner et al., 2014; Winckler et al., 2016). One important research topic is how the ocean was ventilated during this interval, as ocean ventilation is related to the transport of carbon and heat between the atmosphere and the ocean as well as within the ocean itself (e.g., Boyle and Keigwin, 1987; McManus et al., 2004; Skinner et al., 2010; Stephens and Keeling, 2000). For example, the synchronicity between the changes of atmospheric $\mathrm{CO}_{2}$ concentration and Antarctic temperatures suggests that some processes in the 
Southern Ocean (e.g., sea ice cover, stratification, etc.) might have played an important role in the deglacial $\mathrm{CO}_{2}$ rise (Fischer et al., 2010; Parrenin et al., 2013; Sigman and Boyle, 2000; also see Fig. 1.2).

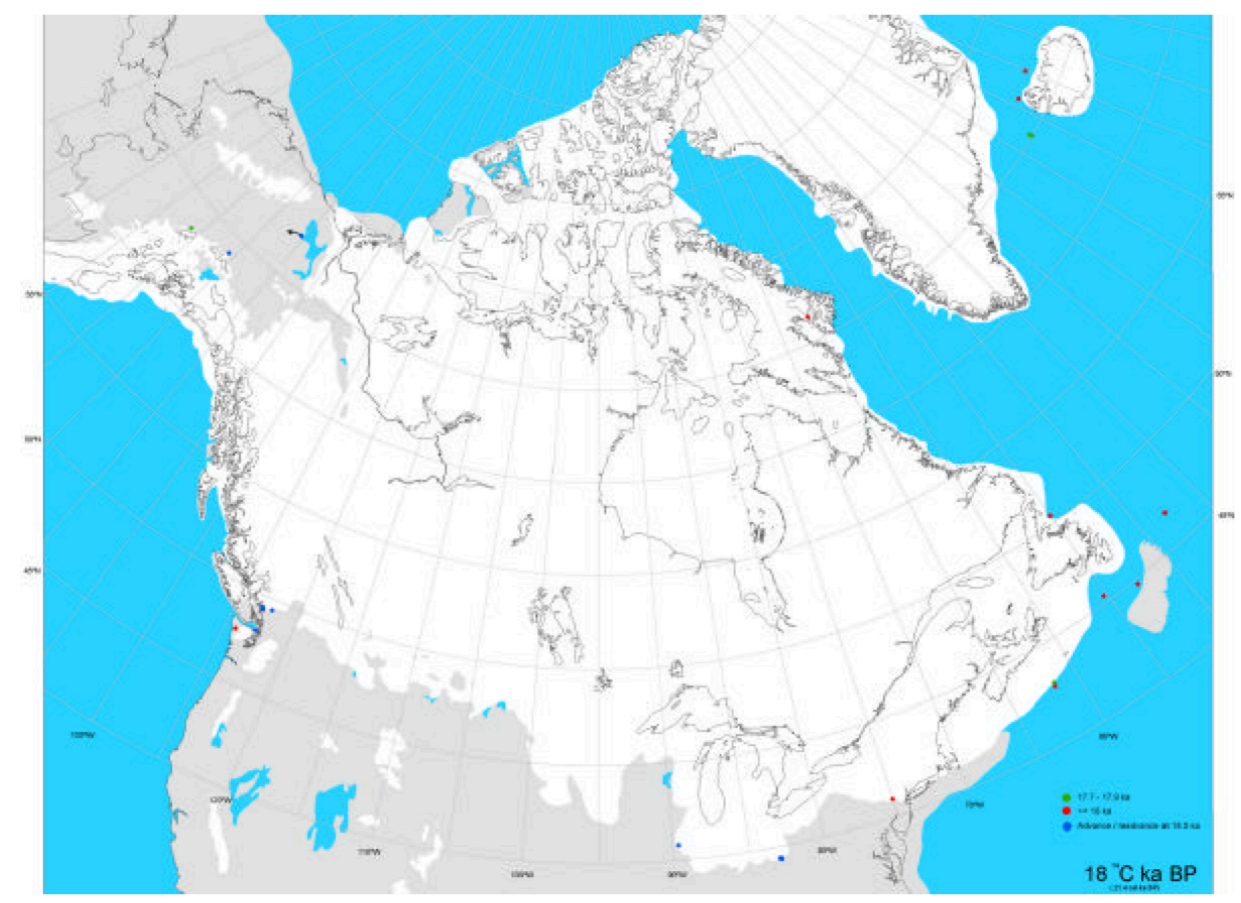

Fig. 1.1 Ice sheet cover on the North American continent at $18{ }^{14} \mathrm{C}$ ka BP (about $21 \mathrm{cal}$ ka BP). Note the sea level drop at this time (e.g., exposure of the Bering Strait). Figure from Dyke (2004).

Among the various chemical and isotopic proxies commonly employed in paleoclimate reconstructions, radiocarbon is one that is often used to study deep ocean ventilation in the past. Since radiocarbon measurements approach the detection limit after about ten half lives $\left({ }^{14} \mathrm{C}\right.$ half life $=5,700 \pm 30 \mathrm{yr}$; Audi et al., 2003), ${ }^{14} \mathrm{C}$ data are usually reported only for the last $\sim 50$ ka (e.g., Reimer et al., 2013). However, ${ }^{14} \mathrm{C}$ appears as an ideal tracer for deglacial changes in deep ocean ventilation, not only because it has an appropriate half-life for this purpose but also 
because the various sources of isotopic fractionation, such as due to air-sea $\mathrm{CO}_{2}$ exchange and photosynthesis, can be corrected for. With the cosmogenic production in the atmosphere as its only source and a well known radioactive decay rate, radiocarbon serves as a natural clock to study the rates of a variety of natural processes in our environment, in particular rates of deep ocean ventilation (e.g., Broecker and Peng, 1982). A compilation of deep ocean radiocarbon data for the past $40 \mathrm{ka}$ or so shows that most of these data $(>70 \%)$ occur in the time interval from 20 to 10 ka BP (Fig. 1.3), reflecting the large interest in using radiocarbon for deglacial ocean reconstructions.

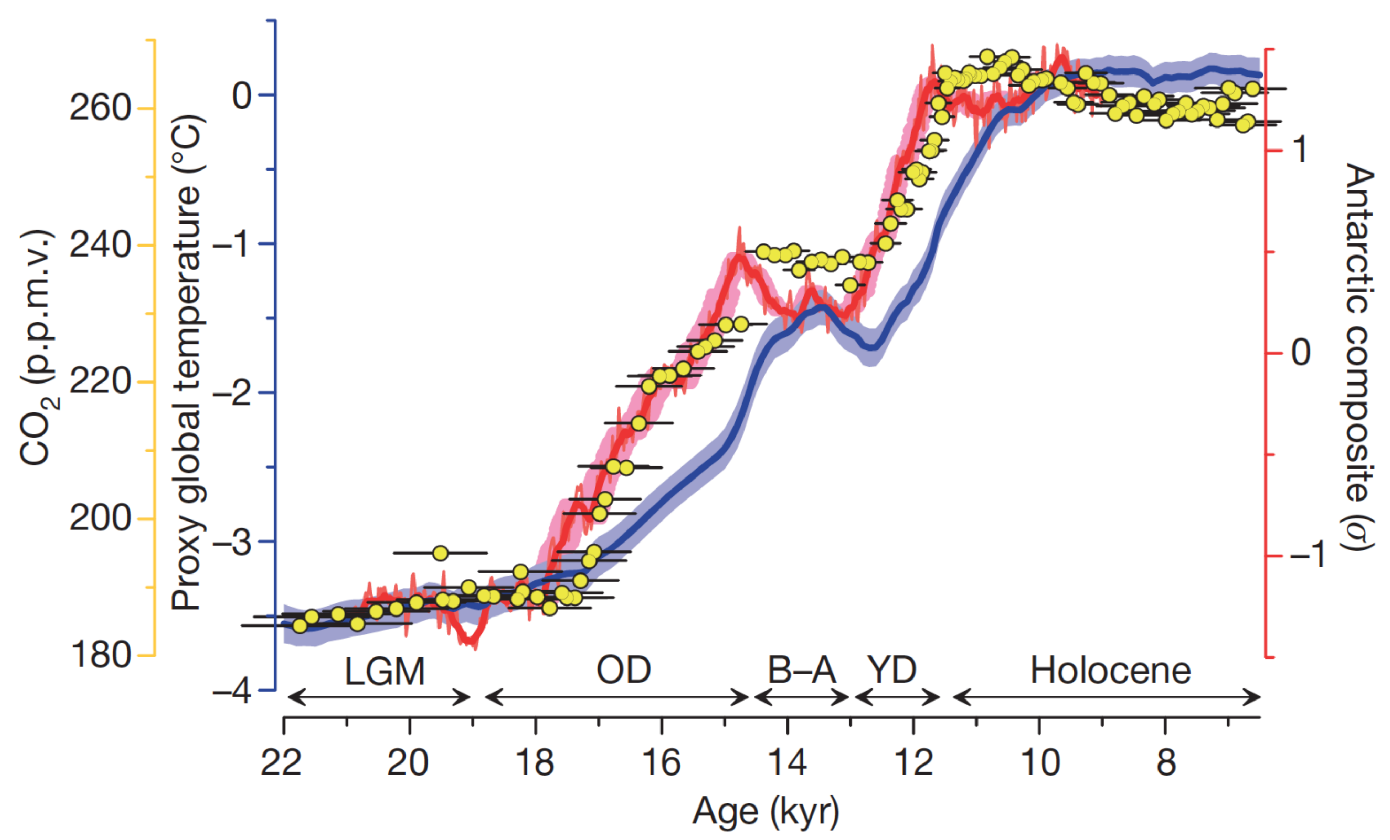

Fig. 1.2. Evolutions of atmospheric $\mathrm{CO}_{2}$ concentration (yellow), global (surface ocean + atmosphere) temperature (anomalies compared to the early Holocene (11.5-6.5 ka BP) mean; blue), and Antarctic ice-core composite temperature (red) during the last deglaciation. Figure from Shakun et al. (2012). 


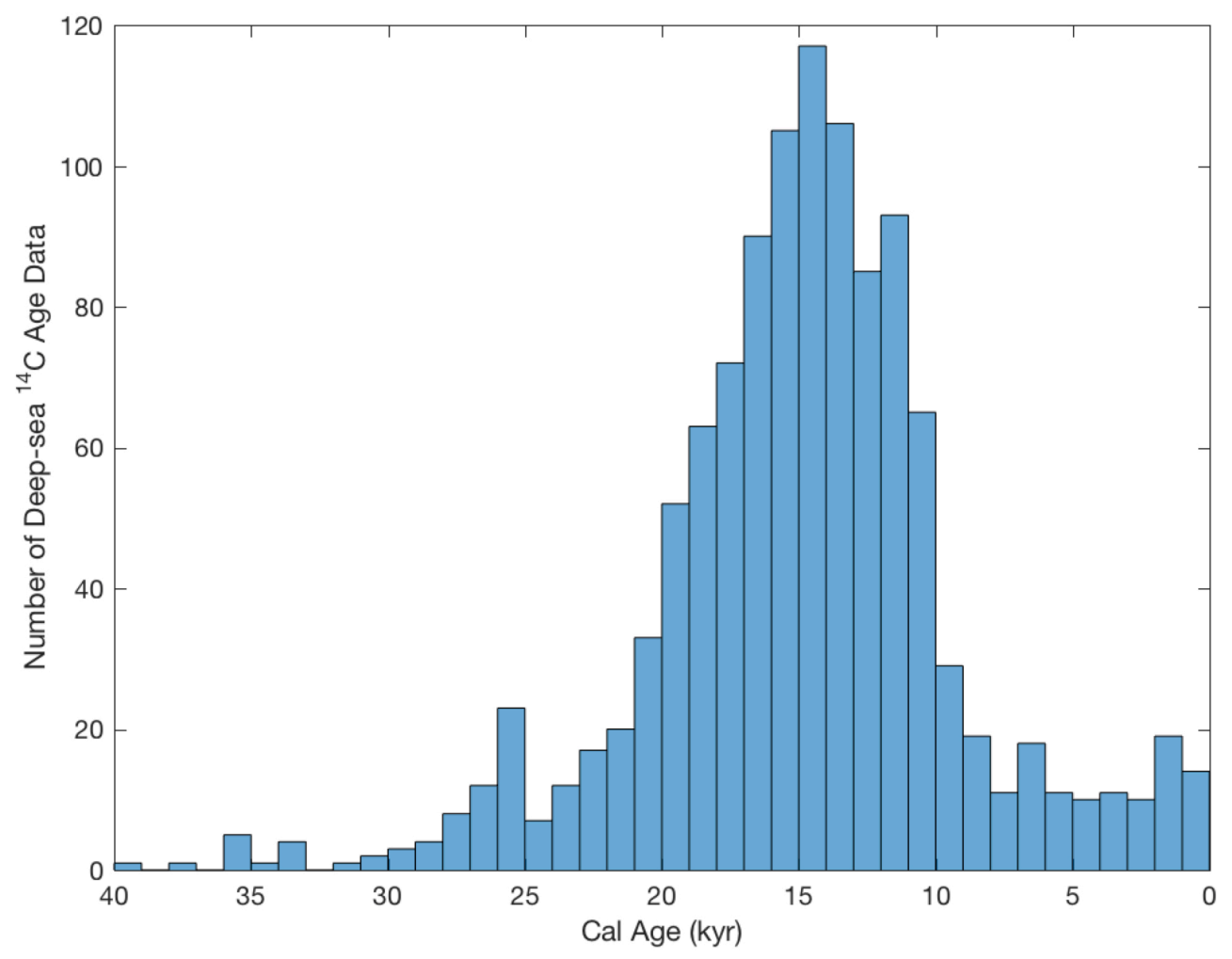

Fig. 1.3. Compilation of published and new deep-sea ${ }^{14} \mathrm{C}$ data for approximately the past 40 ka. This compilation includes more than 1000 measurements, mainly on benthic foraminifera and deep-sea corals, originating from different oceanic basins and spanning the depth interval from about $300 \mathrm{~m}$ to about $5000 \mathrm{~m}$ (for details see Chapter 4 of this thesis).

Despite several advantages, marine radiocarbon records suffer also from notable limitations. For example, it is not always easy to estimate the initial value of the ${ }^{14} \mathrm{C}$ content of a water mass when it was last in contact with the atmosphere (preformed age). Quite naturally, this issue is related to our current poor understanding of the difference in the radiocarbon age between the surface 
seawaters and the atmosphere (the so-called sea surface ${ }^{14} \mathrm{C}$ reservoir age) in the pre-instrumental past.

In addition, since the determination of $\Delta^{14} \mathrm{C}\left({ }^{14} \mathrm{C} /{ }^{12} \mathrm{C}\right.$ ratio after fractionation correction and normalized to that of a standard) of a sample when the carbon was incorporated requires knowledge of the absolute (calendar) age of the sample, chronological uncertainty is a more significant issue for $\Delta^{14} \mathrm{C}$ than for other paleoclimatic proxies. Although ${ }^{14} \mathrm{C}$ ages of deep-sea corals, which can be dated using the ${ }^{234} \mathrm{U}-230 \mathrm{Th}$ technique, are generally thought to be less subject to uncertainties, deep-sea corals do not generally allow the generation of continuous records, unlike deep-sea sediment cores. For ${ }^{14} \mathrm{C}$ dates obtained on fossil shells of benthic foraminifera sampled from sediment cores, the influence of chronological uncertainties could be very large (e.g., Davies-Walczak et al., 2014). Potential factors that contribute to the chronological uncertainties include bioturbation, synchronicity of specific features present in different records, sedimentation rate changes, and surface reservoir age changes. Records for which these uncertainties can be minimized are highly desirable but not common.

An impressive number of deglacial ocean radiocarbon records have been published over mainly the last two decades (see the compilation in Chapter 4 of this thesis). These records provide the basis for many inferences drawn about the history of deglacial ocean ventilation. However, such inferences are not always consistent with each other, possibly due to the uncertainties in core or coral chronology and to processes that are not related to ocean ventilation, such as hydrothermal input of ${ }^{14} \mathrm{C}$-depleted carbon to bottom waters (Lund and Asimow, 
2011; Stott and Timmermann, 2011). A comprehensive analysis of all available radiocarbon records, with due regard for their uncertainties, appears necessary in order to understand what these records can tell us about the deglacial ocean.

The overarching goal of this thesis is to contribute to our understanding of the deglacial ocean ventilation through (i) the generation of new records, (ii) the establishment of a new approach to constrain sediment core chronologies, and (iii) a compilation of data and their analysis in the presence of a quantitative model of ocean ventilation. This thesis is organized as follows:

Chapter 2 describes my effort to use terrestrial macrofossils to construct a deglacial chronology for a marine sediment core, which is the first one of its kind. In stark contrast with the vast majority of deglacial chronologies for deep-sea sediment cores, this chronology is free of assumptions about sea surface ${ }^{14} \mathrm{C}$ reservoir age, and in fact makes it possible to reconstruct reservoir age history when combined with ${ }^{14} \mathrm{C}$ dates of planktonic foraminifera. As shown in Chapter 2, this effort also provides new insights into the evolution of upper ocean $\delta^{13} \mathrm{C}\left({ }^{13} \mathrm{C} /{ }^{12} \mathrm{C}\right.$ ratio normalized to that of a standard) during the last deglaciation.

In Chapter 3, I present a study on the reconstruction of mid-depth ventilation in the western North Atlantic during the late deglaciation ( 14 - 8 ka BP). This work relies on a core characterized by high sedimentation rate and located relatively close to the modern sites of deep water formation. These features make the core ideal for reducing some of the uncertainties in ${ }^{14} \mathrm{C}$ ventilation age reconstruction, in particular the uncertainties due to (i) bioturbation along the 
sedimentary column and (ii) a variable mixture of water masses with distinct radiocarbon ages.

Finally, in Chapter 4, a compilation of deep ocean ${ }^{14} \mathrm{C}$ data for the past $40 \mathrm{ka}$ is undertaken, and the consistency of the deglacial data with modern rates of basinscale ocean ventilation is tested. A quantitative model of modern ocean ventilation is fit to the deglacial deep ocean ${ }^{14} \mathrm{C}$ data, and the residuals of the fit are analyzed in the light of the uncertainties in the basin-scale ${ }^{14} \mathrm{C}$ values. Equipped with the compiled data and the most recent reconstruction of atmospheric ${ }^{14} \mathrm{C}$ (Reimer et al., 2013), I also aim to identify the main process that may have dominated the evolution of ${ }^{14} \mathrm{C}$ activity in the ocean-atmosphere system over the past $25 \mathrm{ka}$ or so.

Chapter 5 presents a summary for the thesis. 


\title{
Chapter 2. An atmospheric chronology for Panama Basin and deglacial Pacific thermocline ventilation
}

\begin{abstract}
Paleoclimate reconstructions are only as good as their chronology. Age models of marine records can be complicated by factors like the changes in surface ${ }^{14} \mathrm{C}$ reservoir age and sedimentation rate. Here I build a chronology for the last $\sim 30$ thousand years that is free of those uncertainties, based on ${ }^{14} \mathrm{C}$ dating of twigs in a pair of cores from the Panama Basin. With this accurate chronology and concurrent ${ }^{14} \mathrm{C}$ dates of Neogloboquadrina dutertrei (a thermocline-dwelling foraminifera), it is shown that the near surface ${ }^{14} \mathrm{C}$ reservoir age was similar to today in the past, and that the planktonic foraminiferal $\delta^{13} \mathrm{C}$ decrease in the early deglaciation was not due to the advection of subsurface low- $\delta^{13} \mathrm{C}$ water. Instead, it must have been driven by a more efficient transport of carbon through the atmosphere.
\end{abstract}

\subsection{Introduction}

The decrease of upper ocean stable carbon isotope ratio $\left(\delta^{13} \mathrm{C}\right)$ as recorded in planktonic foraminiferal tests (e.g., Ninnemann and Charles, 1997; Oppo and Fairbanks, 1989; Pena et al., 2008; Shackleton et al., 1983; Spero and Lea, 2002) coincided with atmospheric $\mathrm{CO}_{2}$ rise in the early deglaciation (Marcott et al., 2014). It has been proposed that the $\delta^{13} \mathrm{C}$ decrease was due to the advection of upwelled water from the Southern Ocean through Subantarctic Mode Water (SAMW) and (or) Antarctic Intermediate Water (AAIW), and subsequent upwelling at low latitudes 
(Ninnemann and Charles, 1997; Spero and Lea, 2002). The water mass presumably isolated in the deep ocean during the glacial period was low in $\delta^{13} \mathrm{C}$, and thus responsible for the $\delta^{13} \mathrm{C}$ decrease and $\mathrm{CO}_{2}$ increase. However, $\delta^{13} \mathrm{C}$ is sensitive to biological processes and modeling results show that a weakening of the biological pump can lead to the $\delta^{13} \mathrm{C}$ decline near the surface ocean (Schmittner and Lund, 2015). The influence of biological processes on radiocarbon $\left({ }^{14} \mathrm{C}\right)$ activity, corrected for isotopic fractionation, is negligible in the ocean, so ${ }^{14} \mathrm{C}$ is ideal for studying ocean ventilation changes. Whether the deglacial upper ocean $\delta^{13} \mathrm{C}$ decline is a signal of water advection and upwelling can be diagnosed with the radiocarbon age of the planktonic foraminifera (PF) relative to the atmosphere ${ }^{14} \mathrm{C}$ reservoir age). However, to estimate reservoir age in marine sediment cores, independent age control is needed.

In the southwestern Panama Basin, close to a site where a deglacial thermocline $\delta^{13} \mathrm{C}$ decrease was first reported (Spero and Lea, 2002), the ${ }^{14} \mathrm{C}$ reservoir age was recently reconstructed using correlations to Greenland ice cores (ODP1240 in Fig. 2.1a, de la Fuente et al., 2015). It was inferred that the surface reservoir age was much larger than today at the inception of the deglaciation, but results based on different proxies display a large discrepancy, suggesting a large uncertainty in the reconstruction. In addition, a common feature of most correlation-based chronologies is that reservoir age can only be derived at abrupt and large climatic shifts, which are few even on millennial timescale and cannot provide a high-resolution reconstruction. The uncertainties about the tie point 
locations in a record and the synchronization of records separated by large distances could further increase the chronology uncertainty.

In this chapter, I present the first high-resolution terrestrial macrofossilbased chronology for a deep ocean sediment core, and apply it to study upper ocean reservoir age and ventilation. The gravity-core and piston-core pair used in this study (KNR176-2 GGC17 and JPC30) is located on the Colombian margin in the Panama Basin, Eastern Equatorial Pacific (EEP) (Fig. 2.1a). This site is close to both the Baudó River mouth and the delta of San Juan River (Fig. 2.1b). These two rivers drain one of the rainiest regions in the world, and San Juan River has the highest water discharge on the western side of the Andes (Poveda and Mesa, 2000). High flow speed and discharge of these short tropical mountain rivers deliver fallen trees to the coast where they drift offshore and eventually sink in the open ocean. The narrow continental shelf along the tectonically active Pacific margin is not an effective sediment trap, especially when sea level was lower during the Last Glacial Maximum (LGM) and deglaciation.

\subsection{Material and Methods}

\subsubsection{Acquisition of wood samples}

I first observed twigs on the split surface of the sediment cores. For periods like the LGM and HS1, I found enough twigs to build a continuous chronology. For periods when wood abundance is low, I scanned the core sections with X-ray computed tomography (CT) at the Computerized Scanning and Imaging Facility of Woods Hole Oceanographic Institution (WHOI), and located twigs using the density 
contrast between wood and sediments. One example of the 3D CT images is displayed in Fig. 2.1c. Wherever possible, I dated twigs with bark, assuming they would have been deposited more rapidly than those without. Fig. 2.1d is the photograph of a dated twig.

2.2.2 Radiocarbon analysis and ${ }^{14} \mathrm{C}$ age calibration

Sample preparation and radiocarbon measurements were conducted at the National Ocean Sciences Accelerator Mass Spectrometry (NOSAMS) facility at WHOI. Wood samples were cleaned using the acid-base-acid method, followed by bulk combustion. For foraminifera samples, tests were ultrasonically cleaned and then hydrolyzed with phosphoric acid. Then $\mathrm{CO}_{2}$ gases were converted to graphite using hydrogen reduction with an iron catalyzer. Graphite was then pressed into targets for Cs sputtering. Wood ${ }^{14} \mathrm{C}$ ages reported from NOSAMS were calibrated to calendar age using IntCal13 (Reimer et al., 2013).

2.2.3 Stable isotope analysis

I acquired the $\delta^{13} \mathrm{C}$ of foraminiferal tests using $\mathrm{CO}_{2}$ splits from the gases for ${ }^{14} \mathrm{C}$ measurements. In this way I can minimize the uncertainty of normal $\delta^{13} \mathrm{C}$ data caused by small sample size, and better represent the mean value. Stable isotope measurements were made on a VG Prism instrument at NOSAMS. Instrument precision is about $0.05 \%$.

2.2.4 Calculation of radiocarbon ratios between foraminiferal tests and the contemporaneous atmosphere 
There are multiple ways to present radiocarbon concentration and the difference of radiocarbon concentrations between different reservoirs. Since the radiocarbon concentration in the atmosphere is not constant through time, the most appropriate way to present the radiocarbon difference between the ocean and the atmosphere is the ratio between them. One way to define the ratio is the relative deviation of a reservoir from the contemporary atmosphere (e.g., Soulet et al., 2016):

$$
\delta^{14} R=\left(\frac{F m_{\text {sample }}}{F m_{\text {atm }}}-1\right) \times 1000 \%,
$$

where Fm is modern fraction. Since in my case, wood radiocarbon directly reflects the atmospheric radiocarbon level, the relative deviation of foraminiferal ${ }^{14} \mathrm{C}$ from the atmosphere can be expressed as:

$$
\delta^{14} R=\left(\frac{F m_{\text {foram }}}{F m_{\text {wood }}}-1\right) \times 1000 \% .
$$

From the equation $\Delta^{14} \mathrm{C}=\left(\mathrm{Fm} * \mathrm{e}^{(\mathrm{cal} \text { age/8267a) }-1)}\right)^{*} 1000, \delta^{14} \mathrm{R}$ can also be derived from:

$$
\delta^{14} R=\left(\frac{\frac{\Delta^{14} C_{\text {sample }}}{1000}+1}{\frac{\Delta^{14} C_{a t m}}{1000}+1}-1\right) \times 1000 \% 0 .
$$

Equation (3) is the same as the "epsilon value" definition in Hines et al. (2015).

We can see that Equation (2) does not require $\Delta^{14} C_{a t m}$, and is thus independent of radiocarbon calibration curves. For the foraminifera-wood pairs, the 
error bar of $\delta^{14} \mathrm{R}$ with respect to age is horizontal rather than diagonal as the calculation is not influenced by age uncertainty (foraminifera and wood are assumed contemporaneous; see also Soulet et al., 2016) (Fig. 2.2).

For the estimation of surface reservoir age, which is the common way of presenting the radiocarbon activity difference between PF and the atmosphere, there are usually multiple uncertainties. For example, when starting from a calendar age constraint (e.g., through correlation to other records), there are uncertainties associated with the conversion of calendar age to atmospheric ${ }^{14} \mathrm{C}$ age, in addition to the uncertainties in obtaining the calendar age. However, by directly taking the difference between wood and $\mathrm{PF}{ }^{14} \mathrm{C}$ ages, the reconstructed reservoir ages (y axis in Fig. 2.5a, similar as that in Fig. 2.2) are also independent of the calendar age and updates of ${ }^{14} \mathrm{C}$ calibration curve.

\subsection{Results and Discussion}

Wood is not uncommon in deep ocean sediments (Maser et al., 1988). Fallen trees are decomposed quickly on land, especially in tropical regions (e.g., Chambers et al., 2000; decomposition rate: $\sim 0.2 \mathrm{yr}^{-1}$ ), and wood can float for up to several months before sinking (e.g., Häggblom, 1982), so the twigs found in deep ocean sediment cores must have been "fresh" before burial given the radiocarbon dating uncertainty. In addition, most twigs found in GGC17/JPC30 still contain bark, indicating that they were buried quickly (Fig. 2.1d). All of the twigs are horizontally laid in the cores, which suggests they experienced minimal bioturbation. The ages of the 28 wood pieces increase with depth in the core, except for one reversal on a very 
small piece in the early Holocene (Fig. 2.1e) when a CT image of decimeter scale burrowing indicates significant bioturbation (Fig. 2.3). The consistent age-depth trends between the two cores where they overlap also supports the reliability of dating wood debris in deep-sea sediments (Fig. 2.1e).

Besides a dating method, ${ }^{14} \mathrm{C}$ is also used to investigate paleo ventilation of subsurface waters. Marchitto et al. (2007) reported signals of very old water at intermediate depth (705 m) off Baja California during Heinrich Stadial 1 (HS1) and the Younger Dryas (YD), which they interpreted to be the signal of old water upwelled in the Southern Ocean. Later work using the same cores suggest that old intermediate water was also present in the late Bølling-Allerød warm period (BA), and that G. ruber recorded seasonal upwelling of old subsurface water transported from the EEP northward by the California Undercurrent (Fig. 2.2) (Lindsay et al., 2015). Older intermediate ventilation ages during the deglaciation have also been noted near the Galapagos Islands (Stott et al., 2009), although this has been questioned (Stott and Timmermann, 2011). In contrast, multiple records closer to the Southern Ocean do not contain the signal of old ventilation age (e.g., De Pol-Holz et al., 2010; Rose et al., 2010).

The cores from the Panama Basin $(707 \mathrm{~m})$ are from the same depth as those off Baja California (705 m). I dated thermocline-dwelling PF Neogloboquadrina dutertrei, the benthic foraminifera (BF) Uvigerina peregrina, and twigs from the same layers. If the old water observed at both surface and intermediate depth off Baja California was indeed transported northward from the EEP, we should see radiocarbon depletion upstream at the core site in this study. However, $\delta^{14} \mathrm{R}$ of both 
$N$. dutertrei and $U$. peregrina showed similar offsets from the atmosphere as today since the LGM (Fig. 2.2). Therefore, the EEP and Southern Ocean could not be the source of the old water signal observed off Baja California. Instead, seafloor itself might be a source of old carbon close to hydrothermal sites (e.g., Galapagos and Baja California; see supplementary text, Fig. 2.4).

Here I present the Panama Basin surface reservoir age since the LGM by taking the difference in ${ }^{14} \mathrm{C}$ ages between wood and $N$. dutertrei, the most commonly dated PF species in the EEP. This reconstruction is independent of the calendar age and future updates of the ${ }^{14} \mathrm{C}$ calibration curve (see Methods). I have the most confidence for HS1 and the LGM because the sedimentation rates are high $(\sim 50 \mathrm{~cm} / \mathrm{kyr}$ on average, Fig. 2.6). Sedimentation rate was reduced (averagely $\sim 15 \mathrm{~cm} / \mathrm{kyr}$ ) and bioturbation effect was more significant during the BA and the YD (supplementary text). Although the reconstructed reservoir ages during those intervals are in general agreement with other studies, confidence is less for later in deglaciation (supplementary text).

In contrast to the previous study based on correlation (de la Fuente et al., 2015), my calculated reservoir age from PF-wood difference during the LGM was not substantially different from today (Fig. 2.5a). The six reservoir age estimates between 18 and 24 ka average to $667 \pm 160 \mathrm{yr}$, which agrees well with Holocene estimates (655 \pm 106 yr, Fig. 2.5a) and that determined from GLODAP background ${ }^{14} \mathrm{C}$ (Key et al., 2004) for the calcifying depths of $N$. dutertrei ( $\sim 565-715$ yr for $\sim 25$ 100m, Fairbanks et al., 1982). Together with a study from the Western Equatorial Pacific (core MD98-2181, Fig. 2.1a) that shows a similar LGM surface reservoir age 
as today based also on wood-PF age difference (Broecker et al., 2004), my results suggest that the glacial surface reservoir age of the equatorial Pacific was not much different from today.

$N$. dutertrei $\delta^{13} \mathrm{C}$ of GGC17/JPC30, which was measured only at those depth intervals that are absolutely dated (see Methods), decreased from $\sim 17.5 \mathrm{ka}$ to $\sim 16 \mathrm{ka}$ (Fig. 2.5b). This shift is consistent with previously published N. dutertrei $\delta^{13} \mathrm{C}$ in the EEP (Pena et al., 2008; Spero and Lea, 2002), and also concurrent with an atmospheric $\delta^{13} \mathrm{C}$ decline of similar amplitude (Schmitt et al., 2012, Fig. 2.5c). If the thermocline $\delta^{13} \mathrm{C}$ decline is an advected signal of strengthened upwelling of relatively old Southern Ocean water, an increase in the thermocline ${ }^{14} \mathrm{C}$ age should be expected. However, we do not see an obvious change of thermocline age during this interval compared to the LGM (Fig. 2.5a).

One possible explanation for surface ocean $\delta^{13} \mathrm{C}$ decrease without ${ }^{14} \mathrm{C}$ age increase is a decline of local marine productivity. Model results show that productivity and thus $\delta^{13} \mathrm{C}$ in the near surface Pacific could decline as a response to a reduction of the Atlantic overturning circulation (Schmittner and Lund, 2015). However, published records suggest an increase of ocean productivity during HS1 in the Panama Basin (Kienast et al., 2006), and generally during the deglaciation in the Equatorial Pacific (Winckler et al., 2016).

Based on the available evidence, the $\delta^{13} \mathrm{C}$ decrease near the surface ocean mostly came from exchange with the atmosphere. Abundant studies suggest a Southern Ocean source for the isotopically light carbon added into the atmosphere, 
e.g., carbon release from the deep ocean mainly through the Antarctic Zone (e.g., Anderson et al., 2009; Jaccard et al., 2016; Skinner et al., 2010) and a significant decrease of export production in the Subantarctic Zone (e.g., Martínez-García et al., 2014). The inferred scenario makes sense because the Equatorial Undercurrent, which replenishes the Panama Basin thermocline, is dominated by waters that are ventilated in the tropical and subtropical regions today (Goodman et al., 2005). The absence of a clear deglacial anomaly in the difference between the radiocarbon activity of BF and the atmosphere (Fig. 2.2) is also consistent with the small influence of AAIW in the EEP (Fiedler and Talley, 2006). My results support the hypothesis that if most of the upwelled carbon in the Southern Ocean was released directly into the atmosphere rather than mixed through the upper ocean, the existing abyssal radiocarbon data during the LGM are enough to explain the drop of atmospheric $\Delta^{14} \mathrm{C}$ during HS1 (Burke and Robinson, 2012).

The main nutrient return path to the low-latitude thermocline is through Southern Ocean upwelling and then oceanic "tunneling" (Sarmiento et al., 2004), and increased productivity in the equatorial Pacific during deglaciation involved increased nutrient supply from the Southern Ocean (Winckler et al., 2016). However, because of the air-sea exchange of $\mathrm{CO}_{2}$ and the fast mixing rate in the atmosphere, the atmosphere is a much more efficient way to transport $\delta^{13} \mathrm{C}$ signals. Therefore, the transport of isotopically light carbon from the Southern Ocean to the lowlatitude thermocline and that of nutrients were probably decoupled during deglaciation. 
Although the dominance of waters ventilated in (sub)tropical regions keeps the thermocline reservoir age relatively stable in the Panama Basin, significant shifts in Southern Ocean upwelling might still contribute to reservoir age changes. Beginning $\sim 16 \mathrm{ka}$, within HS1, there was a decrease of $N$. dutertrei reservoir age of about $100{ }^{14} \mathrm{C}$ yr (Fig. 2.5a). I propose that this indicates a rapid southward migration of the Southern Hemisphere westerlies and upwelling in the middle of HS1, which agrees with a decrease of SOIW fraction in the Panama Basin thermocline (Pena et al., 2013) and also the reported southward shift of the intertropical convergence zone centered on HS1 (e.g., Peterson et al., 2000) (supplementary text). The expression of this shift in the reservoir age record was probably smoothed (Fig. 2.5a), at least in part due to bioturbation. A rapid southward shift of the Southern Ocean upwelling in itself could contribute to the sudden $\mathrm{CO}_{2}$ rise in mid-HS1 (Fig. 2.5d) by increasing the fraction of carbon in the deep Southern Ocean that was re-connected with the atmosphere (e.g., Skinner et al., 2010). After this event, probably most of the glacial sequestered old carbon had been purged, consistent with a quite well-ventilated deep Southern Ocean after $\sim 16$ ka (Jaccard et al., 2016). In addition, the dust flux in the Southern Ocean and thus iron fertilization had reached a relatively stable level after the decrease in early HS1 (Lambert et al., 2012). The combination of these effects could lead to the lower rate of $\mathrm{CO}_{2}$ increase in late HS1 (Fig. 2.5d, Marcott et al., 2014). 


\subsection{Summary}

A reliable chronology is the most fundamental component of paleoclimate studies, and it is even more important for radiocarbon-related proxies (e.g., $\Delta^{14} \mathrm{C}$ ), which depend on calendar age. Reconstructions from a marine sediment core that was absolutely dated using twigs found in the core show that the ventilation ages of the intermediate and thermocline Eastern Equatorial Pacific during the last deglaciation were not much different from today. Surface reservoir age is in general the major uncertainty in the chronology of marine records. However, because of the atmospheric dominance of carbon isotopes in the (sub)tropical surface oceans, I argue that applying the modern surface reservoir age for low-latitude marine records is reasonable where a good estimate of past reservoir ages is lacking. This study also suggests that chronologies based on correlations should be used carefully. Combined with stable carbon isotope data, the radiocarbon results suggest that $\mathrm{CO}_{2}$ was likely released directly into the atmosphere from high-latitude surface oceans during the last deglaciation, rather than mixed through the low-latitude upper ocean. 


\section{Figures}
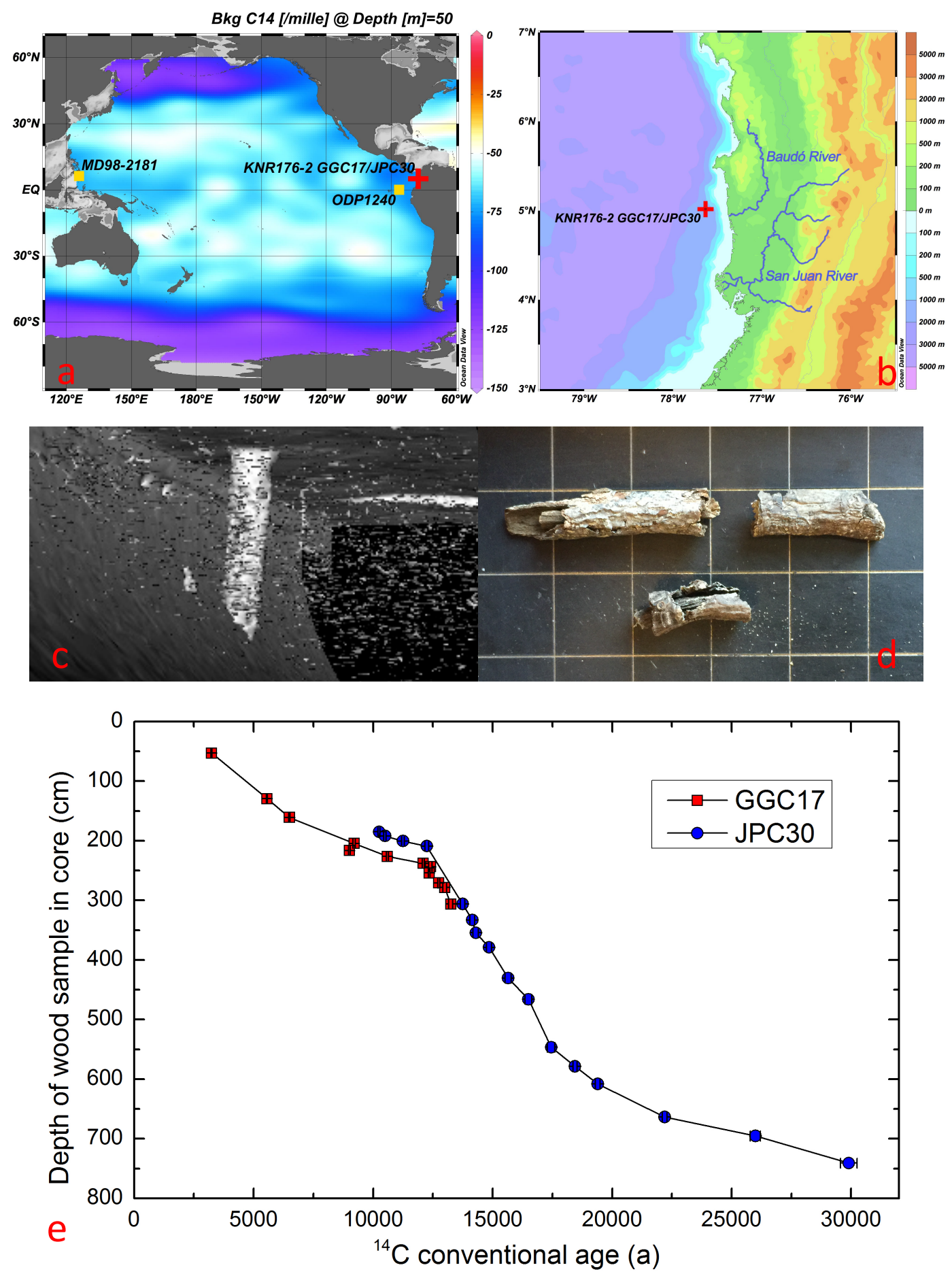

Fig. 2.1 Physical setting and radiocarbon results on twigs in KNR176-2 GGC17/JPC30 from the Panama Basin. (a) Location of the cores (red plus: $5.02^{\circ} \mathrm{N}$, 
$77.63^{\circ} \mathrm{W}, 707 \mathrm{~m}$ ) plotted on a map of GLODAP pre-industrial $\Delta^{14} \mathrm{C}$ of the Pacific at $50 \mathrm{~m}$ (Key et al., 2004), the depth of thermocline base and the central depth where $N$. dutertrei calcifies in the Panama Basin (Fairbanks et al., 1982). White color corresponds to a radiocarbon age $\sim 400 \mathrm{yr}$ older than the atmosphere $(-50 \%)$. Yellow squares (ODP1240, MD98-2181) are other tropical marine sediment cores discussed in this paper. (b) Location of GGC17/JPC30 with respect to the San Juan and Baudó Rivers. (c) CT scanning image revealing twigs buried in sediment core sections. (d) Photograph of twigs with bark found in the cores. The square in the background is $1 \mathrm{~cm}$ by $1 \mathrm{~cm}$. (e) ${ }^{14} \mathrm{C}$ age-depth relationship of GGC17/JPC30. Most error bars are within the symbols. There is an offset of $\sim 30 \mathrm{~cm}$ between the two cores due to coretop sediment loss by the piston corer. 


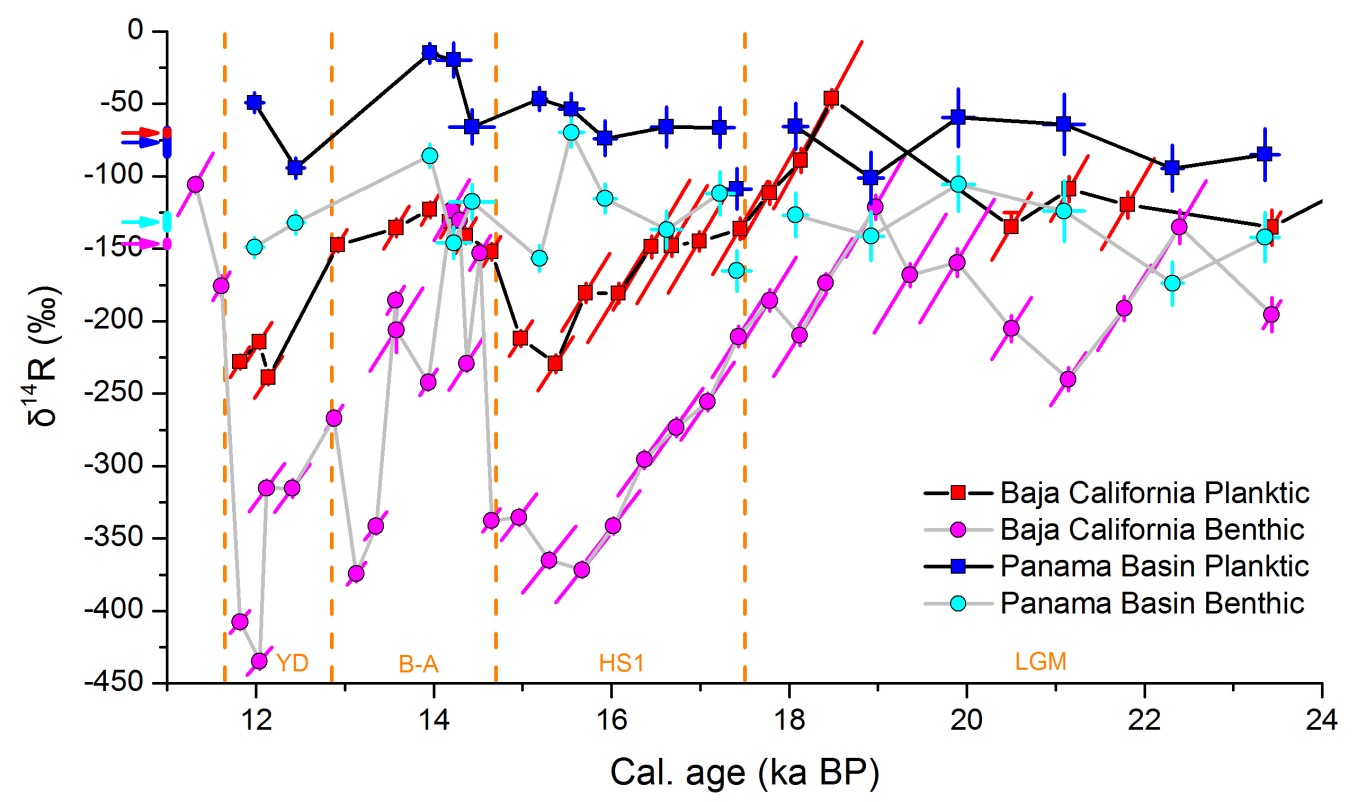

Fig. 2.2 Relative deviation of radiocarbon activity in foraminiferal tests from the contemporary atmosphere (expressed as $\delta^{14} \mathrm{R}$ (Soulet et al., 2016), see Methods) for the Panama Basin (this study) and the Baja California cores (Lindsay et al., 2015; Marchitto et al., 2007). $\delta^{14} \mathrm{R}$ determined from foraminifera/wood pairs is conserved with time (Methods). Four arrows near the vertical axis show the modern $\delta^{14} \mathrm{R}$ (with vertical lines on the axis showing the range) from different sites that correspond to the four colored curves (Key et al., 2004). Blue: the calcifying depths of $N$. dutertrei from the Panama Basin ( 25-100m, Fairbanks et al., 1982); Red: the calcifying depths of G. ruber from Baja California $(\sim 0-25 \mathrm{~m}$; G. ruber is argued to record upwelling signal of the water transported from the EEP (Lindsay et al., 2015)); Cyan and Magenta: the depth range from the LGM to today for the Panama Basin and Baja California cores, respectively $(\sim 600-700 \mathrm{~m})$. Isolated points at $\sim 17.4 \mathrm{cal} \mathrm{ka}$ in the 
Panama Basin records coincide with large negative excursions of $\delta^{13} \mathrm{C}$, suggesting a possible local release of methane from the sediments (Fig. 2.7). 


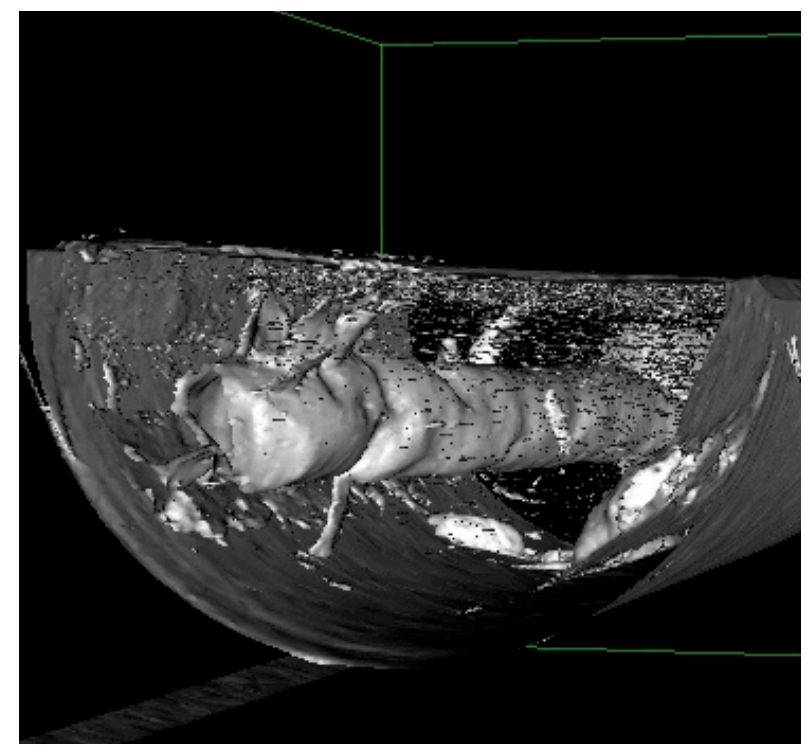

Fig. 2.3 Image of CT scanning that shows a worm burrow extending more than $30 \mathrm{~cm}$ in the early Holocene sediments of GGC17. 


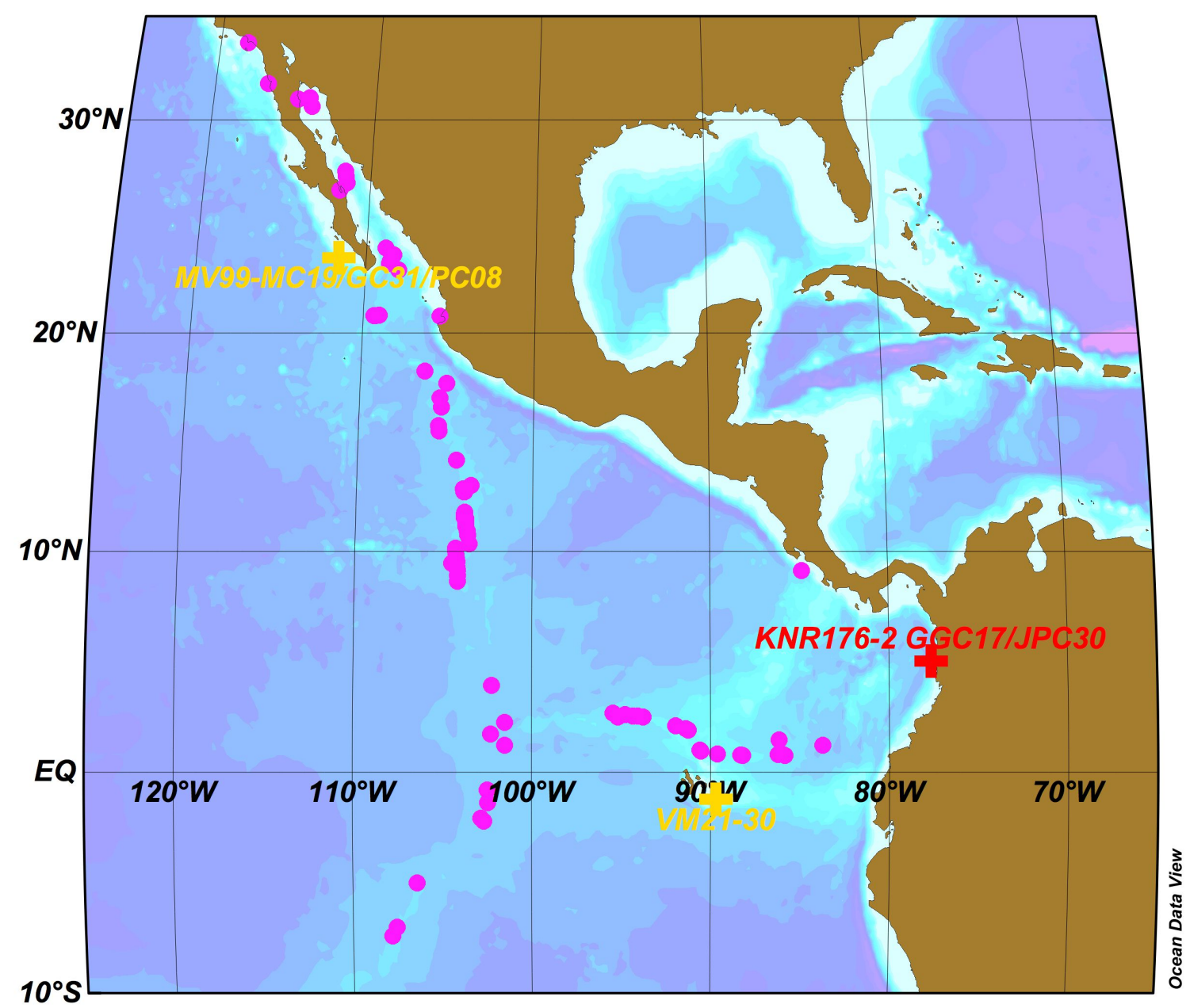

Fig. 2.4 Locations of sediment cores KNR176-2 GGC17/JPC30 (this study), MV99MC19/GC31/PC08 (Lindsay et al., 2015; Marchitto et al., 2007) and VM21-30 (Stott et al., 2009) plotted with the observed sites of hydrothermal venting systems in the Eastern Equatorial and Northeastern Pacific (data source: InterRidge Vents Database Ver. 3.3, http://vents-data.interridge.org/ventfields_list_all). 


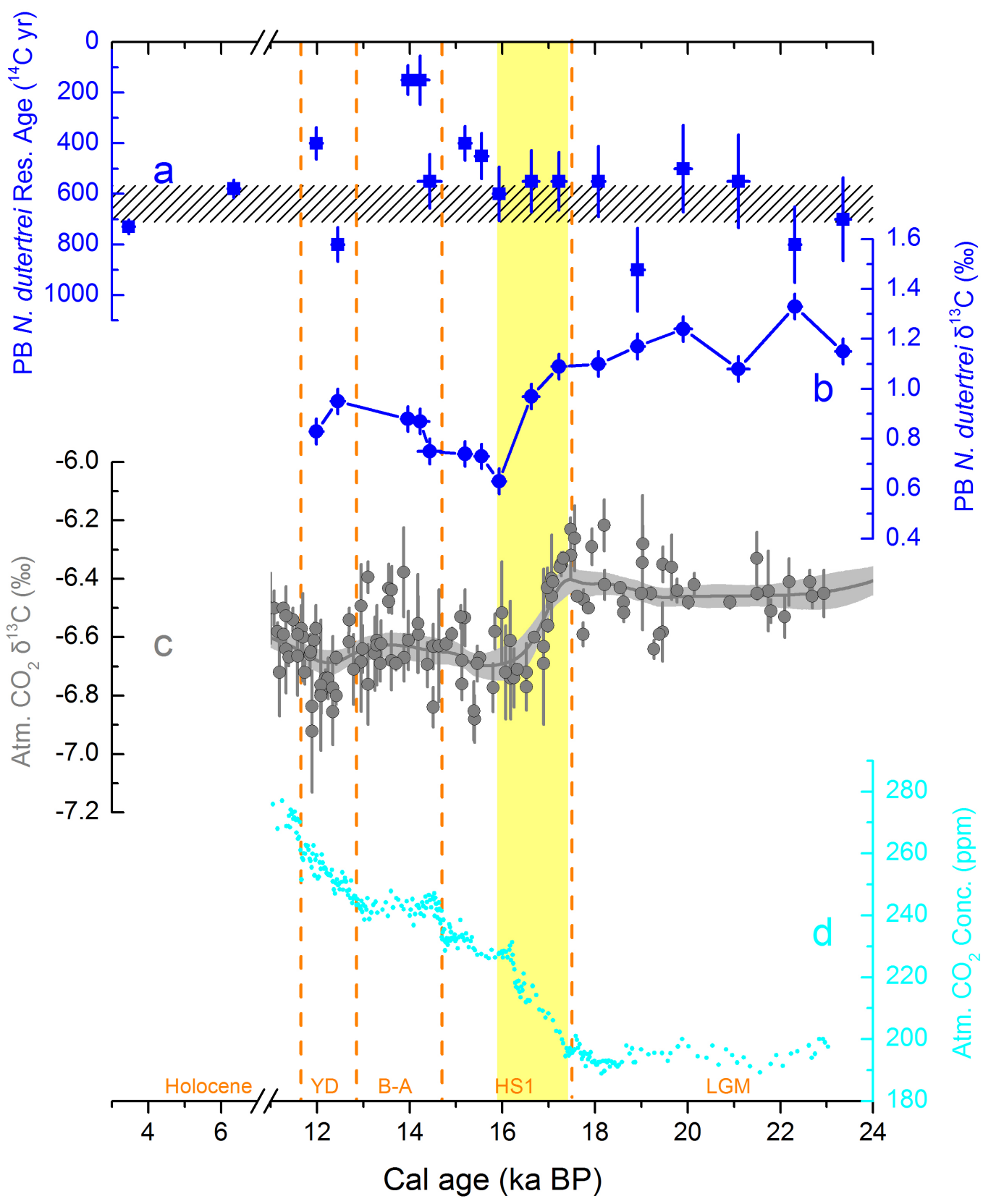

Fig. 2.5 Panama Basin (PB) surface reservoir age in comparison with other proxies during the LGM and the last deglaciation. (a) PB surface ${ }^{14} \mathrm{C}$ reservoir age (with 1 sigma uncertainty) based on $N$. dutertrei from GGC17/JPC30, with the b-spline average shown as the smooth line. Hatched area represents the calculated GLODAP 
reservoir age of the depths where $N$. dutertrei calcifies (Fairbanks et al., 1982; Key et al., 2004). The only two Holocene surface reservoir age estimations on $N$. dutertrei agree well with the GLODAP range. (b) $\delta^{13} \mathrm{C}$ of $N$. dutertrei from GGC17/JPC30. (c) $\delta^{13} \mathrm{C}$ of atmospheric $\mathrm{CO}_{2}$ reconstructed from Antarctic ice cores (Schmitt et al., 2012). The dark grey line and the light grey area around are the Monte Carlo average of the measurements and the associated $1 \sigma$ error envelop. (d) Atmospheric $\mathrm{CO}_{2}$ concentration from the West Antarctic Ice Sheet Divide ice core (Marcott et al., 2014). All chronologies are as originally reported. 


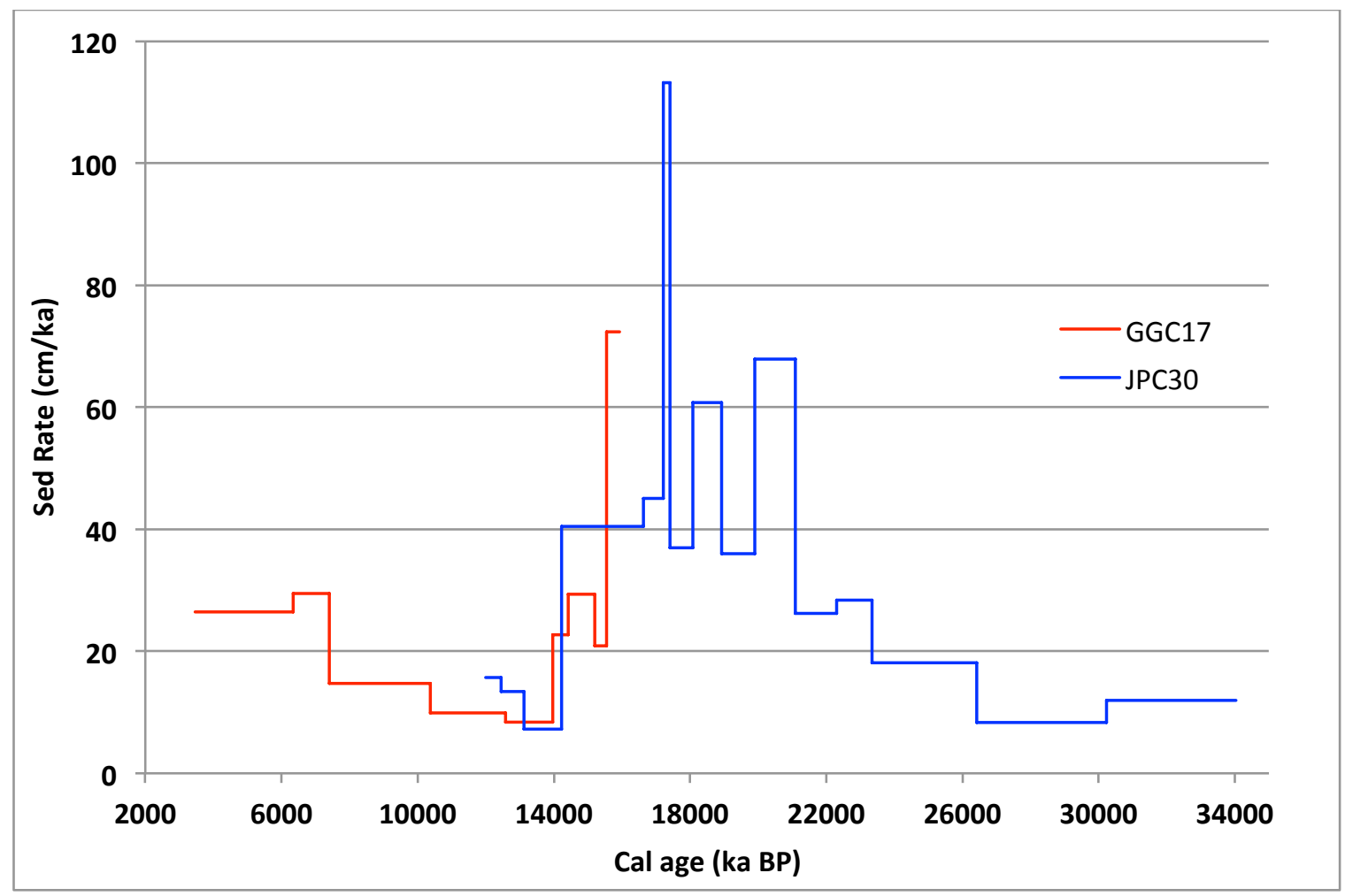

Fig. 2.6 Sedimentation rate of GGC17 and JPC30. 


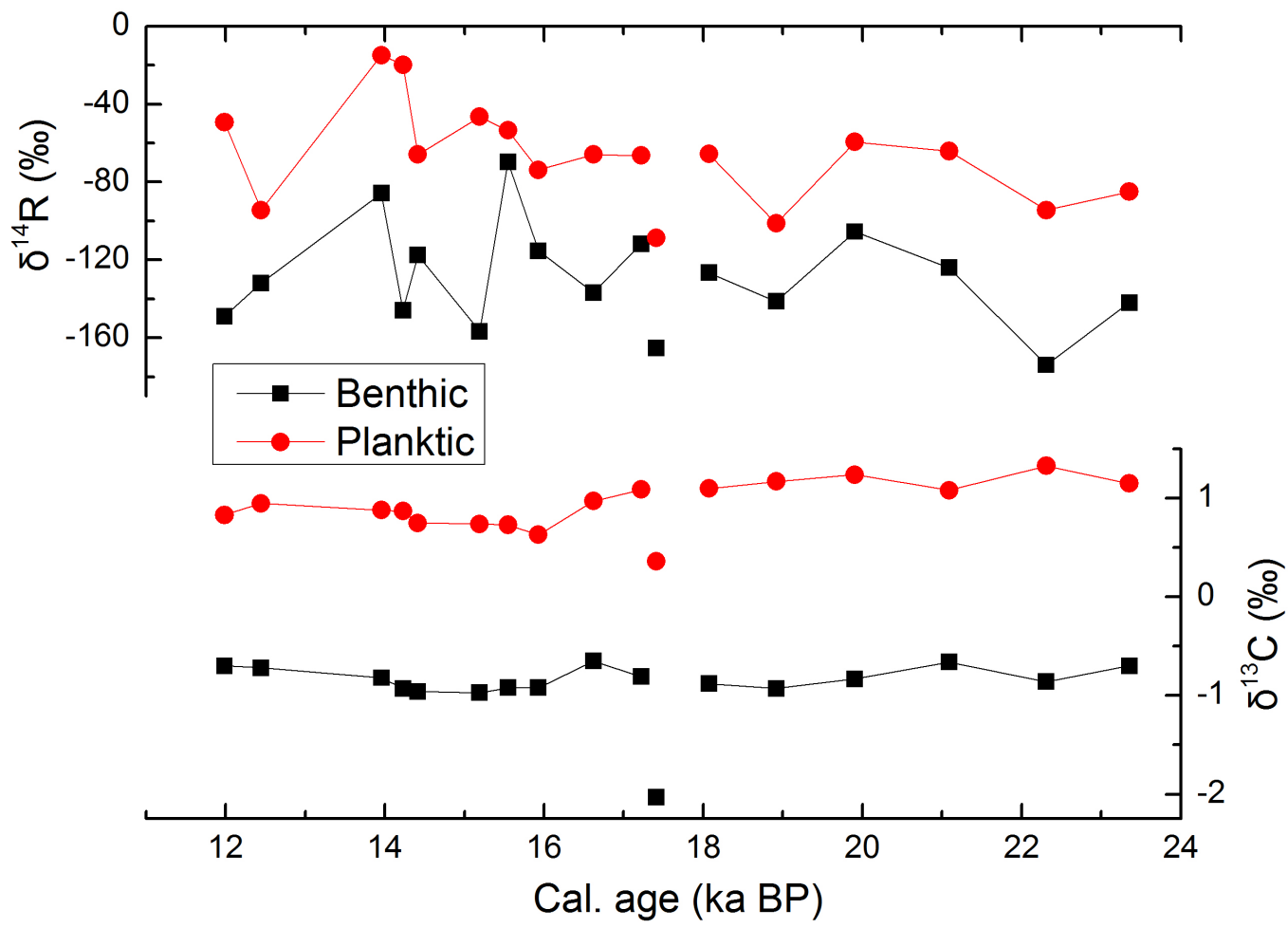

Fig. $2.7 \delta^{14} \mathrm{R}$ and $\delta^{13} \mathrm{C}$ of $N$. dutertrei and U. peregrina in GGC17/JPC30. The low $\delta^{14} \mathrm{R}$ values at $\sim 17.4$ cal ka (isolated points) coincide with large negative excursions of $\delta^{13} \mathrm{C}$. One possible explanation for this is a local release of methane from the sediments, which has very low $\Delta^{14} \mathrm{C}$ and $\delta^{13} \mathrm{C}$. 


\section{Supplementary Materials}

Supplementary text

(1) Wood Abundance in the sediment cores

Terrestrial plant remains are abundant in coastal sediments, and chronologies built on dating them have been reported (e.g., Bondevik et al., 2006; Kovanen and Easterbrook, 2002; Southon et al., 1990). However, since the shoreline moved as sea level rose during the deglaciation, it is not possible to get a long series of deglacial reservoir ages from these environments. Wood debris has also been found at abyssal depths where it supports deep ocean fauna (e.g., Schwabe et al., 2015). This study shows that it is possible to build a chronology entirely based on wood for some deep-sea sediment cores. The most suitable locations for this kind of work are probably near narrow continental shelves and (or) river mouths.

The occurrence of small wood pieces, especially twigs, is notable on the split core surface of KNR176-2 GGC17/JPC30. Very few of these twigs are younger than $\sim 12{ }^{14} \mathrm{C} \mathrm{ka}$, or $\sim 14 \mathrm{cal} \mathrm{ka}$. By CT scanning the sediment core sections younger than $12{ }^{14} \mathrm{C}$ ka (Fig. 2.1c), we were able to find more wood pieces buried within the core and fill in the gaps of wood occurrence. The relatively low abundance of wood after $\sim 14$ cal ka generally coincides with a decrease of sedimentation rate (Fig. 2.6 and Fig. 2.1e). Since the river runoff in this region was shown to be higher after $14 \mathrm{ka}$ than before (Pahnke et al., 2007), decreased wood abundance and sedimentation rate are most likely dominated by the flooding of the continental shelf as sea level rose during the deglaciation (e.g., Bard et al., 1996), which trapped more wood and sediment on the shelf. 


\section{(2) Bioturbation}

The fact that the twigs are horizontally laid in the sediments indicates that they have not been moved much by benthic animals because the resistance is large when moved vertically. There is only one wood age anomaly that is on a small piece and from the early Holocene, where we see the following evidences of significant bioturbation of foraminifera. (1) The ${ }^{14} \mathrm{C}$ age difference between $U$. peregrina and wood is extremely large in the early Holocene (Table S1) where we also observe the drop of $U$. peregrina abundance, which suggests an upward transport of the foraminifera in the sediments by bioturbation. The decrease of $U$. peregrina abundance might be due to a lower export production during the Holocene (Kienast et al., 2006). (2) A CT scanning image clearly shows a worm burrow that extends more than $30 \mathrm{~cm}$ in the early Holocene section of the core (Fig. 2.3).

Another period where we see indications of bioturbation is the BA-YD when sedimentation rate was lower than other intervals (Fig. 2.1). For example, PF minus wood ${ }^{14} \mathrm{C}$ age is negative at $226.5 \mathrm{~cm}$ in GGC17, which is hard to explain without post-depositional influences (Table S1). In addition, at $201 \mathrm{~cm}$ in JPC30, the foraminifera-wood ${ }^{14} \mathrm{C}$ age difference is much larger than its neighboring values. This is not impossible, but considering that there is no replicate, we excluded this sample from discussion. In this study, we tend to adopt rigorous quality control by excluding data that are possibly influenced by processes like bioturbation and methane seepage (Fig. 2.7).

(3) Hydrothermal source of old carbon 
Both cores in the studies of Marchitto et al. (2007) and Stott et al. (2009) are very close to mid-ocean ridges and associated hydrothermal vents (Fig. 2.4). Since there is no large $\delta^{13} \mathrm{C}$ anomaly associated with the carbon of hydrothermal sources (Stott and Timmermann, 2011), it is possible that the old carbon without large $\delta^{13} \mathrm{C}$ anomalies in those studies was from hydrothermal activities (Lund and Asimow, 2011; Stott and Timmermann, 2011), especially during the deglaciation when the activities are thought to have been enhanced in the EEP (Lund et al., 2016). However, since the site in this study is not very far from the Galapagos (Stott et al., 2009) (near the southwestern boundary of the Panama Basin, Fig. 2.4) and the two sites are from similar water depths, the absence of low $\delta^{14} \mathrm{R}$ in this study suggests that if the observed deglacial old carbon was hydrothermal, its influence was spatially limited.

(4) Reservoir age during intervals with low sedimentation rates (BA and YD)

Although the confidence in the surface reservoir reconstruction for the BA and the YD is not as high due to lower sedimentation rate, my results are consistent with some other studies. We find that the surface reservoir age dropped to $\sim 150 \mathrm{yr}$ during the BA (Fig. 2.5a). This agrees with the results from ODP1240: the surface reservoir age of $\sim 100 \mathrm{yr}$ at the beginning of BA (de la Fuente et al., 2015), and the $\varepsilon_{\mathrm{Nd}}$ data that suggest the SOIW fraction in EEP thermocline dropped to a minimum ( 2-3\%) during the BA (Pena et al., 2013). In addition, surface reservoir age estimates based on tephra layers from the subtropical Southwest Pacific within the BA vary from $\sim 150$ to $400 \mathrm{yr}$, but are younger than the modern value (Sikes and Guilderson, 2016). These together suggest that the upper equatorial and subtropical 
South Pacific were quite isolated from older waters and reached better isotopic equilibrium with the atmosphere during the BA. For the YD, although my data have larger standard deviation, the average reservoir age (600 yr) is close to that during the first half of HS1 (Fig. 2.5a). This may indicate that the ocean states in the EEP were similar during those two intervals.

(5) Southward shift of Southern Hemisphere westerlies and SO upwelling in midHS1

First, a significant southward shift of the Southern Hemisphere westerlies and the Southern Ocean upwelling in the middle of HS1 is compatible with the increase of $N$. dutertrei $\varepsilon_{\mathrm{Nd}}$ (SOIW fraction decrease) across HS1 (Pena et al., 2013). An estimated reservoir age decrease of $\sim 1000 \mathrm{yr}$ within HS1 in the Subantarctic Atlantic agrees with the inferred scenario as well (Skinner et al., 2010), and the amplitude contrast (100 vs $1000 \mathrm{yr}$ ) between EEP and this site close to the SOIW formation region matches the SOIW fraction in the EEP ( 10\%; Pena et al., 2013). A rapid southward shift of Southern Hemisphere westerlies and upwelling is also consistent with the reported southward shift of the intertropical convergence zone within HS1 (Broecker and Putnam, 2012; Peterson et al., 2000). This shift of atmospheric circulation regime was accompanied by further drying in the Northern (Wang et al., 2001) and wetting in the Southern Hemisphere (Wang et al., 2004), which are argued to be responses to iceberg discharge in the North Atlantic and contribute to a rapid $\mathrm{CO}_{2}$ increase and a $\mathrm{CH}_{4}$ spike at 16.2 ka (Bauska et al., 2016; Rhodes et al., 2015). However, the rapid southward shift of the Southern Ocean 
upwelling could also contribute to the abrupt $\mathrm{CO}_{2}$ rise (as discussed in the main text). 
Supplementary tables

Table 2.1. Modern fraction (Fm) and ${ }^{14} \mathrm{C}$ age of wood, planktonic and benthic foraminifera samples in KRN176-2 GGC17/JPC30

\begin{tabular}{|c|c|c|c|c|c|c|c|c|c|c|c|c|}
\hline \multirow{2}{*}{$\begin{array}{l}\text { Depth } \\
(\mathrm{cm})\end{array}$} & \multicolumn{4}{|c|}{ Wood } & \multicolumn{4}{|c|}{ Planktonic Foraminifera } & \multicolumn{4}{|c|}{ Benthic Foraminifera } \\
\hline & $\mathrm{Fm}$ & $\operatorname{err}(1 \sigma)$ & $\begin{array}{c}14 C \text { age } \\
(y r)\end{array}$ & $\begin{array}{c}\text { err } \\
(1 \sigma)\end{array}$ & $\mathrm{Fm}$ & $\operatorname{err}(1 \sigma)$ & $\begin{array}{c}14 C \text { age } \\
(y r)\end{array}$ & $\begin{array}{c}\text { err } \\
(1 \sigma)\end{array}$ & $\mathrm{Fm}$ & $\operatorname{err}(1 \sigma)$ & $\begin{array}{c}14 C \text { age } \\
(y r)\end{array}$ & $\begin{array}{l}\text { err } \\
(1 \sigma)\end{array}$ \\
\hline \multicolumn{13}{|c|}{ GGC17 } \\
\hline 53 & 0.6678 & 0.0018 & 3240 & 20 & 0.6098 & 0.0016 & 3970 & 20 & & & & \\
\hline 129.5 & 0.5008 & 0.0016 & 5560 & 25 & 0.4654 & 0.0015 & 6140 & 25 & & & & \\
\hline $160.75^{*}$ & 0.4454 & 0.0014 & 6500 & 25 & 0.3773 & 0.0014 & 7830 & 30 & 0.2781 & 0.0014 & 10300 & 40 \\
\hline $204.5^{*}$ & 0.3178 & 0.0018 & 9210 & 45 & 0.2949 & 0.0015 & 9810 & 40 & 0.2364 & 0.0016 & 11600 & 55 \\
\hline $216.5^{* *}$ & 0.3256 & 0.0016 & 9010 & 40 & & & & & & & & \\
\hline $226.5^{*}$ & 0.2671 & 0.0015 & 10600 & 45 & 0.2747 & 0.0014 & 10400 & 40 & 0.2320 & 0.0014 & 11750 & 50 \\
\hline 238 & 0.2216 & 0.0010 & 12100 & 35 & 0.2183 & 0.0012 & 12250 & 45 & 0.2026 & 0.0015 & 12800 & 60 \\
\hline $243.5^{* * *}$ & 0.2135 & 0.0019 & 12400 & 70 & 0.2039 & 0.0012 & 12750 & 50 & 0.1924 & 0.0011 & 13250 & 45 \\
\hline $254^{* * *}$ & 0.2144 & 0.0011 & 12350 & 40 & 0.1958 & 0.0012 & 13100 & 50 & 0.1852 & 0.0012 & 13550 & 55 \\
\hline 271 & 0.2042 & 0.0012 & 12750 & 45 & 0.1947 & 0.0012 & 13150 & 50 & 722 & 15 & 14150 & 70 \\
\hline 278.5 & 0.1979 & 0.0018 & 13000 & 75 & 0.1873 & 0.0012 & 13450 & 50 & 0.1841 & 0.0011 & 13600 & 45 \\
\hline 306 & 0.1924 & 0.0019 & 13250 & 80 & 0.1782 & 0.0015 & 13850 & 70 & 0.1702 & 0.0011 & 14200 & 50 \\
\hline \multicolumn{13}{|c|}{ JPC30 } \\
\hline 184.75 & 0.2799 & 0.0015 & 10250 & 45 & 0.2661 & 0.0015 & 10650 & 45 & 0.2382 & 0.0014 & 11550 & 50 \\
\hline 192 & 0.2713 & 0.0017 & 10500 & 50 & 0.2457 & 0.0013 & 11300 & 45 & 0.2355 & 0.0015 & 11600 & 50 \\
\hline $201^{*}$ & 0.2464 & 0.0016 & 11250 & 55 & 0.2083 & 0.0016 & 12600 & 65 & 0.1917 & 0.0015 & 13250 & 65 \\
\hline 209 & 0.2179 & 0.0023 & 12250 & 85 & 0.2136 & 0.0011 & 12400 & 45 & 0.1861 & 0.0015 & 13500 & 65 \\
\hline 306 & 0.1806 & 0.0021 & 13750 & 95 & 0.1687 & 0.0016 & 14300 & 75 & 0.1559 & 0.0014 & 14950 & 70 \\
\hline 333 & 0.1718 & 0.0022 & 14150 & 100 & 0.1604 & 0.0011 & 14700 & 55 & 0.1526 & 0.0016 & 15100 & 80 \\
\hline 354.5 & 0.1682 & 0.0023 & 14300 & 110 & 0.1499 & 0.0012 & 15250 & 65 & 0.1404 & 0.0014 & 15750 & 80 \\
\hline 379 & 0.1571 & 0.0021 & 14850 & 110 & 0.1468 & 0.0016 & 15400 & 85 & 0.1372 & 0.0015 & 15950 & 85 \\
\hline 430.5 & 0.1422 & 0.0022 & 15650 & 130 & 0.1278 & 0.0016 & 16550 & 100 & 0.1221 & 0.0014 & 16900 & 90 \\
\hline 466 & 0.1280 & 0.0022 & 16500 & 140 & 0.1204 & 0.0015 & 17000 & 100 & 0.1145 & 0.0015 & 17400 & 100 \\
\hline 546.5 & 0.1137 & 0.0022 & 17450 & 160 & 0.1064 & 0.0012 & 18000 & 90 & 0.0996 & 0.0015 & 18550 & 120 \\
\hline 578.5 & 0.1006 & 0.0011 & 18450 & 90 & 0.0911 & 0.0013 & 19250 & 120 & 0.0831 & 0.0012 & 20000 & 120 \\
\hline 608 & 0.0894 & 0.0011 & 19400 & 100 & 0.0818 & 0.0013 & 20100 & 130 & 0.0767 & 0.0012 & 20650 & 130 \\
\hline 663.5 & 0.0629 & 0.0008 & 22200 & 100 & & & & & & & & \\
\hline 695.25 & 0.0394 & 0.0010 & 26000 & 210 & & & & & & & & \\
\hline 740.75 & 0.0243 & 0.0011 & 29900 & 350 & & & & & & & & \\
\hline
\end{tabular}

Note:

*: Bioturbated samples that are not included in the discussions (see supplementary text for details)

**: The only wood age reversal in the record. It is based on a small piece of wood, and from the early Holocene when significant bioturbation happened.

***: These two wood ${ }^{14} \mathrm{C}$ ages are the same within 1 sigma error, so we combine the data from the two samples together. 
Table 2.2. U. peregrina and $N$. dutertrei $\delta^{13} \mathrm{C}$ of GGC17/JPC30 presented in the order of calendar age. Composite depth scale is the depth scale of GGC17, with the original JPC30 depth added $30 \mathrm{~cm}$ (see Fig. 2.1e). Instrument precision of $\delta^{13} \mathrm{C}$ is $\sim 0.05 \%$.

\begin{tabular}{ccccc}
\hline $\begin{array}{c}\text { Composite depth } \\
(\mathrm{cm})\end{array}$ & $\begin{array}{c}\text { Cal age } \\
\text { (ka BP) }\end{array}$ & err $(1 \sigma)$ & U. peregrina $\delta^{13} \mathrm{C}$ & N. dutertrei $\delta^{13} \mathrm{C}$ \\
\hline 215 & 11.99 & 0.10 & 0.83 & -0.7 \\
222 & 12.45 & 0.10 & 0.95 & -0.72 \\
238 & 13.96 & 0.08 & 0.88 & -0.82 \\
239 & 14.23 & 0.19 & 0.87 & -0.93 \\
249 & 14.43 & 0.25 & 0.75 & -0.96 \\
271 & 15.19 & 0.08 & 0.74 & -0.97 \\
278.5 & 15.55 & 0.14 & 0.73 & -0.92 \\
306 & 15.93 & 0.13 & 0.63 & -0.92 \\
336 & 16.62 & 0.17 & 0.97 & -0.65 \\
363 & 17.22 & 0.16 & 1.09 & -0.81 \\
384.5 & 17.41 & 0.16 & 0.36 & -2.03 \\
409 & 18.07 & 0.14 & 1.1 & -0.88 \\
460.5 & 18.92 & 0.15 & 1.17 & -0.93 \\
496 & 19.91 & 0.18 & 1.24 & -0.83 \\
576.5 & 21.09 & 0.23 & 1.08 & -0.66 \\
608.5 & 22.31 & 0.12 & 1.33 & -0.86 \\
638 & 23.35 & 0.16 & 1.15 & -0.7 \\
\hline
\end{tabular}




\title{
Chapter 3. Strong mid-depth water production in the subpolar North Atlantic during the Younger Dryas
}

\begin{abstract}
The Younger Dryas (YD) cold event, the most well-known climate reversal during the last deglaciation, is commonly attributed to a disruption of the Atlantic Meridional Overturning Circulation by a freshwater forcing. However, the changes of deep water formation in the North Atlantic inferred from different studies are not consistent during the YD. In this chapter, a marine sediment core with high deposition rate and located close to deep water formation regions, which minimizes a range of uncertainties for ${ }^{14} \mathrm{C}$ ventilation age, is employed to reconstruct the middepth water formation strength. Compared to today, the mid-depth ventilation age was smaller during the YD. Combining evidence of surface warming, I argue that the strong intermediate water production was contributed by the extensive formation of seasonal sea ice and brine rejection on shallow shelf areas (especially the Grand Banks close to my study site). The extensive sea ice formation could potentially export salt into the deep ocean and keep the surface relatively fresh, which weakened the open ocean deep convection but produced a large volume of dense deep water annually. It is also shown that the mid-depth water production during the early Holocene and the Bølling-Allerød warm period was probably weaker than today, but not absent.
\end{abstract}




\subsection{Introduction}

The Younger Dryas (YD) is the most significant climate reversal in the Northern Hemisphere since the Last Glacial Maximum (LGM) (Stuiver and Grootes, 2000). It is generally attributed to a disruption of the Atlantic Meridional Overturning Circulation (AMOC) by a rapid input of freshwater to the high-latitude North Atlantic, although where the freshwater entered the ocean is under debate (e.g., Broecker et al., 1989; Tarasov and Peltier, 2005). Furthermore, the status of the overturning circulation around the YD is still poorly known. Some studies show that the AMOC shoaled to intermediate depths during the YD (e.g., Keigwin, 2004). Other studies suggest that even the intermediate circulation was weakened, indicating a more or less fully collapsed AMOC (e.g., Eltgroth et al., 2006; Weldeab et al., 2016).

${ }^{14} \mathrm{C}$ is a dynamic tracer used to study ocean ventilation strength in the past. After correction for isotopic fractionation (reported as $\Delta^{14} \mathrm{C}$ ), the influence of biological processes on ${ }^{14} \mathrm{C}$ in the ocean is very small (e.g., Fiadeiro, 1982), which a big advantage over other tracers. Reconstructions of ${ }^{14} \mathrm{C}$ ventilation age based on marine sediment cores are usually of low resolution due to limited sedimentation rate. For instance, the YD is normally only represented by a single point (e.g., Keigwin, 2004), so it is not easy to show the ventilation evolution around this interval in detail. There exist deep-sea coral-based ${ }^{14} \mathrm{C}$ records in the North Atlantic, but they are combinations of samples from different depths (e.g., Eltgroth et al., 2006) or different locations (e.g., Robinson et al., 2005), so the temporal evolution of the ventilation strength might be compromised by spatial heterogeneity. There are 
new deep-sea coral records from the Equatorial Atlantic that have better spatial consistency (Chen et al., 2015), but ${ }^{14} \mathrm{C}$ ventilation ages have larger uncertainty with greater distance from deep water formation regions (e.g., Franke et al., 2008). In addition, a long distance from the deep water production region makes it hard to diagnose deep water production strength as both the change of water mass mixing and the change of ventilation strength can influence the deep-sea ${ }^{14} \mathrm{C}$ activity (e.g., Skinner, 2009).

In this chapter, I use a high-sedimentation-rate core located in the subpolar North Atlantic to reconstruct the mid-depth ventilation strength in the North Atlantic around the YD.

\subsection{Material and Methods}

\subsubsection{Core Location}

The core used in this study (KNR197-10 GGC36) was taken aboard R/V Knorr in the summer of 2010. It is located at the Tail of the Grand Banks $\left(43^{\circ} 05.94^{\prime} \mathrm{N}, 49^{\circ} 02.00^{\prime} \mathrm{W}, 1520 \mathrm{~m}\right.$; Fig. 3.1), the "gate" through which the Deep Western Boundary Current system enters the subtropical North Atlantic. Therefore, the core location is ideal to recover the strength of mid-depth ventilation, regardless of the location of intermediate water formation in the subpolar or polar North Atlantic. GGC36 is taken near a station of the World Ocean Circulation Experiment (WOCE) array ACM-6 (Clarke et al., 1998). Hydrographic data show that the core site is bathed in the Labrador Sea Water today (Schott et al., 2004).

\subsubsection{Foraminiferal fauna}


Sediment samples from GGC36 were dried, weighed and washed over a $63 \mu \mathrm{m}$ sieve. Then the fraction larger than $63 \mu \mathrm{m}$ was weighed to determined the sand fraction in the dry sediment (i.e., the mass fraction of particles larger than $63 \mu \mathrm{m})$. Lithic grains larger than $250 \mu \mathrm{m}$ were counted as a proxy for the abundance of ice-rafted debris (IRD).

The percentage of cold water planktonic foraminifera (PF) species Neogloboquadrina pachyderma (sinistral, Nps) can be used to reconstruct sea surface temperature variability in the North Atlantic (e.g., Eynaud, 2011). Tests of planktonic foraminifera larger than $150 \mu \mathrm{m}$ are identified and counted to determine the percentage of Nps.

Since the abundance of benthic foraminifera (BF) is usually lower than PF, it is often impossible to do measurements that need a large amount of samples, e.g., radiocarbon analysis, with single species or genus of $\mathrm{BF}$. In order to locate layers with enough single taxa for radiocarbon measurements, we counted the most abundant species or genera of BF (Nonionellina, Elphidium, Cibicidoides (mostly C. lobatulus), Melonis and Globobulimina (mostly G. affinis). A bigger advantage of doing this is that we can choose to date BF at their abundance peaks so that the influence of bioturbation can be reduced (Broecker et al., 1984).

\subsubsection{Isotope analysis and chronology}

The age model of GGC36 is based on radiocarbon dating Nps. Studies have shown that the surface ${ }^{14} \mathrm{C}$ reservoir age in the subpolar North Atlantic increased by about 300 - 500 yrs during the YD compared to today (e.g., Bard et al., 1994; Stern and Lisiecki, 2013). Since the core site is located near the subpolar-subtropical 
boundary, I use a $\Delta \mathrm{R}$ of $200 \pm 200{ }^{14} \mathrm{C}$ yr for the calendar age calibration during the YD. For the Holocene and the Bølling-Allerød warm period (BA), I do not apply additional reservoir age correction (i.e., $\Delta \mathrm{R}=0$ ). Conventional ${ }^{14} \mathrm{C}$ age is converted to calendar age using Marine13 (Reimer et al., 2013).

For samples around the YD, PF-BF pairs are dated to reconstruct the ${ }^{14} \mathrm{C}$ age difference between the surface and intermediate depths, preferably at benthic abundance peaks. A single BF taxon is dated wherever its abundance is high enough, which is not common. Otherwise, mixed BF tests are dated. There are several radiocarbon dates from periods with relatively constant $\mathrm{BF}$ abundance, but no measurements are done in the abundance valleys where there is a higher chance of bioturbation influence. Radiocarbon analysis was done at the National Ocean Sciences Accelerator Mass Spectrometer Facility (NOSAMS).

Clean large specimens of Cibicidoides lobatulus were picked for the analysis of oxygen isotope composition $\left(\delta^{18} 0\right)$. The measurements were made on a VG Prism instrument at NOSAMS. Instrument precision is about $0.05 \%$.

\subsection{Results}

Conventional radiocarbon ages are presented in Table 3.1. Except for the age reversal at 191-192 cm, all planktonic radiocarbon ages increase with depth in core. The age-depth relationship and sedimentation rate are shown in Fig. 3.2. The sedimentation rate of GGC36 was very high during the BA, with a mean of $\sim 250$ $\mathrm{cm} / \mathrm{kyr}$. It decreased significantly during the YD, although the mean rate $(\sim 40$ $\mathrm{cm} / \mathrm{kyr}$ ) still enables us to get a high-resolution record without large influence of bioturbation. The deposition rate increased again during the early Holocene to 
higher than $50 \mathrm{~cm} / \mathrm{kyr}$ on average. After $\sim 8 \mathrm{ka} \mathrm{BP}$, the sedimentation rate dropped almost 10 -fold to an average value of $\sim 6 \mathrm{~cm} / \mathrm{kyr}$ until the core top (0.5 ka BP).

The percentage of Nps reached a distinct minimum early in the YD (Fig. 3.3). There were some variations of \%Nps during the BA, but most of the values stayed around $90 \%$, close to the core top value of $91 \%$ (Fig. 3.3). \%Nps declined across the BA-YD transition to $\sim 30 \%$, which could have been more abrupt than appears due to potential mixing effect of bioturbation. \%Nps started to increase after $\sim 12.2 \mathrm{ka}$, and reached a level between $60-70 \%$ during the late YD. It decreased again across the YD-Holocene transition to a level comparable to the core top.

$\mathrm{BF}$ abundance was generally much higher during the YD than other intervals and stayed very low after $\sim 11$ ka BP (Fig 4). Since the sedimentation rate was also very low after $\sim 8 \mathrm{ka}$, we do not intend to reconstruct the ventilation age during that interval, due to potential large impact of bioturbation. Although B-P ventilation age varied within each climatic interval, it was clearly smaller during the YD $\left(67 \pm 44{ }^{14} \mathrm{C}\right.$ $\mathrm{yr}, \mathrm{n}=3)$ than the BA $\left(340 \pm 53{ }^{14} \mathrm{C} \mathrm{yr}, \mathrm{n}=5\right)$ and the early Holocene $\left(426 \pm 77{ }^{14} \mathrm{C} \mathrm{yr}\right.$, $\mathrm{n}=5$ ) (Fig. 3.3). For reference, the pre-industrial ${ }^{14} \mathrm{C}$ age difference between the surface and the core depth near my study site is $\sim 200 \mathrm{yr}$ (GLODAP, Key et al., 2004).

$\delta^{18} \mathrm{O}$ of $C$. lobatulus oscillated between $\sim 2.9-3.6 \%$ during the BA (Fig. 3.3). After that, there was a decrease of $\sim 0.5 \%$ at the onset of the YD. $\delta^{18} \mathrm{O}$ of $C$. lobatulus stayed lower than $3.0 \%$ and migrated towards $\sim 2.5 \%$ o during the YD. In the early Holocene, the value fluctuated around $2.5 \%$, which is close to the core-top value $(2.6 \%)$. 
The abundance of BF, PF, Nps, IRD and sand fraction all have elevated values between $\sim 12.1$ and 12.8 ka (Fig. 3.5). The coincidence of this plateau with the decrease of sedimentation rate (as defined by two dates at $\sim 12.25$ and $\sim 12.75 \mathrm{ka}$, Fig. 3.2) indicates that it was at least partially created by a reduced input of clay and silt.

\subsection{Discussion}

3.4.1 Surface warming during the Younger Dryas

Bioturbation could lead to a net effect that foraminiferal tests are moved from the layers of high abundance to the adjacent low abundance layers. However, the elevated abundance of both Nps and other PF species during the YD suggests that the decrease of \%Nps was not an artifact of bioturbation (Fig. 3.5).

The species that most drove down the YD \%Nps is Globigerina bulloides, a common species in warmer waters in the North Atlantic. Some studies have shown that the depth habitat of Nps varies from place to place and they may migrate vertically through time, which is likely associated with limiting salinity or temperature (Kozdon et al., 2009; Simstich et al., 2003). As for G. bulloides, it is widely accepted that in the North Atlantic they live near the surface (e.g., HillaireMarcel et al., 2001; Jonkers et al., 2013) and bloom in the summer (Jonkers et al., 2013). Therefore, a \%Nps decrease driven mostly by G. bulloides production suggests that the temperature near sea surface probably increased during the summer.

During the YD, summer insolation in the high-latitude Northern Hemisphere was high, and the cooling was mainly a winter phenomenon (e.g., Buizert et al., 2014; 
Denton et al., 2005). Much colder winters than today led to extensive sea ice formation in the North Atlantic during the YD, as shown by many records including some near the site in this study (Gil et al., 2015; Pearce et al., 2013). Extensive sea ice formation would tend to reduce the heat loss of the upper ocean to the atmosphere in winter, therefore making the subsurface water warmer. This effect was probably more significant near the polar front where salty subtropical water could subduct beneath fresh subpolar water (e.g., Dokken et al., 2013), just like the Tail of the Grand Banks in this study. Summer melting of the sea ice would have produced a freshwater lid at the surface of the ocean, leading to a shallow mixed layer and strong stratification. This process would isolate the subsurface water, which is warmer than today due to less heat loss in winter, from the mixed layer, and warm the mixed layer as well because of the stronger stratification and higher insolation. Therefore during the YD, both the surface and subsurface were likely warmer than today in the summer near the polar front where warm subtropical water could subduct beneath the sea ice and seasonal sea ice formation and melting occurred.

\subsubsection{North Atlantic intermediate water production around the Younger Dryas}

Uncertainty of ${ }^{14} \mathrm{C}$ ventilation ages could originate from multiple factors, e.g., the unknown source region of deep water and corresponding surface reservoir age, mixing processes in the ocean, and variation of the atmospheric $\Delta^{14} \mathrm{C}$ (Franke et al., 2008). As mentioned above, the uncertainty is smaller as the location of the record gets closer to the water formation regions (Franke et al., 2008), so the site in this 
study is ideal in reconstructing the mid-depth ventilation strength of the North Atlantic.

Modeling results suggest that B-P ventilation age is less influenced by the atmospheric $\Delta^{14} \mathrm{C}$ variation than the projection ventilation age (Adkins and Boyle, 1997) in the North Atlantic (Franke et al., 2008). In addition, within the interval where we have data $(\sim 14-8 \mathrm{ka})$, the most significant change of atmospheric $\Delta^{14} \mathrm{C}$ is a trend reversal at $\sim 12.5 \mathrm{ka}$ (from increasing to decreasing, Reimer et al., 2013). If the influence is large enough, we would expect to see a drop of ventilation age from 14-12.5 ka to $\sim 12.5-8 \mathrm{ka}$ assuming no other changes, which is clearly not the observed pattern that is associated with climate shifts across the YD (Fig. 3.3). As for the surface ${ }^{14} \mathrm{C}$ reservoir age, studies have shown that it increased in the subpolar North Atlantic during the YD (e.g., Bard et al., 1994; Stern and Lisiecki, 2013). However, it is not possible that the change of B-P ventilation age during the YD is caused by the surface reservoir age increase in the high-latitude North Atlantic, because a larger amplitude of surface reservoir age increase at higher latitudes than the Tail of the Grand Banks would increase the B-P age in this study rather than decrease it. Therefore, the change of ventilation age during the YD is most likely caused by a change in the intermediate water production.

It has been proposed that the intermediate water production in the Labrador Sea resumed around 7ka (Hillaire-Marcel et al., 2001). Low sedimentation rate and BF abundance after $\sim 8 \mathrm{ka}$ in this study (Figs. 3.2 and 3.4) prevent us to test that. However, the B-P ventilation ages we get suggest that the mid-depth ventilation in the early Holocene and the BA was weaker and likely more intermittent than today 
(cf. the high-frequency fluctuation of $\mathrm{BF} \delta^{18} \mathrm{O}$, Fig. 3.3), but they do not support a complete absence of intermediate water production (Fig. 3.3). Melting of the Laurentide Ice Sheet was significant during the BA and the early Holocene before 7ka (Dyke, 2004), which probably inhibited the open ocean convection in the Labrador Sea. However, convection in other regions (e.g., in the Irminger Sea, Pickart et al., 2003) might contribute to the moderate intermediate water production we observe.

Deep water production happens in mainly two forms: open ocean deep convection (e.g., today in Nordic Seas, Marshall and Schott, 1999) and brine rejection (e.g., today in Weddell Sea, Ivanov et al., 2004). Studies have shown that brine reached intermediate depth in the Nordic Seas during the YD (e.g., Dokken and Jansen, 1999; Meland et al., 2008), likely with some open ocean deep convection also occurring (Meland et al., 2008). An explanation compatible with both a decrease of ventilation age and an increase of near surface temperature during the YD would be that deep water formation through sea ice production and brine rejection also happened close to my study site, which is supported by the small B-P value of $0-50 \mathrm{yr}$ (Fig. 3.3). Potential brine production regions are shelf areas covered by seasonal sea ice and shallower than $\sim 200$ m (Meland et al., 2008). Because most area of the Grand Banks was less than $~ 200 \mathrm{~m}$ below the YD sea level ( $\sim 60 \mathrm{~m}$ below today, Bard et al., 2010; Fig. 3.1), the large area potentially makes it a very important brine factory during this interval. The lowering of the benthic $\delta^{18} \mathrm{O}$ during the YD also supports the idea of brine formation (Fig. 3.3; also see Waelbroeck et al., 2011). Therefore, the most plausible scenario was that extensive 
sea ice formed in the winter over the Grand Banks (and also the shelf along the southwestern Labrador Sea as it was already deglaciated by the YD (Dyke, 2004), Fig. 3.1), which ejected salt, produced dense water that sank to the deep ocean and reduced the heat loss from the surface ocean to the atmosphere, and that sea ice melting led to surface stratification and warming in the summer (Section 3.4.1).

Very old mid-depth ventilation ages have been reported from South of Iceland during the YD and late $\mathrm{BA}$, which was attributed to the incursion of the Antarctic Intermediate Water due to weakened intermediate water production in the North Atlantic (Thornalley et al., 2011a). The absence of such old mid-depth ${ }^{14} \mathrm{C}$ ages in this study from the southern subpolar North Atlantic suggests that AAIW was not likely to be the reason. Later studies propose other explanations for the old ages, e.g., a northern source of old water from the Nordic Seas (Thornalley et al., 2015), or the influence of hydrothermal fluid (Lund and Asimow, 2011). My results suggest that the influence of the old water was probably spatially limited regardless of its source. This further suggests that during the YD and BA, the mid-depth ventilation in the subpolar North Atlantic was probably strong enough that the old water was effectively diluted when exported to the subtropical North Atlantic.

\subsubsection{Duration of the Younger Dryas}

Although a rapid release of rerouted freshwater into the North Atlantic is thought to have triggered the YD cold episode, modeling its influence on the surface salinity of the high-latitude North Atlantic shows that it may have faded away after 10-20 yrs regardless of where the freshwater entered the ocean (Condron and Winsor, 2012). Despite that there was probably continuous baseline flow along the 
new route after the rapid discharge (Teller et al., 2002), its influence on the salinity of the deep water production zones would not be as significant. In addition, freshwater input into the ocean via periglacial melting was probably smaller during the YD than the early Holocene and BA, as shown by both the lower sedimentation rate in this study (mainly reduced fine grain input; Figs. 3.2 and 3.5) and the slower sea level rise during this interval (Bard et al., 2010). Therefore, meltwater from the ice sheets was not likely to keep the surface salinity of the subpolar North Atlantic low through the YD.

Salt rejection and brine export into the deep ocean associated with sea ice formation is another way to keep the surface ocean relatively fresh. The larger seasonal contrast during the YD (much colder winter and slightly colder summer than today, Buizert et al., 2014) would favor annual formation of extensive sea ice. That could keep the surface of the subpolar North Atlantic relatively fresh so that open ocean deep convection was weakened, but still continuously produce a large amount of deep water during the YD (at least to intermediate depths).

Some studies have shown that the YD has two phases, with an initial cold phase followed by a second phase of climate amelioration (e.g., Bakke et al., 2009; Cabedo-Sanz et al., 2013; Gil et al., 2015; Lane et al., 2013). Lane et al. (2013) showed that this amelioration was abrupt at each location but time-transgressive latitudinally, suggesting that the polar front gradually retreated northward during the late YD. My results possibly also suggest a two-phase YD, with the second phase represented by less extensive sea ice formation, which led to more heat loss of the subsurface water (higher \%Nps). Changes of other features around $\sim 12.2 \mathrm{ka}$, e.g., 
sedimentation rate (Figs. 3.2 and 3.5) and benthic faunal composition (Fig. 3.4), might also suggest some climatic shifts, although the meaning is obscure.

The retreat of the polar front and the declined seasonal sea-ice formation would reduce the salt export into the deep ocean and also bring more salty water northward. After some salinity threshold was passed in the Nordic Seas, the open ocean deep convection like today could be reinvigorated and that would draw warm salty water from the subtropics northward more efficiently. This positive feedback would help the sea ice and polar front retreat quickly at the YD-Holocene transition, as possibly shown by the temperature near the surface rapidly returning to the modern state (Fig. 3.3). This mechanism is consistent with the idea that sea-ice is pivotal in explaining the rapid shift of Greenland ice core $\delta^{18} 0$ at the end of the YD (Dansgaard et al., 1989).

\subsection{Summary}

With the hope to minimize the influence of multiple factors (e.g., bioturbation, mixture of waters with different ${ }^{14} \mathrm{C}$ ages) in deep-ocean ${ }^{14} \mathrm{C}$ ventilation age reconstructions, a sediment core with high deposition rate and located in the subpolar western North Atlantic is studied in this chapter. The results show that the mid-depth ventilation in the western North Atlantic during the B-A warm period and the early Holocene was probably not as strong as today, but also not completely absent. During the YD, the intermediate water production was significantly stronger, probably as a result of extensive sea ice formation and brine production in the subpolar shallow shelf areas, especially the Grand Banks. Extensive sea ice could reduce the heat loss from the subsurface ocean to the atmosphere in winter, and 
melting of the sea ice could lead to summer stratification and surface warming, which are consistent with an observation of warming near the surface during the YD in this study. The process of brine rejection would have exported salt into the deep ocean and thus kept the surface relatively fresh in the subpolar North Atlantic. It is proposed here as a key mechanism to explain paleoceanographic observations for the YD. Reinvigorated open ocean deep convection and rapid sea ice retreat could act as a positive feedback to terminate the YD. 


\section{Tables}

Table $3.1{ }^{14} \mathrm{C}$ dates of planktonic and benthic foraminifera in KNR197-10 GGC36

\begin{tabular}{|c|c|c|c|}
\hline Interval (cm) & Species & ${ }^{14} \mathrm{C}$ age $(\mathrm{yr})$ & ${ }^{14} \mathrm{C}$ age error $(\mathrm{yr})$ \\
\hline $0-1$ & N. pachyderma (s.) & 890 & 15 \\
\hline $50.5-52.5$ & N. pachyderma (s.) & 7970 & 30 \\
\hline $50.5-52.5$ & mixed benthics & 8590 & 30 \\
\hline $99-100$ & N. pachyderma (s.) & 8870 & 40 \\
\hline $99-100$ & mixed benthics & 9110 & 35 \\
\hline $150-152$ & N. pachyderma (s.) & 9420 & 40 \\
\hline $150-152$ & mixed benthics & 9940 & 40 \\
\hline $175-176$ & N. pachyderma (s.) & 9600 & 40 \\
\hline $175-176$ & mixed benthics & 10100 & 35 \\
\hline $191-192 *$ & N. pachyderma (s.) & $9440 *$ & 45 \\
\hline 191-192 & mixed benthics & 10250 & 35 \\
\hline $215-216$ & N. pachyderma (s.) & 10400 & 45 \\
\hline $215-216$ & Nonionellina & 10650 & 35 \\
\hline $239-240$ & N. pachyderma (s.) & 10650 & 35 \\
\hline $239-240$ & mixed benthics & 10800 & 35 \\
\hline $255-256$ & N. pachyderma (s.) & 10900 & 35 \\
\hline $255-256$ & Nonionellina & 10900 & 35 \\
\hline $277-278$ & N. pachyderma (s.) & 11100 & 45 \\
\hline $283-284$ & N. pachyderma (s.) & 11450 & 45 \\
\hline $283-284$ & Elphidium & 11500 & 50 \\
\hline $307-308$ & N. pachyderma (s.) & 11650 & 40 \\
\hline $307-308$ & mixed benthics & 12050 & 50 \\
\hline $323-324$ & N. pachyderma (s.) & 11800 & 40 \\
\hline $323-324$ & mixed benthics & 12050 & 40 \\
\hline $347-348$ & N. pachyderma (s.) & 11900 & 35 \\
\hline $347-348$ & mixed benthics & 12250 & 40 \\
\hline $367-368$ & N. pachyderma (s.) & 12050 & 40 \\
\hline $367-368$ & mixed benthics & 12550 & 55 \\
\hline $391-392$ & N. pachyderma (s.) & 12200 & 40 \\
\hline 391-392 & mixed benthics & 12400 & 55 \\
\hline $547-548$ & N. pachyderma (s.) & 12600 & 60 \\
\hline
\end{tabular}

*: planktonic age reversal, not included in the age model 


\section{Figures}

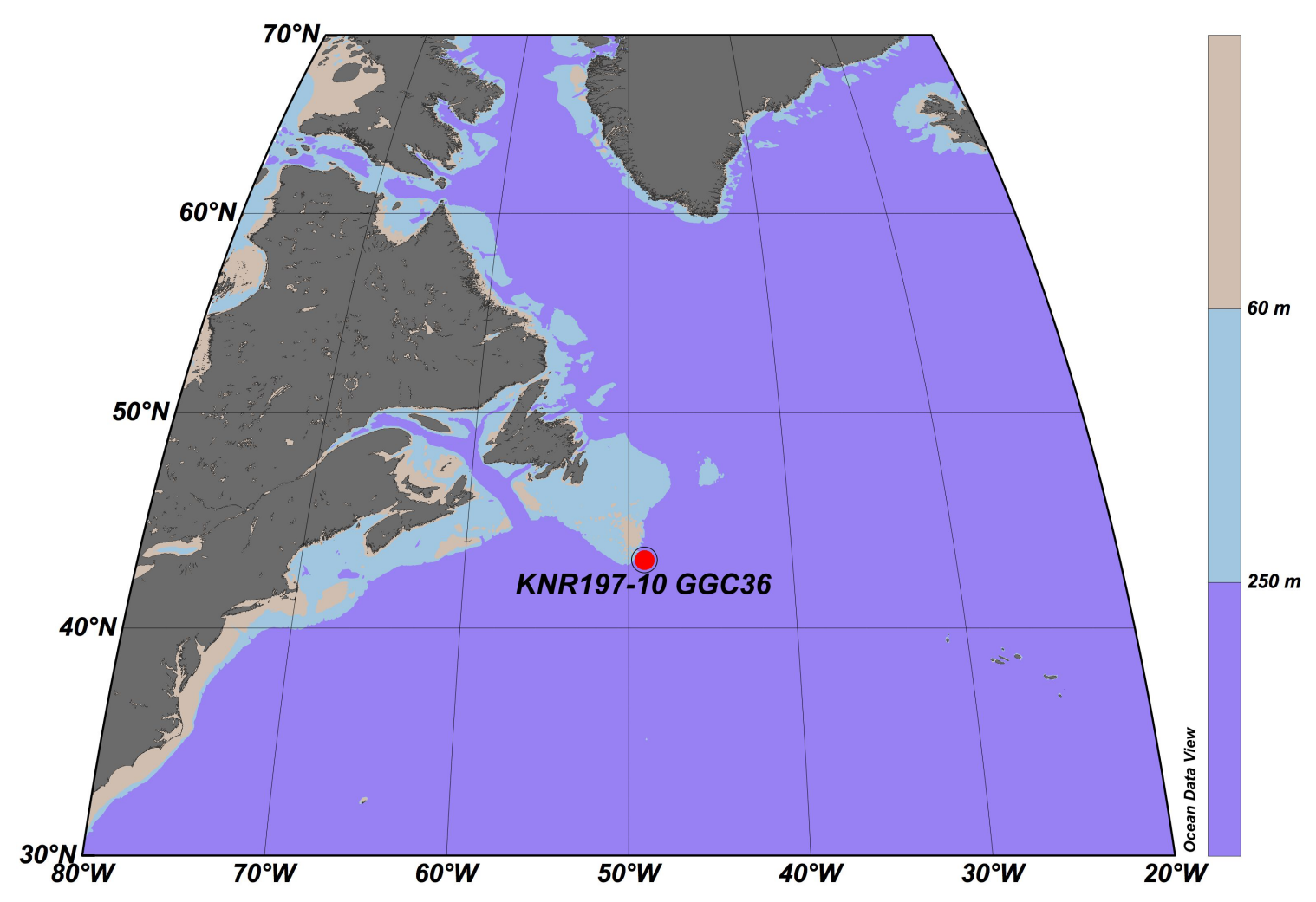

Fig. 3.1. Location of KNR197-10 GGC36 (43ํำ $\left.94^{\prime} \mathrm{N}, 4^{\circ} 02.00^{\prime} \mathrm{W}, 1520 \mathrm{~m}\right)$. Isobaths of $60 \mathrm{~m}$ and $250 \mathrm{~m}$ are shown to denote the areas that are suitable for brine production during the YD (see text). Mollweide projection is used to make an equalarea map. 


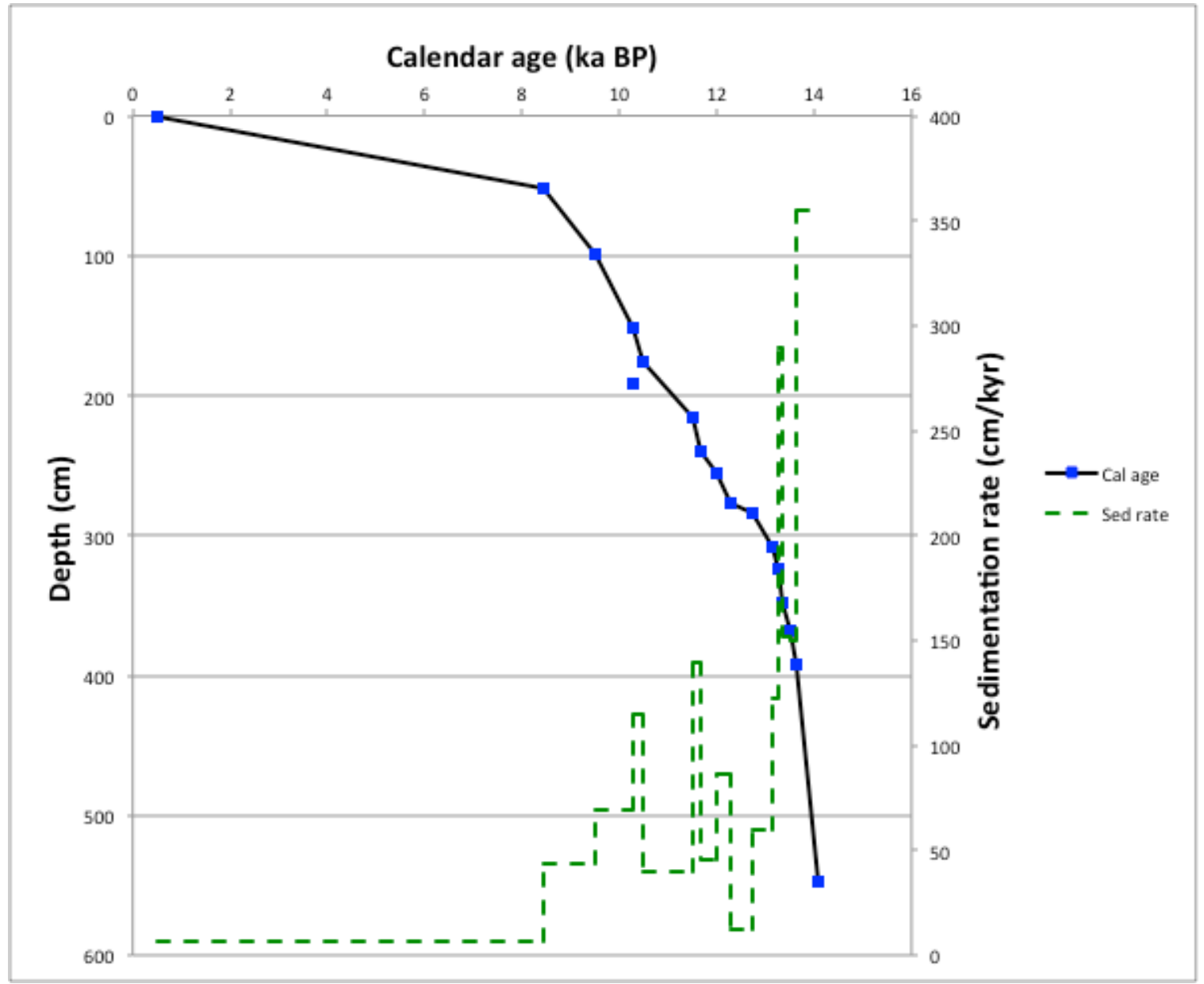

Fig. 3.2. Age-depth model and sedimentation rate of KNR197-10 GGC36. 


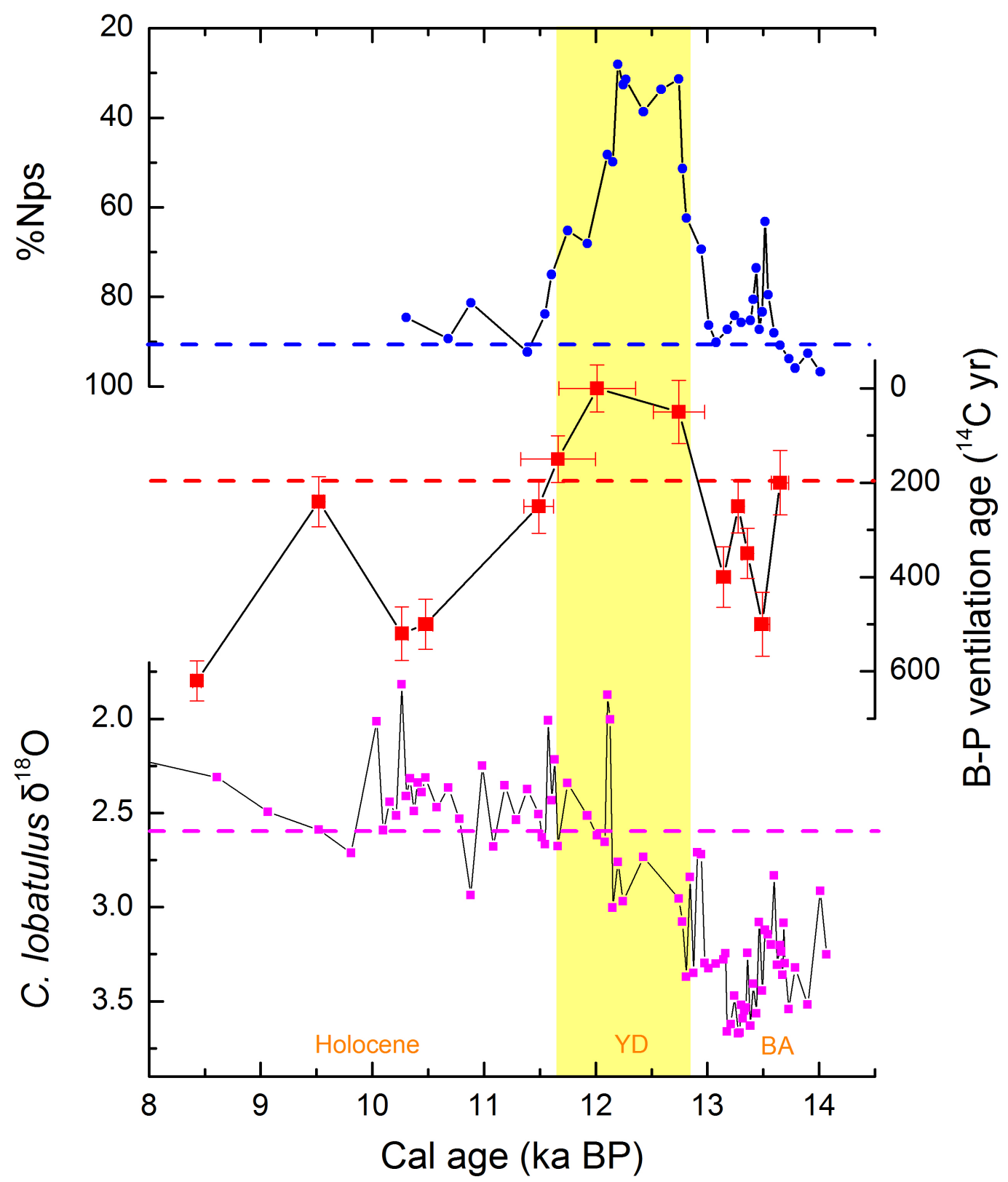

Fig. 3.3. Percentage of Nps in PF, BF minus PF (B-P) ventilation age and $\delta^{18} \mathrm{O}$ of $C$. lobatulus from KNR197-10 GGC36. Dashed lines are core top values for \%Nps and $C$. lobatulus $\delta^{18} \mathrm{O}$, and modern surface-intermediate depth ${ }^{14} \mathrm{C}$ age difference at the study site estimated from GLODAP data $\left(\Delta^{14} C_{\text {natural, }}\right.$, Key et al., 2004), respectively. 


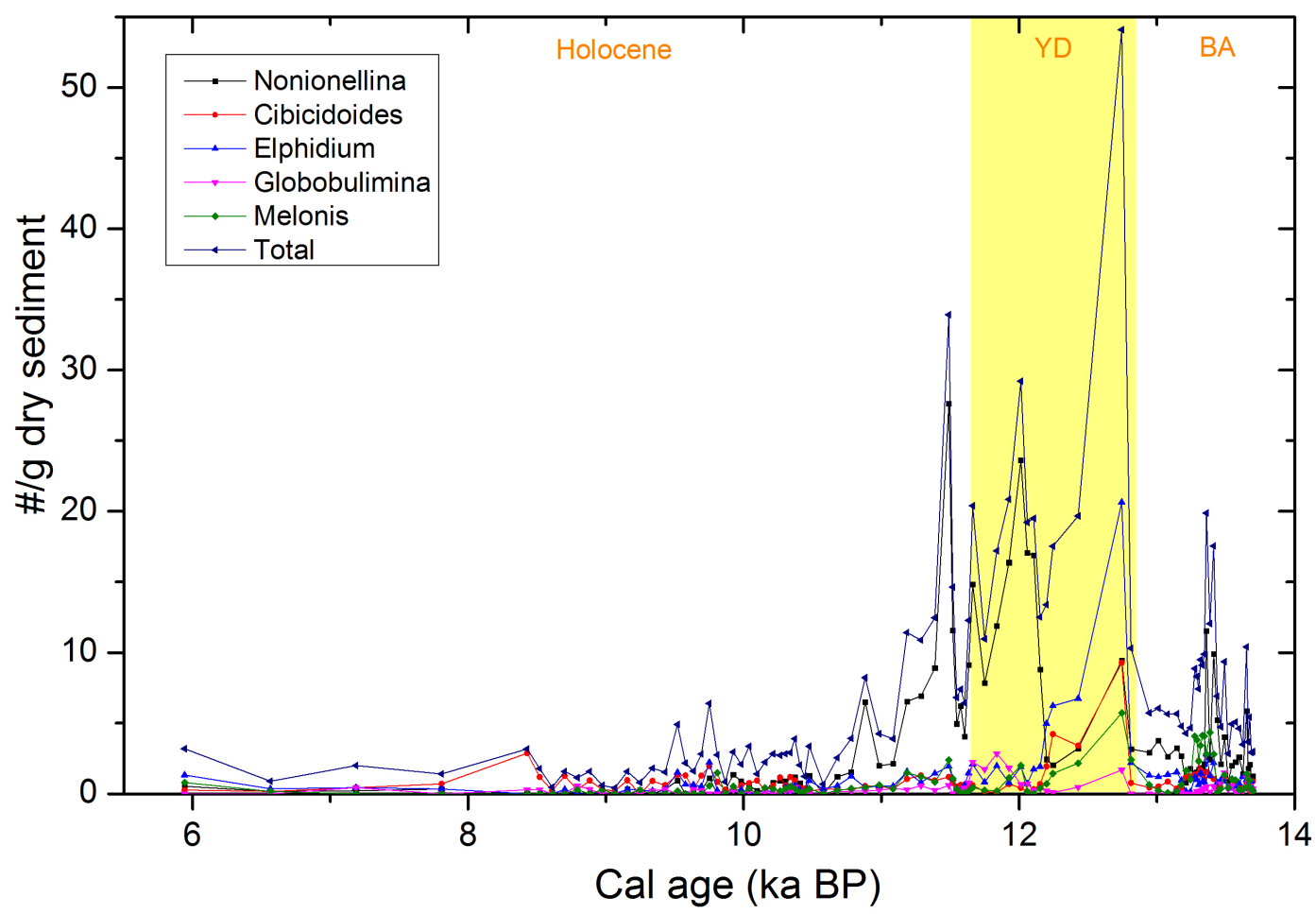

Fig. 3.4. Number of BF tests per gram of dry sediments for different genera and the whole fauna. 


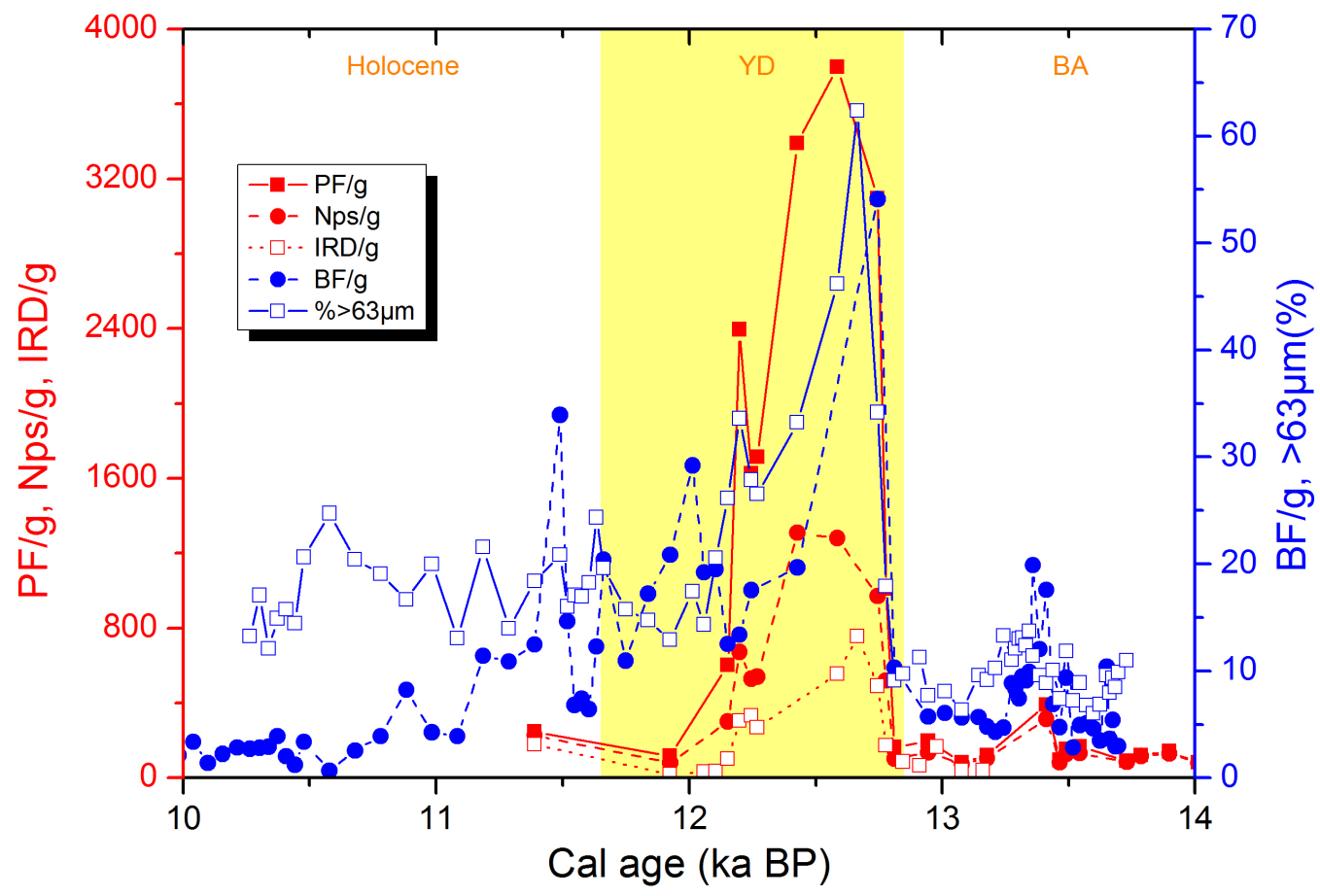

Fig. 3.5. The abundance of PF, Nps, IRD (left axis), BF and sand mass fraction (right axis) in the dry sediments of KNR197-10 GGC36. 


\title{
Chapter 4. A synthesis of deglacial deep-sea radiocarbon records and a test of their consistency with modern ocean circulation
}

\begin{abstract}
In this chapter, I present a synthesis of published and new deep water radiocarbon data based mainly on measurements on fossil benthic foraminifera and deep-sea corals collected from several oceanic basins at water depths between 300 and $5000 \mathrm{~m}$ and spanning the past 40 kyrs. The compilation includes more than
\end{abstract} $1000{ }^{14} \mathrm{C}$ age estimates obtained mostly over the past two decades and computed (for ${ }^{14} \mathrm{C}$-dated records) from the same calibration to atmospheric radiocarbon (IntCal13). The most notable feature in the compilation is a long-term $\Delta^{14} \mathrm{C}$ decline in deep oceanic basins over about the past 25 kyrs. The $\Delta^{14} \mathrm{C}$ decline mirrors the drop in reconstructed atmospheric $\Delta^{14} \mathrm{C}$, suggesting that it may reflect a decrease in the global ${ }^{14} \mathrm{C}$ inventory rather than a redistribution of ${ }^{14} \mathrm{C}$ among different reservoirs. Motivated by this observation, I test the null hypothesis ( $\mathrm{H} 0)$ that the deep water $\Delta^{14} \mathrm{C}$ data jointly do not require changes in basin-scale circulation during the last deglaciation, given the data uncertainties. The test relies on a least-squares fit of a 16-box model of modern ocean ventilation to the deep water $\Delta^{14} \mathrm{C}$ records. I find that the residuals of the fit can be explained by data uncertainties, which largely arise from the large-scale representativeness of site-specific data. Some of the surface water $\Delta^{14} \mathrm{C}$ values implied by the fit are either significantly larger than the contemporaneous atmospheric $\Delta^{14} \mathrm{C}$ or significantly lower than the contemporaneous deep water $\Delta^{14} \mathrm{C}$, which tends to invalidate $\mathrm{H} 0$. However, such values are rare $(\leq 5 \%)$ and not robust against assumptions in the analysis. Although 
studies have suggested, generally on the basis of single records, that ocean circulation has changed in various regions, I show that the compiled $\Delta^{14} \mathrm{C}$ data jointly do not provide strong evidence for basin-scale changes in deep ocean ventilation during the last deglacial period, given the data uncertainties and the model used. Subject to the caveat that the ocean reservoir has not been properly sampled, a global imbalance between cosmogenic production and radioactive decay appears as the most natural explanation for the long-term decline in ${ }^{14} \mathrm{C}$ activity that is observed both in the ocean and in the atmosphere over the past 25 kyrs.

\subsection{Introduction}

Variations in the exchange of $\mathrm{CO}_{2}$ between the ocean and the atmosphere have long been postulated to have contributed to the pre-industrial changes in the concentration of atmospheric $\mathrm{CO}_{2}$ documented in Antarctic ice core records (e.g., Knox and McElroy, 1984; Sarmiento and Toggweiler, 1984; Siegenthaler and Wenk, 1984). Among the processes that could modify air-sea $\mathrm{CO}_{2}$ fluxes on centennial and longer time scales resolved by these records are changes in ocean circulation, particularly in the transport between surface and deep waters. These changes could reduce or increase the temperature, salinity, dissolved inorganic carbon, and alkalinity of surface waters, thereby altering surface water $\mathrm{CO}_{2}$ partial pressure and air-sea $\mathrm{CO}_{2}$ flux (Sarmiento and Gruber, 2006). In particular, the Southern Ocean, where transport of deep waters to the surface would be favored by upwelling along density surfaces, has been suggested to be an important region for understanding past changes in atmospheric $\mathrm{CO}_{2}$ concentration (for recent reviews, see Fischer et 
al., 2010; Sigman et al., 2010) and also climate (Marshall and Speer, 2012). Indeed, circulation changes in the Southern Ocean have been postulated from a variety of paleoclimatic indicators (e.g., Anderson et al., 2009; Jaccard et al., 2016; Schmitt et al., 2012; Skinner et al., 2010).

In palaeoceanography, quantitative information about the exchange between surface and deep waters is often deduced from the "age" of deep waters relative to that of the surface waters or the atmosphere (for recent studies see, e.g., Burke and Robinson, 2012; Chen et al., 2015; Keigwin and Lehman, 2015; Rae et al., 2014; Skinner et al., 2015). The age of deep ocean waters over the past 40 kyrs or so is typically estimated from measurements of the radiocarbon (half-life of 5,700 $\pm 30 \mathrm{yr}$; Audi et al., 2003) activity of fossil samples of benthic foraminifera and deepdwelling corals. Many studies relied on such measurements to draw inferences about deep ocean "ventilation" during the last deglaciation, a period during which the atmospheric $\mathrm{CO}_{2}$ concentration is estimated to have increased by about $80 \mathrm{ppmv}$ (e.g., Monnin et al., 2001). Notably, Marchitto et al. (2007) and Bryan et al. (2010) suggested that Antarctic Intermediate Water (AAIW) was significantly older than today during the Heinrich Stadial 1 (HS1, ca. 17.6-14.7kyr B.P.) and the Younger Dryas (YD, ca.12.9-11.7kyr B.P.) using sediment cores from the Eastern North Pacific and the Northern Indian Ocean, respectively. Both studies argued that the presence of low ${ }^{14} \mathrm{C}$ concentration in AAIW during these two intervals was due to increased ventilation of Southern Ocean deep waters that would have released carbon accumulated at abyssal depths during the last glacial period into the overlying AAIW and the atmosphere. 
These results, however, have not gone unchallenged. Samples from the Eastern South Pacific (De Pol-Holz et al., 2010) and Western South Pacific (Rose et al., 2010) do not support an aging of AAIW during the HS1 and the YD. Moreover, there is debate over whether an isolated, deep ocean reservoir existed during the Last Glacial Maximum (LGM). a time interval centered at ca. 21 kyr B.P. On the one hand, samples from several ocean basins suggest the presence of relatively old deep waters during the LGM, e.g., in the East Equatorial Pacific (Keigwin and Lehman, 2015), the Western North Atlantic (Robinson et al., 2005), and the Atlantic sector of the Southern Ocean (Skinner et al., 2010). On the other hand, some studies concluded that the ages of deep ocean waters during the LGM were not substantially different from today (e.g., Broecker et al., 2004; Broecker and Clark, 2010; Lund et al., 2011). In the same vein, model calculations tend to challenge the notion that exchange with an isolated deep ocean reservoir produced the ${ }^{14} \mathrm{C}$ activity drop observed at intermediate depths during the last deglaciation (e.g., Hain et al., 2011).

Many factors can influence a particular deep ocean radiocarbon record in addition to basin-scale changes in bottom water age. For instance, estimating the initial radiocarbon concentration (usually expressed as $\Delta^{14} \mathrm{C}$, the ${ }^{14} \mathrm{C} /{ }^{12} \mathrm{C}$ ratio compared to the preindustrial atmospheric value after correction for isotopic fractionation effects) of a fossil sample of benthic foraminifera or deep-sea coral requires accurate knowledge about the calendar age of the sample. The calendar ages of such samples, however, can suffer from various uncertainties due, e.g., to the movement post mortem of foraminiferal shells along the sedimentary column (bioturbation), changes in the difference in ${ }^{14} \mathrm{C}$ ages between the ocean surface 
waters and the atmosphere (reservoir age changes), and gains or losses of radioactive parents or daughters in corals (open-system behaviour; e.g., Robinson et al., 2006). Each of these sources of uncertainty can lead to a sizeable error in the reconstructed value of bottom water $\Delta^{14} \mathrm{C}$. In general, the errors in calendar chronology and hence in bottom water $\Delta^{14} \mathrm{C}$ tend to be larger for older samples.

Other factors compound the interpretation of deep-sea radiocarbon records in terms of bottom water age. For example, changes in the radiocarbon age of ocean bottom water may not necessarily reflect changes in the true age of the water, since the radiocarbon concentration of waters entering the deep sea may vary with time (e.g., Wunsch, 2003). Mixing between different water masses is also likely to bias age estimates deduced from radiocarbon ages, as radiocarbon concentration is a nonlinear function of radiocarbon age. Finally, inferences made from single records, which constitute the majority of the literature on the subject, often assume that changes observed in the record are representative of a large oceanic region. However, single records may not represent basin-scale changes of bottom water age in a straightforward manner, especially if they originate from a region characterized by large gradients in radiocarbon concentration. The above considerations suggest that an analysis of multiple records that gives due consideration to errors is needed for a rigorous interpretation of deep ocean radiocarbon data in terms of palaeoceanographic events.

In this chapter, I report a compilation of deep water $\Delta^{14} \mathrm{C}$ estimates for the last 40 kyrs and examine the compiled data in the presence of a simple (box) model of modern ocean ventilation. Specifically, I test the null hypothesis (H0) that 
deglacial radiocarbon records from different oceanic basins jointly do not require changes in basin-scale ventilation during this period, given their significant errors and their scarcity (by modern standards). The null hypothesis $\mathrm{HO}$ is tested from a least-squares fit of the model to deep water $\Delta^{14} \mathrm{C}$ records. It will be rejected if the residuals of the fit (the differences between the observed and fitted values of deep water $\Delta^{14} \mathrm{C}$ ) are larger than the uncertainties and (or) if the inferred surface water ${ }^{14} \mathrm{C}$ lies outside of upper or lower bounds. The upper bound is provided by the reconstruction of atmospheric $\Delta^{14} \mathrm{C}$ (Reimer et al., 2013): since ${ }^{14} \mathrm{C}$, a cosmogenic radionuclide, is produced in the atmosphere, ${ }^{14} \mathrm{C}$ in surface water is expected to be always smaller than atmospheric $\Delta^{14} \mathrm{C}$, although pathological cases where surface ocean $\Delta^{14} \mathrm{C}$ is higher than atmospheric $\Delta^{14} \mathrm{C}$ could be constructed. As a result, inference of surface water $\Delta^{14} \mathrm{C}$ values larger than the contemporaneous atmospheric $\Delta^{14} \mathrm{C}$ would question the plausibility of $\mathrm{H} 0$. The lower bound is provided by the $\Delta^{14} \mathrm{C}$ values that are found in the deep ocean. Although factors such as a larger sea ice extent could increase the surface reservoir ages in high-latitude regions where deep waters are formed (e.g., Bard, 1988), and hence decrease $\Delta^{14} \mathrm{C}$ values in deep waters, the lowest $\Delta^{14} \mathrm{C}$ values in the ocean are expected to lie at depths rather than near the surface. As a result, inference of surface $\Delta^{14} \mathrm{C}$ values lower than the contemporaneous deep $\Delta^{14} \mathrm{C}$ values would also tend to invalidate $\mathrm{H} 0$.

This chapter is organized as follows. In section 4.2, I describe (i) my compilation of published and new deep water radiocarbon data, (ii) the treatment of these data for the present analysis, (iii) the box model of modern ocean ventilation, and (iv) the inverse method used to quantitatively combine the data with the model. 
The results of the analysis are presented in section 4.3. In section 4.4, I discuss the factors that can influence the ability of my approach to test H0. I summarize the results and clarify their palaeoceanographic implications in section 4.5. Finally, possible perspectives of research are mentioned in section 4.6.

It is worth being explicit about the limitations of this study. One obvious limitation arises from the spatial distribution and scarcity (by modern standards) of deep water $\Delta^{14} \mathrm{C}$ data. The spatial distribution and scarcity of the data may bias inferences of past ocean conditions, although an effort is made to account for the resulting uncertainties (section 4.2.1). Likewise, the temporal resolution of radiocarbon records is relatively poor, implying that centennial and higher frequency variability is typically not resolved, and may alias onto longer-period changes. Also, as alluded to above, estimates of deep water, palaeo- $\Delta^{14} \mathrm{C}$ suffer from significant uncertainties, such as due to chronological errors. Another limitation resides in the very coarse resolution of the model that is used to interpret the data. Although use of a very coarse resolution model is consistent with the nature of $\mathrm{HO}$ and benefits from simplicity of interpretation, it implies that the palaeo-data be averaged over large oceanic volumes and that the errors in the volume averages be properly estimated. Despite these limitations, the question of whether radiocarbon data jointly require changes to ocean circulation in a basin-averaged sense is important given the postulated role of such changes in deglacial variations of atmospheric $\mathrm{CO}_{2}$ concentration and climate. One goal of the present study is to address the sufficiency of the present radiocarbon data set to infer ocean circulation changes during the last deglaciation. 


\subsection{Methods}

\subsubsection{Deep Water Radiocarbon Data}

The sources of deep water radiocarbon data compiled for this study are listed in Table 4.1, where the data appear in order of decreasing latitude (see the supplementary material for the detailed data). The published data were updated through December 2015. The compilation also includes unpublished data from the Keigwin lab at WHOI (Table 4.1). Overall, it comprises 1154 estimates of deep water ${ }^{14} \mathrm{C}$ age for the past $40 \mathrm{kyrs}$, which originate from ${ }^{14} \mathrm{C}$ measurements on fossil samples of benthic foraminifera ( $74.5 \%$ of the data in Table 4.1$)$, deep-sea corals (24.4\%), deep-dwelling planktonic foraminifera (0.7\%), and bivalves/spiral shells $(0.4 \%)$. The data distribution is very irregular: most of the samples originate from near the oceanic margins, and large oceanic regions are devoid of any data (e.g., the South Indian Ocean; Fig. 4.1). The depths of the samples vary from about $300 \mathrm{~m}$ to about 5000 m (Fig. 4.2). Approximately $50 \%$ of the samples come from depths greater than $1500 \mathrm{~m}$, and only about $25 \%$ of the samples come from depths greater than $2500 \mathrm{~m}$. Factors contributing to the depth distribution include the difficulty in obtaining carbonate material for palaeoceanographic reconstruction in deep, corrosive water, and the small number of corals dredged below ca. $2500 \mathrm{~m}$.

In contrast to most other palaeoceanographic indicators, the magnitude of a ${ }^{14} \mathrm{C}$ estimate is a function of the sample calendar age, as this is used to correct for radioactive decay until the time of sample collection. The calendar ages of benthic foraminiferal samples used to reconstruct bottom water $\Delta^{14} \mathrm{C}$ are generally based on (i) ${ }^{14} \mathrm{C}$ dates of co-occurring planktonic foraminifera in the core, (ii) estimates of 
surface water reservoir age, and (iii) the relationship between atmospheric ${ }^{14} \mathrm{C}$ and calendar ages (" ${ }^{14} \mathrm{C}$ calibration”; e.g., Reimer et al., 2013). Samples associated with apparent age reversal are excluded in my compilation. For some other benthic foraminiferal samples, calendar ages have been determined from assumptions about phase relationships with other, relatively well-dated records ("wiggle matching"). The calendar ages of deep-sea corals, on the other hand, are typically established from ${ }^{234} \mathrm{U} /{ }^{230} \mathrm{Th}$ dates and the assumption of a closed system. Calendar ages of the samples considered in this study come from the literature (Table 4.1), with one notable exception: for the samples whose calendar age is determined from radiocarbon dating, I recalibrate all radiocarbon ages to calendar ages with the most recent relationship of IntCal13 (Reimer et al., 2013) if this was not done in the original publications. For this calculation, I use the surface reservoir ages from the original publications (Table 4.1). Note that about three quarters $(74 \%)$ of the compiled radiocarbon data fall within the time interval from 20 to 10 kyr B.P. (Fig. 4.3), which is the interval of interest in this study.

\subsubsection{Estimation of box $\Delta^{14} \mathrm{C}$ values}

I partition the compiled deep water $\Delta^{14} \mathrm{C}$ data into ten different oceanic volumes corresponding to the ten intermediate and deep boxes of the model used for this study (Fig. 4.1; Table 4.2; Section 4.2.2). The global sea level during the LGM is estimated to be about 130 m lower than today (Clark et al., 2009), which implies that the depths of the glacial and deglacial samples should have been shallower than today by $130 \mathrm{~m}$ or less. However, the deglacial changes in global sea level have only a minor effect on the repartition of samples amongst the intermediate and deep 
ocean boxes (Fig. 4.2). As a result, the modern depths of the samples are used. Data from the Arctic Ocean and the Nordic Seas are not included in my analysis, for these regions are not covered by the ten subsurface boxes of the model (Section 4.2.2).

To increase the statistical stability of $\Delta^{14} \mathrm{C}$ values for the model boxes, estimates of deep water $\Delta^{14} \mathrm{C}$ in each box are averaged in adjacent temporal bins of uniform duration and spanning together the interval from 20 to $10 \mathrm{kyr}$ B.P. If only one deep water $\Delta^{14} \mathrm{C}$ datum is available for a bin, then the $\Delta^{14} \mathrm{C}$ value for that bin is set equal to this datum. If no deep water $\Delta^{14} \mathrm{C}$ data are available for a bin, no attempt to estimate a $\Delta^{14} \mathrm{C}$ value for that bin is made since my method of analysis can account for missing data (section 4.2.3).

The width (duration) of the bins is selected on the basis of the uncertainties in the calendar ages of the compiled data (Fig. 4.4). The average of two standard deviations of the calendar ages between 10 and $20 \mathrm{kyr}$ B.P. amounts to $336 \mathrm{yr}$. This value is probably a lower estimate due to some factors that were not considered in the original publications, such as sedimentation rate changes between chronological tie points (interpolation errors), reservoir age changes, and open system behaviour for deep-sea corals. Nevertheless, based on this value, a bin width of $600 \mathrm{yr}$ is chosen for the calculation of deep water $\Delta^{14} \mathrm{C}$ values, unless stipulated otherwise. For the bin duration of $600 \mathrm{yr}$, the $\Delta^{14} \mathrm{C}$ estimates are averaged or assigned in the bins [20.0-19.4] kyr B.P., [19.4-18.8] kyr B.P., ..., [10.4-9.8] kyr B.P. The bin $\Delta^{14} \mathrm{C}$ values are defined at the center of the bins and occur at the same times for all boxes, e.g., the $\Delta^{14} \mathrm{C}$ values for the bin [20.0-19.4] kyr B.P. are all defined at $19.7 \mathrm{kyr}$ B.P. The effect of a different bin width on my results is explored in section 4.4.3. 


\subsubsection{Estimation of bin $\Delta^{14} \mathrm{C}$ errors}

The bin $\Delta^{14} \mathrm{C}$ values have various sources of uncertainty arising from (i) errors in the original $\Delta^{14} \mathrm{C}$ data (e.g., instrumental and chronological errors), (ii) the assumption that site-specific data reflect basin-scale averages, and (iii) temporal variability of deep water $\Delta^{14} \mathrm{C}$ within a bin. Instrumental errors for the compiled data between 10 and 20 kyr B.P. amount to only about $10 \%$ on average and are likely to be small compared to other sources of uncertainty. Chronological errors are notoriously difficult to constrain, particularly for ${ }^{14} \mathrm{C}$-dated sediment cores due to limited knowledge about changes in sedimentation rates and reservoir ages.

On the other hand, errors in the large-scale representativeness of sitespecific $\Delta^{14} \mathrm{C}$ data can be apprehended from the spatial distribution of $\Delta^{14} \mathrm{C}$ of dissolved inorganic carbon (DIC) observed in the modern ocean. The standard deviations of water-column $\Delta^{14} \mathrm{C}$ measurements corrected for bomb ${ }^{14} \mathrm{C}$ and synthesized by GLODAP (Key et al., 2004) are calculated for each of the ten oceanic volumes corresponding to the subsurface boxes of the model. These standard deviations (noted here as $\sigma_{\mathrm{MBC}}$, where "MBC" stands for "modern bomb-corrected") range from 11 to $45 \%$ o ( $\sim 115$ to $440{ }^{14} \mathrm{C}$ yr, assuming a modern fraction of 1$)$, depending on the oceanic volume (Table 4.2). They constitute useful measures of the dispersion of $\Delta^{14} \mathrm{C}$ in the oceanic volumes corresponding to the model boxes, with the caveats that they may not necessarily apply to the past and that not all regions of the modern ocean have been sampled.

Given the caveats above, the following approach is considered to estimate the errors in the bin $\Delta^{14} \mathrm{C}$ for the intermediate and deep boxes of the model. The errors 
in the bin $\Delta^{14} \mathrm{C}$ for a given box are set equal to the standard deviation of deep water $\Delta^{14} \mathrm{C}$ data in the bin that contains data from the largest number of records for that box. This approach has the benefit of accounting for both the spatial (e.g., inter-core) variability and the temporal (e.g., intra-core) variability, and more importantly, for site-specific factors that contribute to deep water $\Delta^{14} \mathrm{C}$ uncertainties. On the other hand, it does not consider the errors in the original $\Delta^{14} \mathrm{C}$ data. Notice that, since there is only one record for the intermediate Indian Ocean, the bin $\Delta^{14} \mathrm{C}$ errors for this box are set equal to those for the intermediate South Pacific.

I find that the errors in the bin $\Delta^{14} \mathrm{C}$ estimated through this approach are in general substantially larger than (i) the published errors in the original $\Delta^{14} \mathrm{C}$ data (Fig. 4.5) and (ii) the standard deviations of modern, water-column $\Delta^{14} \mathrm{C}$ measurements (Table 4.2). This feature appears desirable, as the errors (i-ii) likely underestimate bin $\Delta^{14} \mathrm{C}$ uncertainties due to the fact that neither (i) nor (ii) individually reflects the uncertainty in the large-scale representativeness of sitespecific palaeoceanographic records. The effects of different bin $\Delta^{14} \mathrm{C}$ errors on my results are examined in section 4.4.1.

\subsubsection{Box Model}

The model used in this study is a 16-box model of the world oceans (excluding the Arctic Ocean), called CYCLOPS. This model was initially developed by Keir (1988), has been the subject of different extensions (e.g., Hain et al., 2010; Sigman et al., 1998), and has been applied in a variety of palaeoceanographic investigations (for recent studies see, e.g., Galbraith et al., 2015; Hain et al., 2011, 2014). It includes six surface boxes, and ten intermediate and deep boxes (Fig. 4.6). 
The lateral boundaries of the surface boxes coincide with latitude and longitude lines, except in the North Atlantic (Keir, 1988). Lateral boundaries of subsurface boxes are not everywhere the same as those of surface boxes (Fig. 4.1): whereas the zonal boundaries of Southern Hemisphere surface boxes are latitude lines, the interfaces between the Circumpolar Deep Water box and the intermediate and deep boxes in the Atlantic, Indian, and Pacific Oceans are sloping in the meridional direction in order to reflect the southward uplift of density surfaces in the Southern Ocean (Keir, 1988).

The circulation of water in the box model is represented by volume transports defined at the interfaces between boxes (Fig. 4.6). The volume transports were estimated from measurements of a variety of tracers in the modern ocean, including dissolved phosphorous, dissolved oxygen, DIC, alkalinity, and the ${ }^{13} \mathrm{C} /{ }^{12} \mathrm{C}$ ratio and $\Delta^{14} \mathrm{C}$ of DIC (Keir, 1988). Two types of volume transports are distinguished in the model: one-way transports supposed to represent advection fluxes (e.g., upwelling and downwelling) and two-way transports intended to represent "mixing" fluxes. The volume transports depict conventional features of the modern circulation, such as the formation of deep waters in the northern North Atlantic (at a rate of $9.5 \mathrm{~Sv}$, where $\left.1 \mathrm{~Sv}=10^{6} \mathrm{~m}^{3} \mathrm{~s}^{-1}\right)$, the upwelling in the Southern Ocean $(21.5$ Sv), and the transports of waters to the rest of the ocean (Fig. 4.6). Worthy of note is the presence of a vertically sheared meridional flow in the Atlantic Ocean, with southward motion in the deep box and northward motion in the intermediate and surface boxes. This flow is the model analogue of the Atlantic meridional overturning circulation and amounts to $21.5 \mathrm{~Sv}$, broadly consistent with more 
recent observational estimates (e.g., Lumpkin and Speer, 2003, 2007; Lumpkin et al., 2008; Rayner et al., 2011).

\subsubsection{Definition of radiocarbon concentration}

The radiocarbon concentrations in the model are defined as follows. Consider the conventional definition of $\Delta^{14} \mathrm{C}$ :

$$
\Delta{ }^{14} \mathrm{C}=\left(F m \times e^{\frac{\text { calage }}{8223}}-1\right) \times 1000 \% \text {. }
$$

Here $F m$ is the "fraction modern" reported from the instrument, i.e., the ${ }^{14} \mathrm{C} /{ }^{12} \mathrm{C}$ ratio of the sample normalized to that of a standard (McNichol et al., 2001), "cal age" is the calendar age of the sample, and the normalizing value of $8,223 \mathrm{yr}$ is the mean life based on the 5,700-yr half-life (Audi et al., 2003). From (1), I define the radiocarbon concentrations in the model as:

$$
C=\frac{\Delta^{14} \mathrm{C}}{1000}+1=F m \times e^{\frac{\text { cal age }}{8223}} .
$$

Thus, $C$ represents the ${ }^{14} \mathrm{C} /{ }^{12} \mathrm{C}$ ratio of the sample when the carbonate was formed, normalized to that of the standard. For example, a value $\Delta^{14} \mathrm{C}=-200 \%$, such as observed in the modern deep Pacific (e.g., Broecker and Peng, 1982), would correspond to a radiocarbon concentration $C=0.8$, whereas a $\Delta^{14} \mathrm{C}$ value of 1000\% (a lower bound corresponding to infinite calendar age) would correspond to $C=0$.

\subsubsection{Governing equation for radiocarbon}


The radiocarbon concentration in each deep and intermediate box of the model evolves according to the governing equation:

$$
\frac{d C_{i}}{d t}=\frac{1}{V_{i}} \sum_{j \neq i} J_{j i} C_{j}-\frac{C_{i}}{V_{i}} \sum_{j \neq i} J_{i j}-\lambda C_{i} .
$$

Here $C_{i}$ is the radiocarbon concentration in box $i, V_{i}$ is the volume of box $i, J_{j i}$ is the volume transport from box $j$ to box $i$, and $\lambda=1 / 8,223 \mathrm{yr}^{-1}$ is the ${ }^{14} \mathrm{C}$ radioactive decay constant. Although $C_{i}$ is a concentration ratio, its governing equation can be cast in the form of a governing equation for a concentration with at least $1^{\text {st }}$ order accuracy (Fiadeiro, 1982). On the right-hand side of (3), the first term represents the supply of ${ }^{14} \mathrm{C}$ due to water transport from the surrounding boxes, the second describes the removal of ${ }^{14} \mathrm{C}$ from water export to the surrounding boxes, and the last is the rate of disappearance of ${ }^{14} \mathrm{C}$ due to radioactive decay within the box. Other effects such as due to biological processes (negligible at least to $1^{\text {st }}$ order according to Fiadeiro (1982)) and water-sediment fluxes are neglected. For convenience, the governing equations (3) are expressed in the compact form

$$
\frac{d \boldsymbol{c}}{d t}=\boldsymbol{A}^{\prime} \boldsymbol{c}+\boldsymbol{B}^{\prime} \boldsymbol{c}_{s} .
$$

Here $\boldsymbol{c}$ is a $n$-dimensional vector that includes the radiocarbon concentrations in the ten subsurface boxes $(n=10), \boldsymbol{A}^{\prime}$ is a $n \times n$ transition matrix whose elements are functions of the volume transports and (or) the radioactive decay constant, $\boldsymbol{B}^{\prime}$ is a $n \times p$ distribution matrix, and $\boldsymbol{c}_{s}$ is a $p$-dimensional vector that includes the radiocarbon concentrations in the six surface boxes $(p=6)$. 
The transition matrix $\boldsymbol{A}^{\prime}$ determines the response of $\boldsymbol{c}$ to initial conditions and to perturbations in $\boldsymbol{B}^{\prime} \boldsymbol{c}_{s}$. The distribution matrix $\boldsymbol{B}^{\prime}$ bears its name from the fact that it prescribes, or "distributes", the effect of surface concentrations on intermediate and deep concentrations. For intermediate and deep boxes that are not in direct contact with a surface box, the corresponding row in $\boldsymbol{B}^{\prime}$ is filled with zeros.

In this study, equation (4) is integrated numerically using an implicit scheme,

$$
\boldsymbol{c}(t+\Delta t)=\boldsymbol{A c}(t)+\boldsymbol{B} \boldsymbol{c}_{s}(t)
$$

where $\boldsymbol{A}=\left(\boldsymbol{I}-\Delta t \boldsymbol{A}^{\prime}\right)^{-1}, \boldsymbol{B}=\Delta t\left(\boldsymbol{I}-\Delta t \boldsymbol{A}^{\prime}\right)^{-1} \boldsymbol{B}^{\prime}$ (see Appendix for a derivation), $\boldsymbol{I}$ is the $n \times n$ identity matrix, and $\Delta t$ is the time step. In equation (5), the discrete times $t$ at which $\boldsymbol{c}$ is calculated coincide with the times at which the bin $\Delta^{14} \mathrm{C}$ values are defined (section 4.2.1.1), i.e., $\Delta t=600 \mathrm{yr}$ unless stated otherwise.

\subsubsection{Inverse Method}

\subsubsection{Statement of the problem}

The deep water $\Delta^{14} \mathrm{C}$ data summarized in section 4.2.1 are combined quantitatively with the box model described in section 4.2.2. To this end, I use an inverse method that relies on a whole-domain approach (e.g., Amrhein et al., 2015; Wunsch, 2006). The method is as follows. Consider first the model as defined by equation (5). Let $t_{0}=19.7 \mathrm{kyr}$ B.P. be the initial time of the investigation, i.e., the first time for which an estimate of $\Delta^{14} \mathrm{C}$ is available for an intermediate and (or) deep ocean box (for the bin width of $600 \mathrm{yr}$ ). The governing equation (5) is applied recursively from $t_{0}+\Delta t$ to $t_{0}+l \Delta t$, where $l=1,2, \ldots, L$ is an integer, which yields 


$$
\boldsymbol{c}\left(t_{0}+l \Delta t\right)=\boldsymbol{A}^{l} \boldsymbol{c}\left(t_{0}\right)+\sum_{k=1}^{l} \boldsymbol{A}^{k-1} \boldsymbol{B} \boldsymbol{c}_{s}\left(t_{0}+(l-k) \Delta t\right) .
$$

This expression represents the radiocarbon concentrations in the subsurface boxes at time $t_{0}+l \Delta t, \boldsymbol{c}\left(t_{0}+l \Delta t\right)$, in terms of the initial concentrations in these boxes, $\boldsymbol{c}\left(t_{0}\right)$, and of the radiocarbon concentrations in the surface boxes, $\boldsymbol{c}_{s}$, at all times from $t_{0}$ to $t_{0}+(l-1) \Delta t$.

Consider then the data, which are values of radiocarbon concentration in the ten intermediate and deep boxes of the model as described in section 4.2.1.1 and estimated from (2). The data available at time $t$ are incorporated into a $q$ dimensional vector $\boldsymbol{y}(t)$, where $q$ ranges from 1 to 10 (the total number of subsurface boxes). The data are related to the radiocarbon concentrations of the model through the equation,

$$
\boldsymbol{y}(t)=\boldsymbol{E}(t) \boldsymbol{c}(t)+\boldsymbol{n}(t)
$$

where $\boldsymbol{E}(t)$ is a $q \times n$ matrix and $\boldsymbol{n}(t)$ is a $q$-dimensional vector of observational errors. The matrix $\boldsymbol{E}(t)$ describes data availability at time $t$. For example, if only one datum is available at time $t$, then $\boldsymbol{E}(t)$ is a row vector with a value of 1 for the component corresponding to the box for which the datum is available and a value of 0 for the other components. If no datum is available at time $t$ at all, then equation (7) is simply not defined. The observation vector $\boldsymbol{y}$ at time $t_{0}+l \Delta t$ can be written, using equations (6-7), as 


$$
\boldsymbol{y}\left(t_{0}+l \Delta t\right)=\boldsymbol{E}\left(t_{0}+l \Delta t\right)\left[\boldsymbol{A}^{l} \boldsymbol{c}\left(t_{0}\right)+\sum_{k=1}^{l} \boldsymbol{A}^{k-1} \boldsymbol{B} \boldsymbol{c}_{s}\left(t_{0}+(l-k) \Delta t\right]+\boldsymbol{n}\left(t_{0}+l \Delta t\right)\right.
$$

or, equivalently, as

$$
\boldsymbol{y}\left(t_{0}+l \Delta t\right)=\boldsymbol{E}\left(t_{0}+l \Delta t\right) \boldsymbol{A}^{l} \boldsymbol{c}\left(t_{0}\right)+\boldsymbol{E}\left(t_{0}+l \Delta t\right) \boldsymbol{G}(l) \overline{\boldsymbol{c}}_{s}+\boldsymbol{n}\left(t_{0}+l \Delta t\right) .
$$

In the latter equation,

$$
\overline{\boldsymbol{c}}_{s}=\left[\boldsymbol{c}_{s}\left(t_{0}\right)^{T}, \cdots, \boldsymbol{c}_{s}\left(t_{0}+(l-1) \Delta t\right)^{T}, \boldsymbol{c}_{s}\left(t_{0}+l \Delta t\right)^{T}, \cdots, \boldsymbol{c}_{s}\left(t_{0}+(L-1) \Delta t\right)^{T}\right]^{T}
$$

is the $p L$-dimensional vector including the ${ }^{14} \mathrm{C}$ concentrations in all surface boxes and at all times from $t_{0}$ to $t_{0}+(L-1) \Delta t$ (superscript $T$ designates the vector transpose), and

$$
\boldsymbol{G}(l)=\left(\boldsymbol{A}^{l-1} \boldsymbol{B}, \cdots, \boldsymbol{B}, \mathbf{0}, \cdots, \mathbf{0}\right)
$$

is a $n \times p L$ matrix. A vector of observations can be defined for all times $t=t_{0}+$ $\Delta t, t_{0}+2 \Delta t, \cdots, t_{0}+L \Delta t$, for which deep water $\Delta^{14} \mathrm{C}$ data are available, and these vectors can be concatenated to yield the $r$-dimensional vector

$$
\overline{\boldsymbol{y}}=\overline{\boldsymbol{y}}_{0}+\overline{\boldsymbol{G}} \overline{\boldsymbol{c}}_{s}+\overline{\boldsymbol{n}}
$$

The vector $\overline{\boldsymbol{y}}$ includes all the radiocarbon data in the intermediate and deep boxes from 19.1 to $10.1 \mathrm{kyr}$ B.P. It excludes the data at $t_{0}=19.7 \mathrm{kyr}$ B.P., which are incorporated in $\boldsymbol{c}\left(t_{0}\right)$ and hence in $\overline{\boldsymbol{y}}_{0}$. Since there is no data at $t_{0}=19.7 \mathrm{kyr}$ B.P. in the deep Indian box, the initial ${ }^{14} \mathrm{C}$ concentration in that box is set equal to the initial 
${ }^{14} \mathrm{C}$ concentration in the deep South Pacific box, stimulated by the observation that these two boxes have similar pre-bomb ${ }^{14} \mathrm{C}$ activities according to GLODAP (Table 4.2). The choice of initial values is ultimately not very important as they have negligible influence on the solution after several time steps (not shown).

The first, second, and third terms on the right-hand side of (12) are obtained from the concatenation in time of, respectively, the first, second, and third terms on the right-hand side of (9). Equation (12) therefore reveals that the deep water $\Delta^{14} \mathrm{C}$ data from 19.1 to $10.1 \mathrm{kyr}$ B.P. can be viewed as resulting from three different contributions. The term $\overline{\boldsymbol{y}}_{0}$ represents the contribution due to the initial distribution (at $t_{0}=19.7$ kyr B.P.) of ${ }^{14} \mathrm{C}$ concentration in the intermediate and deep boxes. The term $\overline{\boldsymbol{G}} \overline{\boldsymbol{c}}_{s}$ is the contribution due to the time-varying surface water $\Delta^{14} \mathrm{C}$ distribution, which influences deep water $\Delta^{14} \mathrm{C}$ via the circulation. Finally, the term $\overline{\boldsymbol{n}}$ represents the contribution due to observational errors.

With the definition $\delta \overline{\boldsymbol{y}}=\overline{\boldsymbol{y}}-\overline{\boldsymbol{y}}_{0}$, equation (12) reduces to

$$
\delta \overline{\boldsymbol{y}}=\overline{\boldsymbol{G}} \overline{\boldsymbol{c}}_{s}+\overline{\boldsymbol{n}} .
$$

Equation (13) provides a formal statement of the inverse problem, i.e., the inference of surface water ${ }^{14} \mathrm{C}$ concentrations $\left(\overline{\boldsymbol{c}}_{S}\right)$ from deep water ${ }^{14} \mathrm{C}$ concentration data $(\delta \overline{\boldsymbol{y}})$ from 19.1 to 10.1 kyr B.P. under modern circulation conditions (as represented in $\overline{\boldsymbol{G}}$ ) and given the presence of observational errors $(\overline{\boldsymbol{n}})$. In other words, the surface water ${ }^{14} \mathrm{C}$ concentrations are inferred from a fit of the deep water $\Delta^{14} \mathrm{C}$ data to the box model of modern ocean ventilation, given the presence of errors in the data. 


\subsubsection{Method of solution}

Equation (13) is a system of linear algebraic equations that is solved for $\overline{\boldsymbol{c}}_{s}$ as follows. First, each equation in (13) is divided by an estimate of the standard deviation of the corresponding element of $\overline{\boldsymbol{n}}$ (row scaling; Wunsch, 2006) (below each quantity in (13) resulting from this operation is referred to with an asterisk, e.g., $\delta \overline{\boldsymbol{y}}$ resulting from this operation is referred to as $\delta \overline{\boldsymbol{y}}_{*}$ ). This operation is an effort to account for the variable errors in the observational estimates of ${ }^{14} \mathrm{C}$ concentration that are included in $\delta \overline{\boldsymbol{y}}$. The standard deviations of the elements of $\overline{\boldsymbol{n}}$ are taken from the errors in the bin $\Delta^{14} \mathrm{C}$ values for the corresponding box (section 4.2.1). Second, I define $\overline{\boldsymbol{c}}_{s 0}$ as a first guess of the solution derived from the atmospheric $\Delta^{14} \mathrm{C}$ reconstruction (Reimer et al. 2013) and modern (pre-industrial) reservoir ages for the six surface boxes. For these reservoir ages, I assume a value of $1000 \mathrm{yr}$ for the Antarctic box, and a value of $400 \mathrm{yr}$ for the other surface boxes, which values are consistent with observational estimates reported by Bard (1988). The solution $\overline{\boldsymbol{c}}_{s}$ is then expressed as the sum of this first guess and a deviation, i.e., $\overline{\boldsymbol{c}}_{s}=\overline{\boldsymbol{c}}_{s 0}+\overline{\boldsymbol{c}}_{s}{ }^{\prime}$. The deviation $\overline{\boldsymbol{c}}_{s}{ }^{\prime}$ is obtained from the solution of the following set of equations (for a similar approach, see Gebbie, 2012),

$$
\delta \overline{\boldsymbol{y}}_{*}^{\prime}=\overline{\boldsymbol{G}}_{*} \overline{\boldsymbol{c}}_{s}{ }^{\prime}+\overline{\boldsymbol{n}}_{*}
$$

where $\delta \overline{\boldsymbol{y}}_{*}{ }^{\prime}=\delta \overline{\boldsymbol{y}}_{*}-\overline{\boldsymbol{G}}_{*} \overline{\boldsymbol{c}}_{s 0}$ and the asterisk indicates the scaled form of the corresponding matrix or vector. Thus, we are solving for the deviation of the surface 
water $\Delta^{14} \mathrm{C}$ from a hypothetical value corresponding to time-invariant (preindustrial) reservoir ages.

The equations in (14) are solved using singular value decomposition, SVD (e.g., Wunsch, 2006). The coefficient matrix $\overline{\boldsymbol{G}}_{*}$ is first decomposed as

$$
\overline{\boldsymbol{G}}_{*}=\boldsymbol{U} \boldsymbol{\Lambda} \boldsymbol{V}^{T},
$$

where $\boldsymbol{U}$ is a $r \times r$ orthonormal matrix containing the left singular vectors of $\overline{\boldsymbol{G}}_{*}, \boldsymbol{V}$ is a $p L \times p L$ orthonormal matrix containing the right singular vectors of $\overline{\boldsymbol{G}}_{*}$, and $\boldsymbol{\Lambda}$ is a $r \times p L$ matrix with the singular values of $\overline{\boldsymbol{G}}_{*}$ ranked in order of decreasing magnitude along the diagonal and with zeros elsewhere. The SVD solution is expressed as

$$
\hat{\overline{\boldsymbol{c}}}_{s}^{\prime}=\sum_{i=1}^{K} \frac{\boldsymbol{u}_{i}^{T} \delta \overline{\boldsymbol{y}}}{\lambda_{i}} \boldsymbol{v}_{i}+\sum_{i=K+1}^{N} \alpha_{i} \boldsymbol{v}_{i}
$$

where $\boldsymbol{u}_{i}$ and $\boldsymbol{v}_{i}$ (both singular vectors) are the $i^{\text {th }}$ column of $\boldsymbol{U}$ and $\boldsymbol{V}$, respectively, $\lambda_{i}$ (a singular value) is the $i^{\text {th }}$ element along the diagonal of $\Lambda, K$ is the number of singular values different from zero, and $\alpha_{i}, i=K+1, \cdots, N$, is an unknown expansion coefficient. On the right-hand side of (16), the first term represents the contribution due to structures in $\overline{\boldsymbol{c}}_{s}{ }^{\prime}$ that can be determined from the data (the range of $\overline{\boldsymbol{G}}_{*}$ ) and the second term represents the contribution due to structures that cannot be determined from the data (the nullspace of $\overline{\boldsymbol{G}}_{*}$ ). It can be shown that the SVD solution (16) is identical to the least-squares solution of (14) (more precisely, a 
weighted least-squares solution, since row scaling is applied) when this exists, i.e., in the absence of a nullspace, for which $K=N$ (e.g., Wunsch, 2006). The so-called "particular SVD solution" includes only the first term and is a biased solution for $K<N$.

The error covariance matrix, or uncertainty, of the SVD solution $\hat{\overline{\boldsymbol{c}}}_{s}^{\prime}$ is

$$
\boldsymbol{P}_{\hat{\boldsymbol{c}}_{s}^{\prime}}=\sum_{i=1}^{K} \sum_{j=1}^{K} \boldsymbol{v}_{i} \frac{\boldsymbol{u}_{i}^{T}\left\langle\overline{\boldsymbol{n}}_{*} \overline{\boldsymbol{n}}_{*}{ }^{T}\right\rangle \boldsymbol{u}_{j}}{\lambda_{i} \lambda_{j}} \boldsymbol{v}_{j}{ }^{T}+\sum_{i=K+1}^{N} \sum_{j=K+1}^{N} \boldsymbol{v}_{i}\left\langle\alpha_{i} \alpha_{j}\right\rangle \boldsymbol{v}_{j}{ }^{T}
$$

where $\left\langle\overline{\boldsymbol{n}}_{*} \overline{\boldsymbol{n}}_{*}^{T}\right\rangle$ is the error covariance matrix for the observational estimates of ${ }^{14} \mathrm{C}$ concentration in $\delta \overline{\boldsymbol{y}}_{*}{ }^{\prime}$ and $\langle\cdot\rangle$ denotes the expected value. The diagonal elements of $\left\langle\overline{\boldsymbol{n}}_{*} \overline{\boldsymbol{n}}_{*}^{T}\right\rangle$ are equal to 1 and the off-diagonal elements of $\left\langle\overline{\boldsymbol{n}}_{*} \overline{\boldsymbol{n}}_{*}^{T}\right\rangle$ are set equal to zero, assuming negligible error covariances, i.e., $\left\langle\overline{\boldsymbol{n}}_{*} \overline{\boldsymbol{n}}_{*}{ }^{T}\right\rangle$ is an identity matrix. The first term on the right-hand side of (17) represents the contribution due to the observational errors, whereas the second is the contribution due to presence of a nullspace in the solution (if any). Since the expansion coefficients $\alpha_{i}, i=K+1, \cdots, N$, are unknown, the second term in (17) is sometimes set to zero. In this case, the uncertainties in the elements of the solution $\left(\hat{\overline{\boldsymbol{c}}}_{s}^{\prime}\right)$ should be viewed as lower estimates.

\subsection{Results}

In this section, I first describe my compilation of deep ocean $\Delta^{14} \mathrm{C}$ data for the past 40 kyrs. The box model of modern ocean ventilation is then fitted to the deep 
ocean $\Delta^{14} \mathrm{C}$ data (bin values) by allowing time-varying $\Delta^{14} \mathrm{C}$ in the model surface boxes. Two solutions of the inverse problem (fit) are presented, which are characterized by a different number $K$ of singular vectors being retained.

\subsubsection{Observational Estimates of Deep Water $\Delta^{14} \mathrm{C}$}

The compiled $\Delta^{14} \mathrm{C}$ data attributed to the intermediate and deep boxes of the model are shown in Figure 7. Notice the absence of data in the deep Indian Ocean. As expected, the oceanic $\Delta^{14} \mathrm{C}$ values are lower than the reconstructed $\Delta^{14} \mathrm{C}$ in the contemporaneous atmosphere, with few exceptions presumably due to chronological errors. Particularly large variations in deep water $\Delta^{14} \mathrm{C}$ are observed in the Intermediate South Pacific, where deep-sea $\Delta^{14} \mathrm{C}$ records are few and tend to show pronounced systematic differences (e.g., De Pol-Holz et al., 2010; Rose et al., 2010; Stott et al., 2009).

The deep water $\Delta^{14} \mathrm{C}$ record from 617 -m water depth near the Galapagos Archipelago (Stott et al., 2009) shows particularly low values compared to other $\Delta^{14} \mathrm{C}$ records for the Intermediate South Pacific (Fig. 4.7). Such low values have been indicated to reflect processes unrelated to ocean circulation (e.g., Lund and Asimow, 2011; Stott and Timmermann, 2011). Accordingly, I exclude the Galapagos record from the data set to which the model is fitted, unless stipulated otherwise; the effect of this record on the fit is discussed in section 4.4.3. For the solutions reported in the other sections (all with a bin width of $600 \mathrm{yr}$ and with bin boundaries occurring at $20.0,19.4, \ldots, 9.8$ kyr B.P.), the number of bins filled with data amounts to 131 (82\% of the bins), i.e., $\bar{y}$ includes a total of 131 elements. 
The most conspicuous feature in the assembled deep water $\Delta^{14} \mathrm{C}$ data (Fig. 4.7) is a long-term decrease from about $25 \mathrm{kyr}$ B.P. to the present, which roughly parallels the decrease in reconstructed atmospheric $\Delta^{14} \mathrm{C}$ over the same time interval (Reimer et al., 2013). In order to quantify the apparent decrease in the assembled deep water $\Delta{ }^{14} \mathrm{C}$ data, I use the rank correlation coefficient Kendall tau $(\tau)$ (Kendall and Gibbons, 1990). Kendall $\tau$ measures the amount of monotonic relationship between two random variables (in the present case, between deep water $\Delta^{14} \mathrm{C}$ and time) and makes weaker assumptions about their underlying distributions than more conventional measures of correlation, such as the Pearson correlation coefficient. I find that Kendall $\tau$ is systematically negative with $p<0.01$ (Table 4.3), indicating that the apparent decrease in deep water $\Delta^{14} \mathrm{C}$ is highly significant in all deep oceanic basins.

The mean of deep water $\Delta^{14} \mathrm{C}$ in the different oceanic regions and in different climatic intervals is considered to further document possible spatial and temporal patterns of deep ocean $\Delta^{14} \mathrm{C}$ over the deglaciation (Table 4.4). The climatic intervals include the LGM (defined here as 24-17.6 kyr B.P.), HS1 (17.6-14.65 kyr B.P.), Bølling-Allerød (BA, 14.65-12.85 B.P.), YD (12.85-11.65 kyr B.P.) and early Holocene (EH, 11.65-8 kyr BP). The dates for the onset of the BA, the onset of the YD, and the termination of the YD are from Rasmussen et al. (2006) (their Table 4). The date for the onset of HS1 is based on an interpretation by de la Fuente et al. (2015) of Greenland ice core $\left[\mathrm{Ca}^{2+}\right]$ records compiled in Rasmussen et al. (2008). It is seen that the LGM to early Holocene $\Delta^{14} \mathrm{C}$ decrease would have ranged from $115 \%$ to $330 \%$, depending on the deep oceanic basin (Table 4.4). Interestingly, some spatial 
patterns seem to have been maintained over time. For example, the $\Delta^{14} \mathrm{C}$ of the deep Atlantic seems to have remained higher than that of the deep North Pacific by $70 \pm 24 \%$ o to $137 \pm 19 \%$, depending on the climatic interval (for reference, the modern pre-bomb $\Delta^{14} \mathrm{C}$ contrast between these two regions amounts to $102 \pm 29 \%$ o according to GLODAP; Table 4.2).

\subsubsection{Model Fit to Deep Water $\Delta^{14} \mathrm{C}$ Data}

Since the coefficient matrix $\overline{\boldsymbol{G}}_{*}$ is a $131 \times 96$ matrix, the fit of the modern ocean ventilation model to the deep water $\Delta^{14} \mathrm{C}$ data, i.e., the solution of eq. (14), is a formally over-determined problem. It is instructive to first consider the singular values of $\overline{\boldsymbol{G}}_{*}$. All of these values (96) are non-zero (Fig. 4.8a), so that $\overline{\boldsymbol{G}}_{*}$ has no solution nullspace. Consequently, a solution constructed with $K=96$ singular vectors retained (eq. 16) should be unbiased and its errors should arise solely from observational uncertainties. On the other hand, this solution would have relatively high variance, particularly because some of the singular values are very small (eq. 17). Accordingly, two different solutions of the inverse problem (i.e., two different fits of the modern ventilation model to deep water $\Delta^{14} \mathrm{C}$ data) are considered below: the "full solution" with $K=96$ is unbiased but has large variance, whereas the "truncated solution" with $K<96$ is biased but has smaller variance.

\subsubsection{Solution with all singular vectors retained}

The full solution is constructed with $K=96$ singular vectors retained in equations (16) and (17). First I examine the extent to which the box model of modern ocean ventilation can be fitted to the deep water $\Delta^{14} \mathrm{C}$ data (bin $\Delta^{14} \mathrm{C}$ values); the surface $\Delta^{14} \mathrm{C}$ values that lead to the fit are considered next. This analysis of 
residuals provides an avenue to test $\mathrm{H} 0$, because large differences between the fitted and observed $\Delta^{14} \mathrm{C}$ values are expected if the observed values are jointly incompatible with modern ocean ventilation (for similar approaches using benthic $\delta^{18} \mathrm{O}$ data, see Amrhein et al., 2015; Gebbie, 2012). To derive the fitted $\Delta^{14} \mathrm{C}$ values, the deep water $\Delta^{14} \mathrm{C}$ anomalies in $\delta \overline{\boldsymbol{y}}$ that are implied by the fit of the model to the data are computed from

$$
\delta \widehat{\overline{\boldsymbol{y}}}=\overline{\boldsymbol{G}} \widehat{\overline{\boldsymbol{c}}}_{s},
$$

where $\hat{\overline{\boldsymbol{c}}}_{s}=\overline{\boldsymbol{c}}_{s 0}+\hat{\overline{\boldsymbol{c}}}_{s}^{\prime}$. The deep water $\Delta^{14} \mathrm{C}$ values implied by the fit are then obtained from the vector sum $\delta \widehat{\bar{y}}+\overline{\boldsymbol{y}}_{0}$.

To test H0, I first compare reconstructed deep water $\Delta^{14} \mathrm{C}$ values derived from (18) with the deep water $\Delta^{14} \mathrm{C}$ data and the bin $\Delta^{14} \mathrm{C}$ values in Figure 9. I find that all $\Delta^{14} \mathrm{C}$ values derived from the fit differ from the bin $\Delta^{14} \mathrm{C}$ values by less than two standard deviations (Fig. 4.10a). The derived $\Delta^{14} \mathrm{C}$ values capture the generally negative trend of deep water $\Delta^{14} \mathrm{C}$ with time that is suggested both in the original data and in the bin $\Delta^{14} \mathrm{C}$ records. By this measure, the deep water $\Delta^{14} \mathrm{C}$ data appear consistent with the modern ocean ventilation as represented in the box model. In fact, the model of modern ocean ventilation appears to over-fit the data: with all singular vectors retained, the full solution replicates the data with a level of accuracy that is generally not warranted given the data uncertainties.

Second, I consider the surface water $\Delta^{14} \mathrm{C}$ values from 20 to $10 \mathrm{kyr}$ B.P. estimated from the fit of the modern ocean ventilation model to the deep-sea $\Delta^{14} \mathrm{C}$ data (Fig. 4.11). These estimated values are compared to the two bounds used to 
test H0: the upper bound provided by the atmospheric $\Delta^{14} \mathrm{C}$ record from IntCal13 and the lower bound provided by the bin $\Delta^{14} \mathrm{C}$ for the subsurface boxes. The estimated surface $\Delta^{14} \mathrm{C}$ shows very large variations, which are associated with the over-fit of the model to the deep water $\Delta^{14} \mathrm{C}$ data: with all singular vectors retained, the full solution is able to closely reproduce the data, at the expense of high variability in surface $\Delta^{14} \mathrm{C}$ (note that the variability of deep water $\Delta^{14} \mathrm{C}$ is smaller than that of surface water $\Delta^{14} \mathrm{C}$ due to the amplitude attenuation caused by ocean circulation as represented in the model; Fig. 4.9). Nevertheless, I find that the full solution generally does not violate the two bounds by more than 2 standard deviations. The estimated surface water $\Delta^{14} \mathrm{C}$ exceeds atmospheric $\Delta^{14} \mathrm{C}$ by more than 2 standard deviations only once (at the initial time step in the surface Atlantic, Fig. 4.11). With all the singular vectors retained, the estimated errors of surface $\Delta^{14} \mathrm{C}$ are relatively large, especially in the boxes that do not directly ventilate the deep ocean. The results from different choices of bin boundaries are similar (Table 4.5). In summary, the results for both deep water and surface water $\Delta^{14} \mathrm{C}$ do not provide strong evidence for rejection of $\mathrm{H} 0$.

\subsubsection{Solution with a fraction of singular vectors retained}

The solution presented in the previous section was obtained by retaining all the singular vectors: it is therefore unbiased and identical to the (weighted) leastsquares solution (e.g., Wunsch 2006). However, it is not without limitations, as it suffers from a relatively large error variance. It also tends to over-fit the data, suggesting that it includes structures that are not justifiable given the data errors. Truncated solutions obtained from a smaller number of singular vectors are 
characterized by smaller error variance and reduced over-fit, thereby facilitating the test of $\mathrm{HO}$, although it would also present a bias.

For the sake of illustration, I consider in this section a truncated solution with 23 singular vectors retained in equations (16-17). These singular vectors are associated with the first 23 singular values, which are separated from subsequent values by an apparent discontinuity (Fig. 4.8a). I find that a good fit to the deep water $\Delta^{14} \mathrm{C}$ data could still be achieved in this case, in spite of the reduced number of structures in the solution, although some of the fitted values now tend to present systematic differences with the data (Fig. 4.12). The truncated solution mitigates the over-fit to the deep water $\Delta^{14} \mathrm{C}$ data, which is a desirable feature (Fig. $4.10 \mathrm{~b}$ ). Moreover, all surface $\Delta^{14} \mathrm{C}$ values inferred from the fit are now confined within the two bounds set by the atmospheric and the deep ocean observations, in spite of the smaller error variance of the solution (Fig. 4.13). This result also holds for different choices of bin boundaries (not shown). Thus, rejection of $\mathrm{H} 0$ appears equally difficult for the truncated solution.

Notable in the truncated solution are relatively large deviations of surface water $\Delta^{14} \mathrm{C}\left(\overline{\boldsymbol{c}}_{s}{ }^{\prime}\right)$ estimated in the model boreal Atlantic Ocean and in the Southern Ocean near Antarctica (Fig. 4.13). Nonetheless, these deviations do not suffice to reject $\mathrm{H} 0$, as they can be adequately explained via regional changes in surface water reservoir ages, such as during the early stage of HS1 in the northern North Atlantic (Fig. 4.13).

The large (relative to other regions) variations of surface water $\Delta^{14} \mathrm{C}$ estimated in the boreal Atlantic and near Antarctica arise from the fact that the deep 
ocean is mostly ventilated from these regions, and thus $\Delta^{14} \mathrm{C}$ in these two regions can be relatively well resolved from deep water data. To demonstrate this, the relationship between the actual and estimated time-dependent distributions of surface water $\Delta^{14} \mathrm{C}$ can be expressed by

$$
\mathbf{T}_{v} \overline{\boldsymbol{c}}_{s}=\hat{\overline{\boldsymbol{c}}}_{s},
$$

where $\mathbf{T}_{v}$ is the solution resolution matrix defined by (e.g., Wunsch 2006)

$$
\mathbf{T}_{v}=\mathbf{V}_{K} \mathbf{V}_{K}^{\mathrm{T}} .
$$

Equation (19) shows that each element of the solution, $\hat{\overline{\boldsymbol{c}}}_{s}$, can be considered as a linear combination of the actual values in $\overline{\boldsymbol{c}}_{s}$. Departures of $\hat{\boldsymbol{\boldsymbol { c }}}_{s}$ from $\overline{\boldsymbol{c}}_{s}$ can thus be investigated from the matrix $\mathbf{T}_{v}$. One approach for such investigation is to repeatedly calculate $\hat{\overline{\boldsymbol{c}}}_{s}$ from (19) for a number of $p L$-dimensional vectors $\overline{\boldsymbol{c}}_{s}$, where each vector has the elements corresponding to a given surface box set to 1 for all times while the other elements (corresponding to other surface boxes) are set to 0 (Amrhein et al. (2015). The values of $\hat{\overline{\boldsymbol{c}}}_{s}$ calculated in this way provide a measure of the ability of the deep water $\Delta^{14} \mathrm{C}$ data to resolve $\Delta^{14} \mathrm{C}$ in the different surface boxes of the model, with a value near 0 indicating poor resolvability and a value near 1 indicating high resolvability.

It is seen that, for $K=23$, the values of $\hat{\overline{\boldsymbol{c}}}_{s}$ averaged on the time interval from 20 to $10 \mathrm{kyr}$ B.P. indicate the highest resolvability in the boreal Atlantic and Antarctic boxes, which directly ventilate the deep ocean in the model (Fig. 4.14). The resolvability for the other boxes is close to zero, suggesting that the estimated 
surface $\Delta^{14} \mathrm{C}$ values in those boxes should be interpreted with caution. Amrhein et al. (2015) obtained a similar result from an analysis of deglacial benthic $\delta^{18} 0$ records and a much more detailed tracer transport model.

\subsection{Discussion}

I have fit a modern ocean ventilation model to deep water $\Delta^{14} \mathrm{C}$ data from 20 to $10 \mathrm{kyr}$ B.P. The fitting problem has been cast as a set of linear algebraic equations and solved using singular value decomposition. Two different solutions (equally acceptable in the sense of their similar abilities to describe the deep water data) have been produced (section 4.3.2). A first solution is unbiased with large variance. It is equivalent to a weighted least-squares solution, with the weighting provided by data errors. The second solution is biased but has smaller variance. For both solutions, I have found that the fit residuals can largely be explained by data errors, i.e., the modern ocean ventilation model is largely consistent with deep water $\Delta^{14} \mathrm{C}$ data from 20 to $10 \mathrm{kyr}$ B.P. For the full solution, most of the surface water $\Delta^{14} \mathrm{C}$ values that are implied by the fit are neither significantly above the contemporaneous atmospheric $\Delta^{14} \mathrm{C}$ nor significantly below the contemporaneous deep-sea $\Delta^{14} \mathrm{C}$ for most of the times $\left(\leq 5 / 96\right.$ surface water $\Delta^{14} \mathrm{C}$ values transgressing these bounds, the precise fraction depending on the assumed bin boundaries). For the truncated solution, all the implied surface $\Delta^{14} \mathrm{C}$ values are compatible with the two bounds, regardless of the bin boundaries. In this section, I assess the robustness of these results against other assumptions in the analysis.

\subsubsection{Effect of A Globally Uniform Error}


In the previous solutions (section 4.3.2), the error in the bin $\Delta^{14} \mathrm{C}$ for a given subsurface box is estimated from the standard deviation of the $\Delta^{14} \mathrm{C}$ data in the bin that comprises the largest number of deep water $\Delta^{14}$ Crecords for that box. Since the error in the bin $\Delta^{14} \mathrm{C}$ varies between the subsurface boxes, they influence the solution through the row scaling. Here I consider a solution obtained by assuming a globally uniform bin $\Delta^{14} \mathrm{C}$ error, so that row scaling has no influence. This error $(87 \% 0)$ is the average of the estimated bin $\Delta^{14} \mathrm{C}$ errors in the subsurface boxes (Table 4.2).

I find that all singular values of $\overline{\boldsymbol{G}}_{*}$ are different from zero, as for the solutions discussed in section 4.3 .2 (Fig. 4.8b). For $K=96$, the deep water $\Delta^{14} \mathrm{C}$ values obtained from the fit are again consistent with the data (Fig. 4.15), although an overfit exists. None of the surface $\Delta^{14} \mathrm{C}$ values deduced from the fit differs by more than two standard deviations from the upper and lower bounds (Fig. 4.16). For $K=23$, the over-fit is mitigated and the fit is still good (not shown). Again, no surface $\Delta^{14} \mathrm{C}$ value is inferred that violates the two bounds. Therefore, rejection of H0 would again be hard to justify.

\subsubsection{Effect of Bin Width}

Bin width influences how I group the deep-sea radiocarbon data in time within each of the intermediate and deep boxes of the model. It thereby determines the magnitude, uncertainty, and timing of the observational estimates of deep water $\Delta^{14} \mathrm{C}$. With an average error (two standard deviations) of $336 \mathrm{yr}$ for the sample calendar ages (Fig. 4.4), a bin width larger than $600 \mathrm{yr}$, as used in the solutions 
discussed in section 4.3.2, does not seem to be generally justified. Here I consider the effects of grouping the data in narrower bins of $400 \mathrm{yr}$.

I find that the fraction of bins for which deep water $\Delta^{14} \mathrm{C}$ data are available decreases slightly for this case: for a bin width of $400 \mathrm{yr}$, about $23 \%$ of the bins (including the completely empty deep Indian box) are data void, compared to $18 \%$ for a bin width of $600 \mathrm{yr}$. On the other hand, the bin $\Delta^{14} \mathrm{C}$ values tend to portray more variability for a bin width of $400 \mathrm{yr}$ than for a bin width of $600 \mathrm{yr}$ (not shown). This result stems from the fact that bin $\Delta^{14} \mathrm{C}$ values are derived from a reduced number of data, and that ${ }^{14} \mathrm{C}$ in a larger fraction of bins is dominated by a single datum (20\% for a bin width of $400 \mathrm{yr}$ vs. $14 \%$ for a bin width of $600 \mathrm{yr}$ ). Besides, since more bins are filled with one datum, my approach to estimate bin $\Delta^{14} \mathrm{C}$ error does not work for the Northern Component Water (NCW) due to the very limited number (16) of observations.

The singular values of $\overline{\boldsymbol{G}}_{*}$ for the bin width of $400 \mathrm{yr}$ are shown in Figure 8c. Interestingly, a few singular values are now vanishing numerically, which results from a large number of empty bins and indicates the presence of a nullspace of $\overline{\boldsymbol{G}}_{*}$. This feature remains robust regardless of the bin boundaries (not shown). The presence of a nullspace of $\overline{\boldsymbol{G}}_{*}$ implies both a bias in the (particular) SVD solution and an unquantifiable contribution to the solution error variance. This solution (retaining all singular vectors associated to singular values higher than 10-10; Fig. 4.8c) corresponds to an over-fit of the model to the deep water $\Delta^{14} \mathrm{C}$ data and a small fraction $(6 / 144)$ of surface water $\Delta^{14} \mathrm{C}$ values transgressing the two bounds (not shown). It does not therefore alter the major results. 


\subsubsection{Effect of Low Deep Water $\Delta^{14} \mathrm{C}$ Values}

The deep water $\Delta^{14} \mathrm{C}$ record from $617-\mathrm{m}$ water depth near the Galapagos (Stott et al., 2009) shows particularly low $\Delta^{14} \mathrm{C}$ values that are difficult to explain from an oceanographic standpoint. Several studies have suggested that this record might have been influenced by hydrothermal processes leading to the release of ${ }^{14} \mathrm{C}$ depleted carbon to ambient bottom waters (e.g., Lund and Asimow, 2011; Stott and Timmermann, 2011). Here I repeat my analysis by adding the Galapagos $\Delta^{14} \mathrm{C}$ record to the deep water ${ }^{14} \mathrm{C}$ data set in order to study its influence on the results.

Since the total amount of data increases compared to that used in section 4.3.2, the coefficient matrix $\overline{\boldsymbol{G}}_{*}$ still has no nullspace when the Galapagos record is included in the analysis (Fig. 4.8d). The major changes in the data set are the presence of larger bin errors and the appearance of higher-frequency variability in the intermediate Pacific (Fig. 4.17). If all singular vectors are retained $(K=96)$, the solution with the Galapagos record included is similar to the full solution of section 4.3.2 (except for the intermediate South Pacific): the fit to the deep water $\Delta^{14} \mathrm{C}$ data is reasonable, and the surface $\Delta^{14} \mathrm{C}$ estimated from the fit significantly transgresses the bounds only at the initial time step in the Atlantic (not shown). If only the first 23 singular vectors are retained, the solution is even closer to the scenario where the Galapagos data are excluded (Figs. 4.17 and 4.18). This result arises from the fact that the influence on the solution of deep water $\Delta^{14} \mathrm{C}$ data for the intermediate South Pacific is very small when $K=23$, as demonstrated below. 
The importance of each deep water $\Delta^{14} \mathrm{C}$ datum in the solution with $K=23$ can be derived from the data resolution matrix, which is defined as (e.g., Wunsch, 2006)

$$
\mathbf{T}_{u}=\mathbf{U}_{K} \mathbf{U}_{K}^{\mathrm{T}},
$$

where $\mathbf{U}_{K}$ is a matrix containing the first $K$ left singular vectors of $\overline{\boldsymbol{G}}_{*}$. The diagonal elements of the matrix $\mathbf{T}_{u}$ reflect the relative importance of the bin $\Delta^{14} \mathrm{C}$ values in determining the surface water $\Delta^{14} \mathrm{C}$. These elements are plotted in Figure 19. It is seen that the data from subsurface volumes (boxes) that are in direct contact with surface volumes are more important than data from other regions in determining the solution, as one might intuitively expect. The importance of data from the intermediate South Pacific is very small in this analysis, consistent with the modest effect of Galapagos data on the solution.

\subsubsection{Effect of Model Architecture}

The box model represents the deep Atlantic with only one box (Fig. 4.6). In this section, I consider a slightly more detailed model, where the deep Atlantic box in the original model is split into two boxes: a northern box and a southern box. Volume transports in the modified model are derived from those in the original model (Fig. 4.6). Thus, in the modified model, the northern box receives a flux of 21.5 Sv from Northern Component Water, exchanges 3.5/2 = 1.75 Sv with the Intermediate Atlantic, and looses $21.5 \mathrm{~Sv}$ of water to the southern box. The southern box receives a flux of $21.5 \mathrm{~Sv}$ from the northern box, exchanges $1.75 \mathrm{~Sv}$ with the Intermediate Atlantic, and looses $21.5 \mathrm{~Sv}$ and exchanges $8 \mathrm{~Sv}$ with Circumpolar Deep 
Water. The other volume transports of the modified model are the same as in the original model (Fig. 4.6). With this circulation scheme, volume is conserved in all boxes, as in the original model.

The modified, 17-box model of modern ocean ventilation is fitted to the deep water $\Delta^{14} \mathrm{C}$ data using the same assumptions as for the solutions with the original model (section 4.3.2). With $K=96$, I find the deep water $\Delta^{14} \mathrm{C}$ data are well reproduced using the 17 box model in spite of an over-fit (Fig. 4.10c). The surface ${ }^{14} \mathrm{C}$ values estimated from the modified model are also very similar to the original ones (one value violates the upper bound at the initial step in the surface Atlantic;

not shown). I extend the comparison between the results from both models by considering fits to the deglacial deep water $\Delta^{14} \mathrm{C}$ data obtained from $K=23$. I find that the fit of the modified model to the deep ocean $\Delta^{14} \mathrm{C}$ data is good (Fig. 4.10d), and that all surface values are within the two bounds (not shown). Therefore, both models appear to display the same aptitude to explain the data.

\subsection{Summary and Palaeoceanographic Implications}

Radiocarbon measurements on fossil samples recovered from the seafloor have been used over the past two decades to draw inferences about changes in deep ocean ventilation during the last deglaciation. The study of ocean palaeo-ventilation is a particularly active field of research, often motivated by its postulated effect on atmospheric $\mathrm{CO}_{2}$ concentration and climate. However, interpretations of deep-sea ${ }^{14} \mathrm{C}$ records remain challenging, given in particular the multiple sources of error that can affect these records and the paucity of the current data base (relatively to modern standards). 
In this study, I have presented a compilation of more than 1,000 deep water $\Delta^{14} \mathrm{C}$ records originating from different oceanic basins and spanning the past 40 kyrs. Notable in the compilation is the observation of a decline in deep water $\Delta^{14} \mathrm{C}$ over the last glacial termination in different basins. The deep water $\Delta^{14} \mathrm{C}$ decline roughly parallels that observed in the atmospheric $\Delta^{14} \mathrm{C}$ reconstruction over the same time interval and appears highly significant (Table 4.3).

In order to interpret the latter results, consider the global budget of radiocarbon as governed by the equation

$$
\frac{d I}{d t}=\operatorname{Prod}-\lambda I,
$$

where $I$ is the ${ }^{14} \mathrm{C}$ inventory in the various reservoirs of the global C cycle and Prod is the ${ }^{14} \mathrm{C}$ production in the atmosphere. As shown by equation (22), a decrease in ${ }^{14} \mathrm{C}$ inventory observed over some time interval would imply that ${ }^{14} \mathrm{C}$ production is insufficient to sustain radiocarbon decay in all $\mathrm{C}$ reservoirs over the interval. The tendency term in (22) integrated from 25 to 0 kyr B.P. would be negative under the following assumptions: (i) $I$ can be approximated by the sum of the atmospheric and deep ocean inventories, (ii) the drop in reconstructed atmospheric $\Delta^{14} \mathrm{C}$ is accurate, and (iii) the negative trends apparent in my deep water $\Delta^{14} \mathrm{C}$ data compilation are representative of the deep ocean as a whole. Previous studies have suggested that cosmogenic production is responsible for the majority of the atmospheric $\Delta^{14} \mathrm{C}$ decline over the past 25 kyrs (e.g., Hughen et al., 2006; Muscheler et al., 2004). Based on deep ocean $\Delta^{14} \mathrm{C}$ records (discussed in the above studies), my work shows 
that under assumptions (i-iii), a global imbalance between ${ }^{14} \mathrm{C}$ production and radioactive decay, rather than a re-distribution between different reservoirs, could explain the long-term $\Delta^{14} \mathrm{C}$ decrease that is observed both in the ocean and atmosphere during this interval (Fig. 4.7).

Motivated by this result, I have tested the null hypothesis (H0) that the deep water $\Delta^{14} \mathrm{C}$ records jointly do not require changes in basin-scale ocean ventilation from 20 to 10 kyr B.P., a time interval characterized by a relative abundance of deep water $\Delta^{14} \mathrm{C}$ data. The data analysis is, in essence, the solution of a regression problem: to test $\mathrm{H} 0$, a quantitative model of modern ocean ventilation is considered and fit to deglacial data, and the results of the fit are analyzed. These results are the fitted values of deep water $\Delta^{14} \mathrm{C}$ and the implied values of surface water $\Delta^{14} \mathrm{C}$. The analysis of fitted values of deep water $\Delta^{14} \mathrm{C}$ is similar to the analysis of residuals in regression problems. Likewise, the analysis of implied values of surface water $\Delta^{14} \mathrm{C}$ is similar to considerations on the reasonableness of regression parameters in regression problems.

In this study, I have found that the residuals are consistent with the estimated data uncertainties, and the implied values of surface water $\Delta^{14} \mathrm{C}$ are reasonable given their uncertainties and the bounds provided by contemporaneous values of atmospheric $\Delta^{14} \mathrm{C}$ and deep-water $\Delta^{14} \mathrm{C}$. Neither the least-squares (full) solution, which is unbiased but has large variance (section 4.3.2.1), nor the truncated reference solution (section 4.3.2.2), which is biased but has small variance, provides strong evidence for rejection of H0. Similarly, none of the sensitivity tests, bearing on data error (section 4.4.1), the consideration of 
Galapagos $\Delta^{14} \mathrm{C}$ data (section 4.4.3), and, to some extent, model architecture (section 4.4.4), provide strong evidence that the deglacial data are incompatible with modern ocean ventilation as represented in the box model. Therefore, at variance with a common claim in the literature, I have found that $\mathrm{H} 0$ cannot be rejected with high confidence, if an effort is made to account for the uncertainties in the largescale representativeness of (site-specific) $\Delta^{14} \mathrm{C}$ records.

Many studies using different proxies have concluded for deglacial changes in ocean circulation (for recent work see, e.g., Keigwin and Boyle, 2008; Negre et al., 2010; Okazaki et al., 2010; Rae et al., 2014; Skinner et al., 2014). Whilst such conclusions are clearly plausible, it should also be stressed that quantitative estimates of the inferred circulation changes and of their uncertainties are typically not reported. Absent such estimates, the degree of (in)consistency of inferences between different studies, and between prior studies and the present study, is difficult to assess. Perhaps more important, my results do not imply that changes in basin-scale ocean ventilation did not take place during the deglaciation. Rather, they show that the presently available radiocarbon database appears inadequate to put such changes on a firm ground. Whether they will still hold as additional deep water $\Delta^{14} \mathrm{C}$ data become available remains to be seen. Additional data would be helpful, not only for better constraining basin-scale ventilation changes (if any) but also for identifying changes on time scales shorter than those considered in this analysis. Moreover, my results do not rule out the possibility of deglacial changes in ventilation at horizontal scales smaller than $\mathrm{O}(1,000 \mathrm{~km})$ and vertical scales smaller 
than $\mathrm{O}(1000 \mathrm{~m})$, as these scales are not resolved by the ocean model used in this study.

As already mentioned, changes in large-scale ocean circulation have been postulated to have contributed to past changes in atmospheric $\mathrm{CO}_{2}$ concentration and climate. For example, some authors have used estimates of deep ocean ${ }^{14} \mathrm{C}$ age to infer variations in deep ocean carbon storage and atmospheric $\mathrm{CO}_{2}$ level during the last (de)glacial periods (e.g., Sarnthein et al., 2013; Skinner et al., 2010). This study shows that deglacial deep ocean $\Delta^{14} \mathrm{C}$ data can be explained by modern, basinscale ventilation rates, assuming variable surface reservoir age at high latitudes where deep waters are formed. Processes that are thought to lead to variations in the reservoir ages of high-latitude surface waters (poleward of about $40^{\circ}$ of latitude) include variable upwelling and mixing with old subsurface waters as well as variable sea ice cover (Bard, 1988). Whether such processes could operate without a commensurate change in basin-scale ventilation rates, detectable from ${ }^{14} \mathrm{C}$ measurements on fossil carbonates, remains to be investigated.

Overall, my results echo those from previous studies that similarly illustrated the difficulty to reject the consistency of sediment data for the LGM and the deglaciation with the modern circulation, given the data uncertainties and paucity (e.g., Amrhein, 2016; Amrhein et al., 2015; Burke et al., 2011; Dail and Wunsch, 2014; Gebbie, 2014; Gebbie and Huybers, 2006; LeGrand and Wunsch, 1995; Marchal and Curry, 2008). 


\subsection{Perspectives}

Besides the obvious need for more data (for both deep and surface waters), I feel that other lines of research should be pursued in order to enhance the value of deep water radiocarbon records in the study of palaeo-circulations. First and foremost, accurate estimates of the core and coral chronologies are critical for reconstructing deep water $\Delta^{14} \mathrm{C}$, since $\Delta^{14} \mathrm{C}$ depends very sensitively on calendar age (e.g., Davies-Walczak et al., 2014). The chronological errors arising from varying sedimentation rate and reservoir age are poorly understood and generally not reported in the original publications. Such errors are not accounted for in the data set compiled in this study, and it is anticipated that rejection of HO would be even more difficult if such errors were considered. Second, a common procedure to obtain $\Delta^{14} \mathrm{C}$ measurements on fossil samples appears highly desirable for the construction of an internally consistent dataset. For example, ${ }^{14} \mathrm{C}$ measurements on benthic shells could be restricted to samples originating from peaks in benthic shell abundance (e.g., Keigwin and Schlegel, 2002) and (or) to cores with high sedimentation rates, so as to minimize bioturbation effects. Third, studies are needed to establish the relationship between $\Delta^{14} \mathrm{C}$ of benthic foraminifera or deepsea corals sampled from the seafloor and the $\Delta^{14} \mathrm{C}$ of ambient bottom water. It is rather surprising that this relationship remains poorly documented, given the wide use of ${ }^{14} \mathrm{C}$ measurements on such samples as palaeoceanographic indicators. In particular, more research should be done on the potential of seafloor processes, such as hydrothermal activities and methane seeps, to affect the ${ }^{14} \mathrm{C} /{ }^{12} \mathrm{C}$ ratios in fossil biogenic carbonates (e.g., Stott and Timmermann, 2011). Finally, deep water 
$\Delta^{14} \mathrm{C}$ records generally originate from near oceanic boundaries, in relatively shallow water and in environments characterized by relatively high deposition rates. Analyzing these records with a model that has sufficient resolution to properly represent ocean circulation in regions where they originate could improve the power of those records to constrain past circulation states. 


\section{Tables}

Table 4.1. Summary of deep water $\Delta^{14} \mathrm{C}$ data compiled in this study

\begin{tabular}{|c|c|c|c|c|c|c|}
\hline Lat. & Long. & $\begin{array}{l}\text { Sediment core } \\
\text { /Coral name }\end{array}$ & $\begin{array}{c}\text { Modern } \\
\text { water } \\
\text { depth }(\mathrm{m})\end{array}$ & Substrate & $\begin{array}{l}\text { Amount of } \\
{ }^{14} \mathrm{C} \text { data }\end{array}$ & References \\
\hline 63.0 & -17.6 & RAPiD-10-1P & 1237 & $\mathrm{BF}$ & 11 & Thornalley et al., 2011b \\
\hline 62.3 & -17.1 & RAPiD-15-4P & 2133 & $\mathrm{BF}$ & 13 & Thornalley et al., 2011b \\
\hline 61.5 & -19.5 & RAPiD-17-5P & 2303 & $\mathrm{BF}$ & 8 & Thornalley et al., 2011b \\
\hline 60.1 & -179.4 & SO202-18-6 & 1100 & $\mathrm{BF}$ & 4 & Max et al., 2014 \\
\hline 59.6 & -144.2 & EW0408-84TC & 682 & $\mathrm{BF}$ & 38 & $\begin{array}{c}\text { Davies-Walczak et al., } \\
2014\end{array}$ \\
\hline 58.9 & 170.7 & S0201-2-101KL & 630 & $\mathrm{BF}$ & 3 & Max et al., 2014 \\
\hline 57.5 & 170.4 & SO201-2-85KL & 968 & $\mathrm{BF}$ & 3 & Max et al., 2014 \\
\hline 56.3 & 170.7 & SO201-2-77KL & 2135 & $\mathrm{BF}$ & 3 & Max et al., 2014 \\
\hline 54.6 & -148.8 & ODP887 & 3647 & $\mathrm{BF}$ & 8 & Galbraith et al., 2007 \\
\hline 54.5 & 144.8 & LV27-2-4 & 1305 & $\mathrm{BF}$ & 6 & Gorbarenko et al., 2010 \\
\hline 54.4 & -148.9 & MD02-2489 & 3640 & $\mathrm{BF}$ & 14 & Rae et al., 2014 \\
\hline 54.0 & 162.4 & SO201-2-12KL & 2145 & $\mathrm{BF}$ & 4 & Max et al., 2014 \\
\hline 53.7 & 165.0 & VIN019-4 GGC17 & 3960 & $\mathrm{BF}$ & 1 & Cook and Keigwin, 2015 \\
\hline 52.7 & 144.7 & S0178-13-6 & 713 & $\mathrm{BF}$ & 3 & Max et al., 2014 \\
\hline 51.3 & 167.7 & MD01-2416 & 2317 & $\mathrm{BF}$ & 6 & $\begin{array}{l}\text { Sarnthein et al., 2007; } \\
\text { Sarnthein et al., } 2006\end{array}$ \\
\hline 51.2 & 167.8 & ODP883 & 2385 & $\mathrm{BF}$ & 2 & Sarnthein et al., 2006 \\
\hline 51.1 & 167.9 & RNDB GGC5 & 2804 & $\mathrm{BF}$ & 2 & Cook and Keigwin, 2015 \\
\hline 51.1 & 169.0 & RNDB PC11 & 3225 & $\mathrm{BF}$ & 4 & $\begin{array}{l}\text { Cook and Keigwin, } \\
\text { 2015; Keigwin and } \\
\text { Lehman, } 2015\end{array}$ \\
\hline 51.1 & 168.1 & RNDB GGC15 & 3700 & $\mathrm{BF}$ & 1 & Cook and Keigwin, 2015 \\
\hline 51.0 & 148.3 & 936 & 1305 & $\mathrm{BF}$ & 3 & Gorbarenko et al., 2004 \\
\hline 50.4 & 167.7 & VIN019-4 GGC37 & 3300 & $\mathrm{BF}$ & 2 & Cook and Keigwin, 2015 \\
\hline 50.1 & 153.2 & V34-98 & 1175 & $\mathrm{BF}$ & 1 & Gorbarenko et al., 2002 \\
\hline 49.7 & 168.3 & RNDB PC13/PG13 & 2329 & $\mathrm{BF}$ & 9 & $\begin{array}{l}\text { Cook and Keigwin, } \\
\text { 2015; Keigwin and } \\
\text { Lehman, } 2015\end{array}$ \\
\hline 49.6 & 150.2 & $\begin{array}{c}\text { Nesmeyanov25-1 } \\
\text { GGC27 }\end{array}$ & 995 & $\mathrm{BF}$ & 3 & $\begin{array}{l}\text { Cook and Keigwin, } \\
\text { 2015; Keigwin, } 2002\end{array}$ \\
\hline 49.4 & 152.9 & LV29-114-3 & 1765 & $\mathrm{BF}$ & 6 & Max et al., 2014 \\
\hline 49.1 & 150.3 & B34-91 & 1227 & $\mathrm{BF}$ & 1 & Keigwin, 2002 \\
\hline 48.9 & -126.9 & JT96-09 & 920 & $\mathrm{BF}$ & 7 & McKay et al., 2005 \\
\hline 48.9 & 150.4 & $\begin{array}{c}\text { Nesmeyanov25-1 } \\
\text { GGC20 }\end{array}$ & 1510 & $\mathrm{BF}$ & 3 & $\begin{array}{l}\text { Cook and Keigwin, } \\
\text { 2015; Keigwin, } 2002\end{array}$ \\
\hline
\end{tabular}




\begin{tabular}{|c|c|c|c|c|c|c|}
\hline 48.8 & 150.4 & $\begin{array}{c}\text { Nesmeyanov25-1 } \\
\text { GGC18 }\end{array}$ & 1700 & $\mathrm{BF}$ & 3 & $\begin{array}{l}\text { Cook and Keigwin, } \\
\text { 2015; Keigwin, } 2002\end{array}$ \\
\hline 48.6 & 150.4 & $\begin{array}{c}\text { Nesmeyanov25-1 } \\
\text { GGC15 }\end{array}$ & 1980 & $\mathrm{BF}$ & 4 & $\begin{array}{l}\text { Cook and Keigwin, } \\
\text { 2015; Keigwin, } 2002\end{array}$ \\
\hline 44.5 & 145.0 & MR0604 PC04A & 1215 & $\mathrm{BF}$ & 6 & Okazaki et al., 2014 \\
\hline 43.5 & -54.9 & OCE326 GGC26 & 3975 & $\mathrm{BF}$ & 4 & Unpublished \\
\hline 43.5 & -54.8 & KNR197-19 CDH42 & 3870 & $\mathrm{BF}$ & 5 & Unpublished \\
\hline 43.1 & -55.8 & OCE326 GGC14 & 3525 & $\mathrm{BF}$ & 3 & $\begin{array}{l}\text { Robinson et al., 2005; } \\
\text { Unpublished }\end{array}$ \\
\hline 43.0 & -55.3 & HU73031-7 & 4055 & $\mathrm{BF}$ & 1 & Robinson et al., 2005 \\
\hline 43.0 & -59.9 & HU72021-3 & 2470 & $\mathrm{BF}$ & 1 & Robinson et al., 2005 \\
\hline 42.2 & 144.2 & GH02-1030 & 1212 & $\mathrm{BF}$ & 15 & Ikehara et al., 2006 \\
\hline 42.1 & -125.8 & W8709A-13PC & 2710 & $\mathrm{BF}$ & 35 & $\begin{array}{c}\text { Lund et al., 2011; Mix et } \\
\text { al., } 1999\end{array}$ \\
\hline 42.0 & -29.0 & $\begin{array}{l}\text { JFA Deep-sea } \\
\text { Corals1 }\end{array}$ & $\begin{array}{c}1684- \\
1829\end{array}$ & $\mathrm{DC}$ & 2 & Adkins et al., 1998 \\
\hline 41.7 & 142.6 & CH84-14 & 978 & $\mathrm{BF}$ & 10 & Duplessy et al., 1989 \\
\hline 41.7 & -124.9 & ODP1019 & 980 & $\mathrm{BF}$ & 10 & Mix et al., 1999 \\
\hline 41.1 & 142.4 & MR01-K03-PC4/5 & 1366 & $\mathrm{BF}$ & 16 & Ahagon et al., 2003 \\
\hline 40.4 & 143.5 & KR02-15-PC6 & 2215 & $\mathrm{BF}$ & 7 & Minoshima et al., 2007 \\
\hline 39.9 & -69.0 & $\begin{array}{c}\text { KNR198 } \\
\text { GGC35/CDH36 }\end{array}$ & 1828 & $\mathrm{BF}$ & 5 & Unpublished \\
\hline 39.2 & -68.0 & KNR198 GGC15 & 3308 & $\mathrm{BF}$ & 3 & Unpublished \\
\hline 39.0 & -61.0 & $\begin{array}{l}\text { Gregg Seamount } \\
\text { Deep-sea Corals }\end{array}$ & $\begin{array}{l}1176- \\
1222\end{array}$ & DC & 8 & $\begin{array}{l}\text { Eltgroth et al., 2006; } \\
\text { Robinson et al., 2005 }\end{array}$ \\
\hline 38.0 & -62.0 & $\begin{array}{l}\text { JFA Deep-sea } \\
\text { Corals2 }\end{array}$ & 1954 & $\mathrm{DC}$ & 1 & Adkins et al., 1998 \\
\hline 38.0 & -60.0 & $\begin{array}{l}\text { Manning Seamount } \\
\text { Deep-sea Corals }\end{array}$ & $\begin{array}{l}1713- \\
1886\end{array}$ & $\mathrm{DC}$ & 13 & $\begin{array}{l}\text { Adkins et al., 1998; } \\
\text { Eltgroth et al., 2006; } \\
\text { Robinson et al., 2005 }\end{array}$ \\
\hline 38.0 & -25.6 & $\begin{array}{l}\text { Smithsonian Deep- } \\
\text { sea Coral }\end{array}$ & $\begin{array}{l}1069- \\
1235\end{array}$ & $\mathrm{DC}$ & 7 & Eltgroth et al., 2006 \\
\hline 37.8 & -10.2 & MD99-2334K & 3146 & $\mathrm{BF}$ & 25 & $\begin{array}{l}\text { Skinner et al., 2010; } \\
\text { Skinner and Shackleton, } \\
\text { 2004; Skinner et al., } \\
2014\end{array}$ \\
\hline 37.2 & -123.2 & F8-90-G21 & 1605 & $\mathrm{BF}$ & 5 & van Geen, 1996 \\
\hline 37.1 & -31.9 & KNR197-10 GGC5 & 2127 & $\mathrm{BF}$ & 1 & Unpublished \\
\hline 36.4 & -48.5 & KNR197-10 GGC17 & 5011 & $\mathrm{BF}$ & 2 & Unpublished \\
\hline 36.1 & -72.3 & KNR178 GGC2 & 3927 & $\mathrm{BF}$ & 4 & Unpublished \\
\hline 36.1 & 141.8 & MD01-2420 & 2101 & $\mathrm{BF}$ & 15 & Okazaki et al., 2012 \\
\hline 35.6 & -121.6 & F2-92-P3 & 799 & $\mathrm{BF}$ & 9 & van Geen, 1996 \\
\hline
\end{tabular}




\begin{tabular}{|c|c|c|c|c|c|c|}
\hline 34.3 & -120.0 & ODP893A & 576.5 & $\begin{array}{l}\text { BF; Spiral } \\
\text { shell }\end{array}$ & 30 & $\begin{array}{l}\text { Ingram and Kennett, } \\
\text { 1995; Magana et al., } \\
\text { 2010; Sarnthein et al., } \\
2007\end{array}$ \\
\hline 34.2 & 137.7 & B004-PC11 & 1076 & $\mathrm{BF}$ & 5 & Ikehara et al., 2011 \\
\hline 34.0 & -63.0 & $\begin{array}{l}\text { Muir Seamount } \\
\text { Deep-sea Corals }\end{array}$ & $\begin{array}{l}2026- \\
2441\end{array}$ & DC & 32 & $\begin{array}{l}\text { Eltgroth et al., 2006; } \\
\text { Robinson et al., } 2005\end{array}$ \\
\hline 33.7 & -57.6 & HU89038-8PC & 4600 & Bivalve & 2 & $\begin{array}{l}\text { Keigwin and Boyle, } \\
2008\end{array}$ \\
\hline 33.7 & -57.6 & OCE326 GGC5 & 4600 & Bivalve & 1 & $\begin{array}{l}\text { Keigwin and Boyle, } \\
2008\end{array}$ \\
\hline 33.7 & -57.6 & KNR31 GPC5 & 4583 & $\mathrm{BF}$ & 1 & Unpublished \\
\hline 32.9 & -76.3 & KNR140 GGC56 & 1400 & $\mathrm{BF}$ & 1 & Robinson et al., 2005 \\
\hline 32.8 & -76.3 & KNR140 GGC51 & 1790 & $\mathrm{BF}$ & 3 & $\begin{array}{c}\text { Keigwin, 2004; } \\
\text { Robinson et al., } 2005\end{array}$ \\
\hline 32.8 & -76.2 & KNR140 GGC50 & 1903 & $\mathrm{BF}$ & 2 & $\begin{array}{l}\text { Keigwin, 2004; } \\
\text { Unpublished }\end{array}$ \\
\hline 32.5 & -76.3 & KNR140 GGC66 & 2155 & $\mathrm{BF}$ & 1 & Keigwin, 2004 \\
\hline 32.4 & -76.4 & KNR140 JPC01 & 2243 & $\mathrm{BF}$ & 1 & Keigwin, 2004 \\
\hline 32.2 & -76.3 & KNR140 PG02 & 2394 & $\mathrm{BF}$ & 1 & Keigwin, 2004 \\
\hline 32.2 & 133.9 & KT89-18-P4 & 2700 & $\mathrm{BF}$ & 7 & Okazaki et al., 2010 \\
\hline 32.0 & -76.1 & KNR140 GGC43 & 2590 & $\mathrm{BF}$ & 1 & Keigwin, 2004 \\
\hline 31.7 & -75.4 & KNR140 JPC37 & 2972 & $\mathrm{BF}$ & 4 & $\begin{array}{c}\text { Keigwin and Schlegel, } \\
2002\end{array}$ \\
\hline 31.7 & -75.4 & KNR140 GGC39 & 2975 & $\mathrm{BF}$ & 4 & $\begin{array}{l}\text { Keigwin and Schlegel, } \\
2002\end{array}$ \\
\hline 30.7 & -74.5 & KNR140 GGC30 & 3433 & BF & 1 & Robinson et al., 2005 \\
\hline 29.7 & -73.4 & KNR140 GGC26 & 3845 & $\mathrm{BF}$ & 1 & Keigwin, 2004 \\
\hline 29.1 & -72.9 & KNR140 JPC12 & 4250 & $\mathrm{BF}$ & 5 & $\begin{array}{c}\text { Keigwin, 2004; } \\
\text { Robinson et al., 2005; } \\
\text { Unpublished }\end{array}$ \\
\hline 28.3 & -74.4 & KNR140 JPC22 & 4712 & $\mathrm{BF}$ & 1 & Keigwin, 2004 \\
\hline 27.9 & -111.7 & DSDP 480 & 655 & $\mathrm{BF}$ & 1 & $\begin{array}{c}\text { Keigwin and Lehman, } \\
2015\end{array}$ \\
\hline 27.5 & -112.1 & $\begin{array}{c}\text { AII125-8 } \\
\text { GGC55/JPC56 }\end{array}$ & 818 & $\mathrm{BF}$ & 14 & Keigwin, 2002 \\
\hline 23.5 & -111.6 & PC08/MC19/GC31 & 705 & $\mathrm{BF}$ & 50 & Marchitto et al., 2007 \\
\hline 18.9 & 115.8 & $50-37 \mathrm{KL}$ & 2695 & BF & 9 & Broecker et al., 1990 \\
\hline 18.3 & 57.7 & RC27-14 & 596 & $\mathrm{BF}$ & 22 & Bryan et al., 2010 \\
\hline 18.0 & 57.6 & RC27-23 & 820 & BF & 23 & Bryan et al., 2010 \\
\hline 15.4 & -51.1 & $\begin{array}{c}\text { Gramberg } \\
\text { Seamount Deep- } \\
\text { sea Corals }\end{array}$ & $\begin{array}{l}1492- \\
1544\end{array}$ & DC & 2 & Chen et al., 2015 \\
\hline 14.9 & -48.2 & $\begin{array}{l}\text { Vayda Seamount } \\
\text { Deep-sea Corals }\end{array}$ & $795-1827$ & DC & 6 & Chen et al., 2015 \\
\hline 10.7 & -44.6 & $\begin{array}{c}\text { Vema Fracture } \\
\text { Zone }\end{array}$ & $\begin{array}{l}1097- \\
1657\end{array}$ & DC & 18 & Chen et al., 2015 \\
\hline
\end{tabular}




\begin{tabular}{|c|c|c|c|c|c|c|}
\hline 9.2 & -21.3 & $\begin{array}{l}\text { Carter Seamount } \\
\text { Deep-sea Corals }\end{array}$ & $973-2100$ & DC & 26 & Chen et al., 2015 \\
\hline 7.2 & 112.1 & V35-05 & 1953 & $\mathrm{BF}$ & 14 & Broecker et al., 1988a \\
\hline 5.6 & -26.9 & $\begin{array}{l}\text { Knipovich } \\
\text { Seamount Deep- } \\
\text { sea Corals }\end{array}$ & $749-2814$ & DC & 17 & Chen et al., 2015 \\
\hline 6.0 & 126.0 & MD98-2181 & 2100 & $\mathrm{BF}$ & 3 & Broecker et al., 2004 \\
\hline 5.0 & -77.6 & KNR176 JPC30 & 707 & $\mathrm{BF}$ & 17 & Unpublished \\
\hline 4.0 & -114.2 & KNR73 6PG & 3806 & $\mathrm{BF}$ & 1 & $\begin{array}{l}\text { Keigwin and Lehman, } \\
2015\end{array}$ \\
\hline 2.3 & -30.6 & GeoB 1503-1 & 2306 & DC & 1 & Mangini et al., 1998 \\
\hline 1.8 & -110.3 & KNR73 4PC & 3681 & $\mathrm{BF}$ & 6 & $\begin{array}{l}\text { Keigwin and Lehman, } \\
2015\end{array}$ \\
\hline 1.0 & 160.5 & V28-238 & 3120 & $\mathrm{BF}$ & 7 & Broecker et al., 1988b \\
\hline 1.0 & 130.0 & MD01-2386 & 2800 & $\mathrm{BF}$ & 16 & Broecker et al., 2008 \\
\hline 0.0 & -86.5 & ME0005-24JC & 2941 & $\mathrm{BF}$ & 2 & $\begin{array}{l}\text { Keigwin and Lehman, } \\
2015\end{array}$ \\
\hline 0.0 & -86.5 & ODP1240 & 2921 & $\mathrm{BF}$ & 14 & de la Fuente et al., 2015 \\
\hline-0.4 & -106.2 & KNR73 3PC & 3606 & $\mathrm{BF}$ & 6 & $\begin{array}{l}\text { Keigwin and Lehman, } \\
2015\end{array}$ \\
\hline-1.0 & 146.0 & MD97-2138 & 1900 & $\mathrm{BF}$ & 2 & Broecker et al., 2004 \\
\hline-1.2 & -89.7 & VM21-30 & 617 & $\mathrm{BF}$ & 22 & Stott et al., 2009 \\
\hline-1.3 & -11.9 & RC24-08 & 600 & $\begin{array}{c}\text { Deep- } \\
\text { dwelling } \\
\text { PF }\end{array}$ & 8 & Cléroux et al., 2011 \\
\hline-1.6 & 162.6 & S67 FFC15 & 4250 & $\mathrm{BF}$ & 2 & $\begin{array}{l}\text { Keigwin and Lehman, } \\
2015\end{array}$ \\
\hline-2.0 & -140.0 & TTN013-18 & 4400 & $\mathrm{BF}$ & 8 & $\begin{array}{c}\text { Broecker and Clark, } \\
2010\end{array}$ \\
\hline-3.3 & -102.5 & PLDS 7G & 3253 & $\mathrm{BF}$ & 3 & $\begin{array}{l}\text { Keigwin and Lehman, } \\
2015\end{array}$ \\
\hline-3.6 & -84.0 & TR163-31 & 3210 & $\mathrm{BF}$ & 4 & Shackleton et al., 1988 \\
\hline-4.2 & -37.1 & $\begin{array}{c}\text { GS07-150-17/1GC- } \\
\mathrm{A}\end{array}$ & 1000 & $\mathrm{BF}$ & 16 & Freeman et al., 2015 \\
\hline-4.5 & -102.0 & VNTR01-10GGC & 3410 & $\mathrm{BF}$ & 2 & $\begin{array}{l}\text { Keigwin and Lehman, } \\
\qquad 2015\end{array}$ \\
\hline-10.3 & -111.3 & TT154-10 & 3225 & $\mathrm{BF}$ & 6 & Broecker et al., 1988a \\
\hline-22.4 & -40.0 & ENG-111 & 621 & DC & 10 & Mangini et al., 2010 \\
\hline-24.2 & -43.3 & 21210009 & 781 & DC & 10 & Mangini et al., 2010 \\
\hline-27.5 & -46.3 & KNR159-5-78GGC & 1829 & $\mathrm{BF}$ & 17 & Lund et al., 2015 \\
\hline-27.5 & -46.5 & KNR159-5-36GGC & 1268 & $\mathrm{BF}$ & 24 & Sortor and Lund, 2011 \\
\hline-36.2 & -73.7 & S0161-SL22 & 1000 & $\mathrm{BF}$ & 19 & De Pol-Holz et al., 2010 \\
\hline-37.0 & 177.2 & $\mathrm{H} 213$ & 2065 & $\mathrm{BF}$ & 2 & Sikes et al., 2000 \\
\hline-37.2 & 177.7 & H209 & 1675 & $\mathrm{BF}$ & 1 & Sikes et al., 2000 \\
\hline-37.4 & 177.0 & RR0503-JPC64 & 651 & $\mathrm{BF}$ & 14 & Rose et al., 2010 \\
\hline-40.4 & 178.0 & MD97-2121 & 2314 & $\mathrm{BF}$ & 6 & Skinner et al., 2015 \\
\hline-41.1 & 7.8 & TN057-21 & 4981 & $\mathrm{BF}$ & 13 & Barker et al., 2010 \\
\hline
\end{tabular}




\begin{tabular}{|c|c|c|c|c|c|c|}
\hline-43.5 & 174.9 & MD97-2120 & 1210 & $\mathrm{BF}$ & 7 & Rose et al., 2010 \\
\hline-44.1 & -14.2 & MD07-3076 & 3770 & $\mathrm{BF}$ & 38 & Skinner et al., 2010 \\
\hline-44.5 & 179.5 & U939 & 1300 & $\mathrm{BF}$ & 1 & Sikes et al., 2000 \\
\hline-45.0 & 148.0 & $\begin{array}{l}\text { Tasmania Deep-sea } \\
\text { Corals }\end{array}$ & $\begin{array}{l}1428- \\
1947\end{array}$ & DC & 60 & Hines et al., 2015 \\
\hline-45.1 & 179.5 & U938 & 2700 & $\mathrm{BF}$ & 1 & Sikes et al., 2000 \\
\hline-46.0 & -75.0 & MD07-3088 & 1536 & $\mathrm{BF}$ & 21 & Siani et al., 2013 \\
\hline-54.0 & -62.0 & $\begin{array}{l}\text { BurdwoodBank } \\
\text { Deep-sea Corals1 }\end{array}$ & 318 & $\mathrm{DC}$ & 2 & $\begin{array}{l}\text { Burke and Robinson, } \\
2012\end{array}$ \\
\hline-55.0 & -62.0 & $\begin{array}{l}\text { BurdwoodBank } \\
\text { Deep-sea Corals2 }\end{array}$ & $816-1516$ & $\mathrm{DC}$ & 10 & $\begin{array}{l}\text { Burke and Robinson, } \\
\text { 2012; Chen et al., } 2015\end{array}$ \\
\hline-59.4 & -68.5 & 47396 & 1125 & DC & 4 & $\begin{array}{l}\text { Robinson and van de } \\
\text { Flierdt, } 2009\end{array}$ \\
\hline-59.7 & -68.7 & 47396B & 1125 & $\mathrm{DC}$ & 1 & Goldstein et al., 2001 \\
\hline-60.0 & -69.0 & $\begin{array}{l}\text { Sars Seamount } \\
\text { Deep-sea Corals }\end{array}$ & $695-1750$ & $\mathrm{DC}$ & 34 & $\begin{array}{l}\text { Burke and Robinson, } \\
\text { 2012; Chen et al., } 2015\end{array}$ \\
\hline-60 & -58 & $\begin{array}{c}\text { Shackleton } \\
\text { Fracture Zone } \\
\text { Deep-sea Corals }\end{array}$ & $806-823$ & DC & 12 & $\begin{array}{l}\text { Burke and Robinson, } \\
\text { 2012; Chen et al., } 2015\end{array}$ \\
\hline-61.0 & -66.0 & $\begin{array}{l}\text { Interim Seamount } \\
\text { Deep-sea Corals }\end{array}$ & 983-1196 & $\mathrm{DC}$ & 6 & $\begin{array}{l}\text { Burke and Robinson, } \\
\text { 2012; Chen et al., } 2015\end{array}$ \\
\hline
\end{tabular}


Table 4.2. Statistics of ${ }^{14} \mathrm{C}$ distribution in different oceanic volumes

\begin{tabular}{|c|c|c|c|c|c|c|c|}
\hline & $\begin{array}{l}\text { Volume } \\
\left(10^{15} \mathrm{~m}^{3}\right)\end{array}$ & $N^{a}$ & $\begin{array}{c}\text { Bin } \Delta^{14} \mathrm{C} \\
\text { error } \\
(\% 0)\end{array}$ & $\begin{array}{c}\overline{\Delta^{14} \mathrm{C}_{M B C}} \\
(\% 0)^{\mathrm{b}}\end{array}$ & $\begin{array}{c}\sigma \\
(\% 0)^{c}\end{array}$ & $\begin{array}{c}\overline{{ }^{14} C \text { age }_{M B C}} \\
\left({ }^{14} \mathrm{C} \text { yr }\right)^{d}\end{array}$ & $\begin{array}{c}\sigma-, \sigma+ \\
\left({ }^{14} \mathrm{C} \text { yr }\right)^{\mathrm{e}}\end{array}$ \\
\hline $\begin{array}{c}\text { Northern } \\
\text { Component } \\
\text { Water (NCW) }\end{array}$ & 10 & 16 & 58 & -74 & 13 & 632 & $-115,+116$ \\
\hline $\begin{array}{c}\text { Intermediate } \\
\text { Atlantic (IntAtl) }\end{array}$ & 93 & 144 & 57 & -86 & 20 & 739 & $-178,+181$ \\
\hline $\begin{array}{l}\text { Deep Atlantic } \\
\text { (Deep Atl) }\end{array}$ & 179 & 193 & 71 & -116 & 27 & 1014 & $-247,+255$ \\
\hline $\begin{array}{l}\text { Circumpolar } \\
\text { Deep Water } \\
\text { (CDW) }\end{array}$ & 150 & 106 & 53 & -134 & 28 & 1183 & $-262,+270$ \\
\hline $\begin{array}{l}\text { Intermediate } \\
\text { Indian } \\
\text { (IntInd) }\end{array}$ & 76 & 45 & 93 & -108 & 37 & 940 & $-334,+348$ \\
\hline $\begin{array}{l}\text { Deep Indian } \\
\text { (Deep Ind) }\end{array}$ & 147 & 0 & $\mathrm{~N} / \mathrm{A}$ & -182 & 23 & 1652 & $-228,+235$ \\
\hline $\begin{array}{l}\text { Intermediate } \\
\text { South Pacific } \\
\text { (Int S Pac) }\end{array}$ & 108 & $\begin{array}{c}52 \\
(74)^{*}\end{array}$ & 93 & -103 & 34 & 894 & $-306,+318$ \\
\hline $\begin{array}{l}\text { Deep South } \\
\text { Pacific } \\
\text { (Deep S Pac) } \\
\text { Intermediate }\end{array}$ & 207 & 113 & 166 & -185 & 19 & 1682 & $-190,+194$ \\
\hline $\begin{array}{l}\text { North Pacific } \\
\text { (Int N Pac) }\end{array}$ & 108 & 271 & 84 & -136 & 45 & 1202 & $-418,+440$ \\
\hline $\begin{array}{l}\text { Deep North } \\
\text { Pacific } \\
\text { (Deep N Pac) }\end{array}$ & 207 & 213 & 109 & -218 & 11 & 2022 & $-115,+116$ \\
\hline
\end{tabular}

a Number of deep water palaeo $\Delta^{14} \mathrm{C}$ data.

b Mean of modern bomb-corrected $\Delta^{14} \mathrm{C}$.

${ }^{c}$ Standard deviation of modern bomb-corrected $\Delta^{14} \mathrm{C}$.

$\mathrm{d}$ Mean of modern bomb-corrected ${ }^{14} \mathrm{C}$ age

e Errors on each side of the mean of modern bomb-corrected ${ }^{14} \mathrm{C}$ age ${ }^{14} \mathrm{C}$ age error computed from $\Delta^{14} \mathrm{C}$ error is asymmetric about the mean due to the nonlinear relationship between ${ }^{14} \mathrm{C}$ age and $\Delta^{14} \mathrm{C}$ ).

*The number in parentheses includes the Galapagos data from Stott et al. (2009). 
Table 4.3. Kendall $\tau$ coefficient for the relationship between deep ocean $\Delta^{14} \mathrm{C}$ and calendar age (25-0 kyr B.P.) $)^{\text {a }}$ The associated $p$ value is less than 0.01 for all boxes.

\begin{tabular}{cccccccccc}
\hline NCW & Int Atl & $\begin{array}{c}\text { Deep } \\
\text { Atl }\end{array}$ & CDW & $\begin{array}{c}\text { Int } \\
\text { Ind }\end{array}$ & $\begin{array}{c}\text { Deep } \\
\text { Ind }\end{array}$ & $\begin{array}{c}\text { Int S } \\
\text { Pac }\end{array}$ & $\begin{array}{c}\text { Dee S } \\
\text { Pac }\end{array}$ & $\begin{array}{c}\text { Int N } \\
\text { Pac }\end{array}$ & $\begin{array}{c}\text { Deep } \\
\text { N Pac }\end{array}$ \\
\hline-0.73 & -0.60 & -0.42 & -0.49 & -0.65 & N/A & -0.42 & -0.30 & -0.62 & -0.60 \\
\hline
\end{tabular}

${ }^{a} \mathrm{~A}$ negative value indicates a decrease of deep ocean $\Delta^{14} \mathrm{C}$ with time. 
Table 4.4. Mean \pm standard error of $\Delta^{14} \mathrm{C}$ for different climatic intervals and different oceanic regions ${ }^{\mathrm{a}}$.

\begin{tabular}{|c|c|c|c|c|c|c|c|c|c|c|c|c|c|c|c|c|c|c|}
\hline \multirow{2}{*}{ Box } & \multicolumn{2}{|l|}{$\mathrm{NCW}$} & \multicolumn{2}{|c|}{ Int Atl } & \multicolumn{2}{|c|}{ Deep Atl } & \multicolumn{2}{|l|}{ CDW } & \multicolumn{2}{|c|}{ Int Ind } & \multicolumn{2}{|c|}{ Int S Pac } & \multicolumn{2}{|c|}{ Deep S Pac } & \multicolumn{2}{|c|}{ Int N Pac } & \multicolumn{2}{|c|}{ Deep N Pac } \\
\hline & $\Delta^{14} C$ & $\mathrm{~N}$ & $\Delta^{14} C$ & $\mathrm{~N}$ & $\Delta^{14} C$ & $\mathrm{~N}$ & $\Delta^{14} C$ & $\mathrm{~N}$ & $\Delta^{14} C$ & $\mathrm{~N}$ & $\Delta^{14} C$ & $\mathrm{~N}$ & $\Delta^{14} C$ & $\mathrm{~N}$ & $\Delta^{14} C$ & $\mathrm{~N}$ & $\Delta^{14} C$ & $\mathrm{~N}$ \\
\hline LGM & $174 \pm 19$ & 7 & $87 \pm 17$ & 17 & $4 \pm 20$ & 20 & $.01 \pm 29$ & 29 & \pm 25 & 25 & 16 & 16 & \pm 21 & 21 & \pm 15 & 15 & 13 & 13 \\
\hline HS1 & $76 \pm 19$ & 1 & $163 \pm 11$ & 11 & $111 \pm 18$ & 18 & $98 \pm 17$ & 17 & $1 \pm 25$ & 25 & $229 \pm 13$ & 13 & $64 \pm 26$ & 26 & $112 \pm 13$ & 13 & $12 \pm 10$ & 10 \\
\hline $\mathrm{BA}$ & $102 \pm 24$ & 4 & $65 \pm 20$ & 20 & $87 \pm 15$ & 15 & $51 \pm 11$ & 11 & $-7 \pm 24$ & 24 & $60 \pm 13$ & 13 & $52 \pm 22$ & 22 & $-4 \pm 12$ & 12 & $-51 \pm 12$ & 12 \\
\hline YD & $44 \pm 8$ & 1 & $64 \pm 24$ & 24 & $60 \pm 14$ & 14 & $58 \pm 14$ & 14 & $-50 \pm 20$ & 20 & $103 \pm 24$ & 24 & $70 \pm 49$ & 49 & $-13 \pm 15$ & 15 & $-68 \pm 8$ & 8 \\
\hline $\mathrm{EH}$ & $49 \pm 12$ & 1 & $26 \pm 20$ & 20 & $10 \pm 16$ & 16 & $-14 \pm 17$ & 17 & $-124 \pm 22$ & 22 & $-9 \pm 20$ & 20 & $-66 \pm 23$ & 23 & $-52 \pm 9$ & 9 & $-95 \pm 10$ & 10 \\
\hline
\end{tabular}

${ }^{a} N$ is the number of data. If $N=1$, the "standard error" is the error of the individual $\Delta^{14} \mathrm{C}$ value. 
Table 4.5. Numbers of surface $\Delta^{14} \mathrm{C}$ values that violate the two bounds for the full solution and for other solutions with different bin boundaries $(K=96$ unless noted otherwise).

\begin{tabular}{ccccccc}
\hline $\begin{array}{c}\text { Center of oldest bin } \\
\text { (kyr B.P.) }\end{array}$ & $20^{*}$ & 19.9 & 19.8 & 19.7 & 19.6 & $19.5^{*}$ \\
\hline $\mathrm{n}_{1}{ }^{\mathrm{a}}$ & 2 & 3 & 3 & 1 & 1 & 0 \\
$\mathrm{n}_{2}{ }^{\mathrm{b}}$ & 0 & 2 & 1 & 0 & 0 & 0 \\
\hline
\end{tabular}

* Solution with a nullspace and with all the non-vanishing singular values retained a Number of surface water $\Delta^{14} \mathrm{C}$ values exceeding contemporaneous IntCal13 $\Delta^{14} \mathrm{C}$ by more than 2 standard deviations

${ }^{\mathrm{b}}$ Number of surface water $\Delta^{14} \mathrm{C}$ values lower than contemporaneous deep water bin $\Delta^{14} \mathrm{C}$ by more than 2 standard deviations 


\section{Figures}

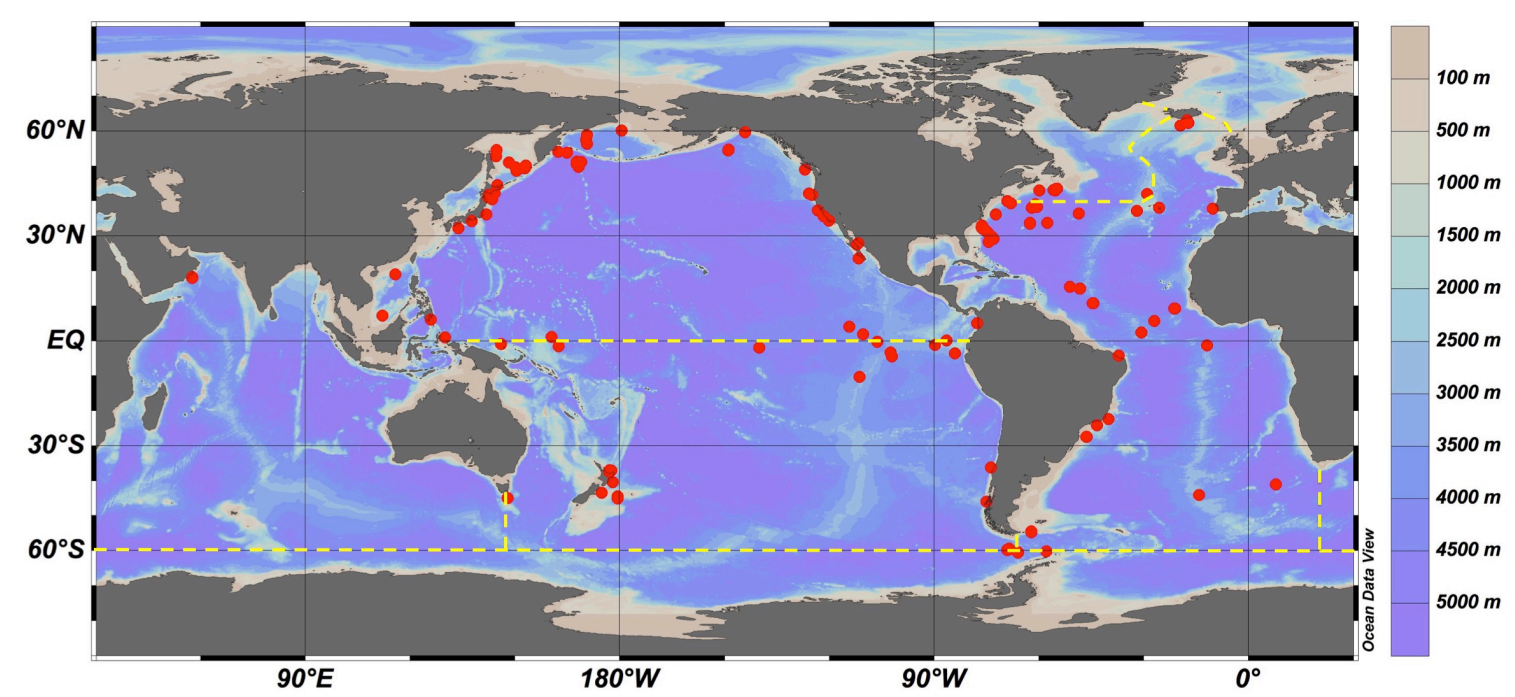

Fig. 4.1. Locations of coring and dredging sites where samples have been collected to estimate deep water $\Delta^{14} \mathrm{C}$ according to my compilation (red dots). Note the absence of data over large oceanic areas, such as the South Indian Ocean. Blue shading denotes the bathymetry. Yellow dashed lines delineate the lateral boundaries of the intermediate and deep boxes of the model (CYCLOPS). The interface between the Circumpolar Deep Water box and the intermediate and deep boxes in the Atlantic, Pacific and Indian Oceans is sloping down northward, which is not rendered in the figure (only the southernmost latitude of the interface is shown). 


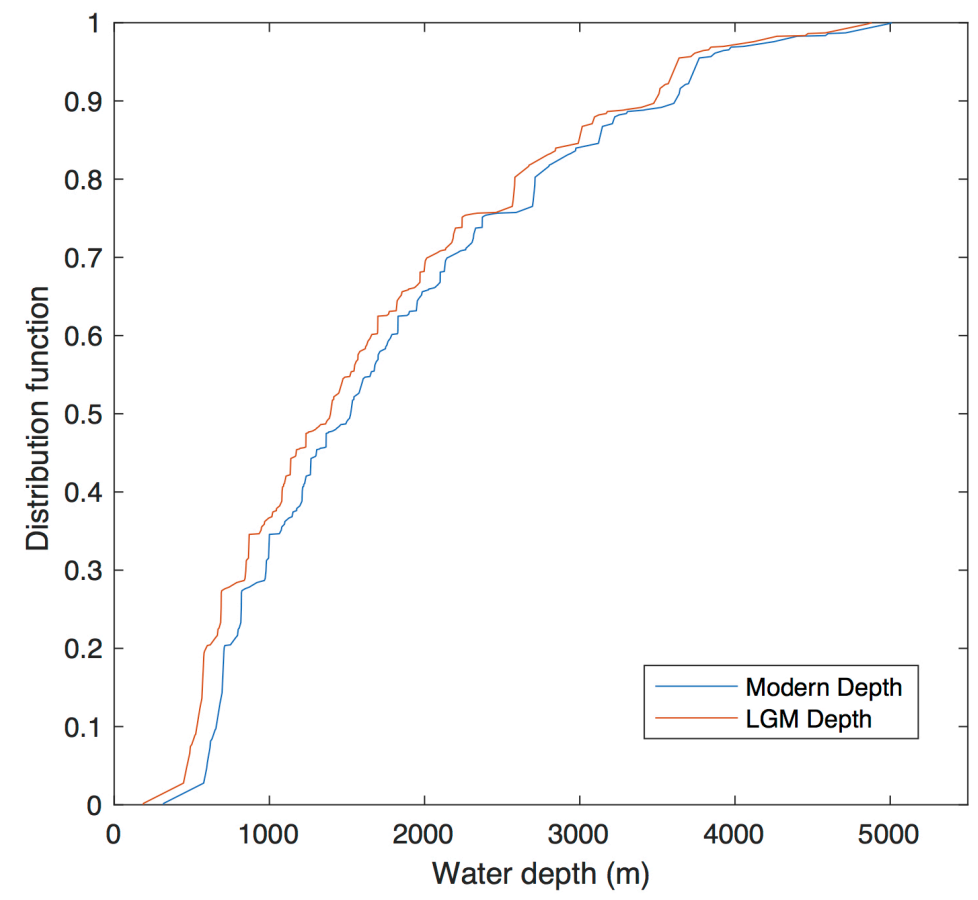

Fig. 4.2. Distribution of the water depths of the samples for which deep water $\Delta^{14} \mathrm{C}$ estimates have been obtained according to my compilation. The blue line shows the distribution based on modern water depths, and the red line shows the distribution based on modern water depths minus $130 \mathrm{~m}$. Notice that the depths of Cléroux et al. (2011)'s estimates, which rely on ${ }^{14} \mathrm{C}$ measurements on deep-living planktonic foraminifera, are kept the same in the two distributions. 


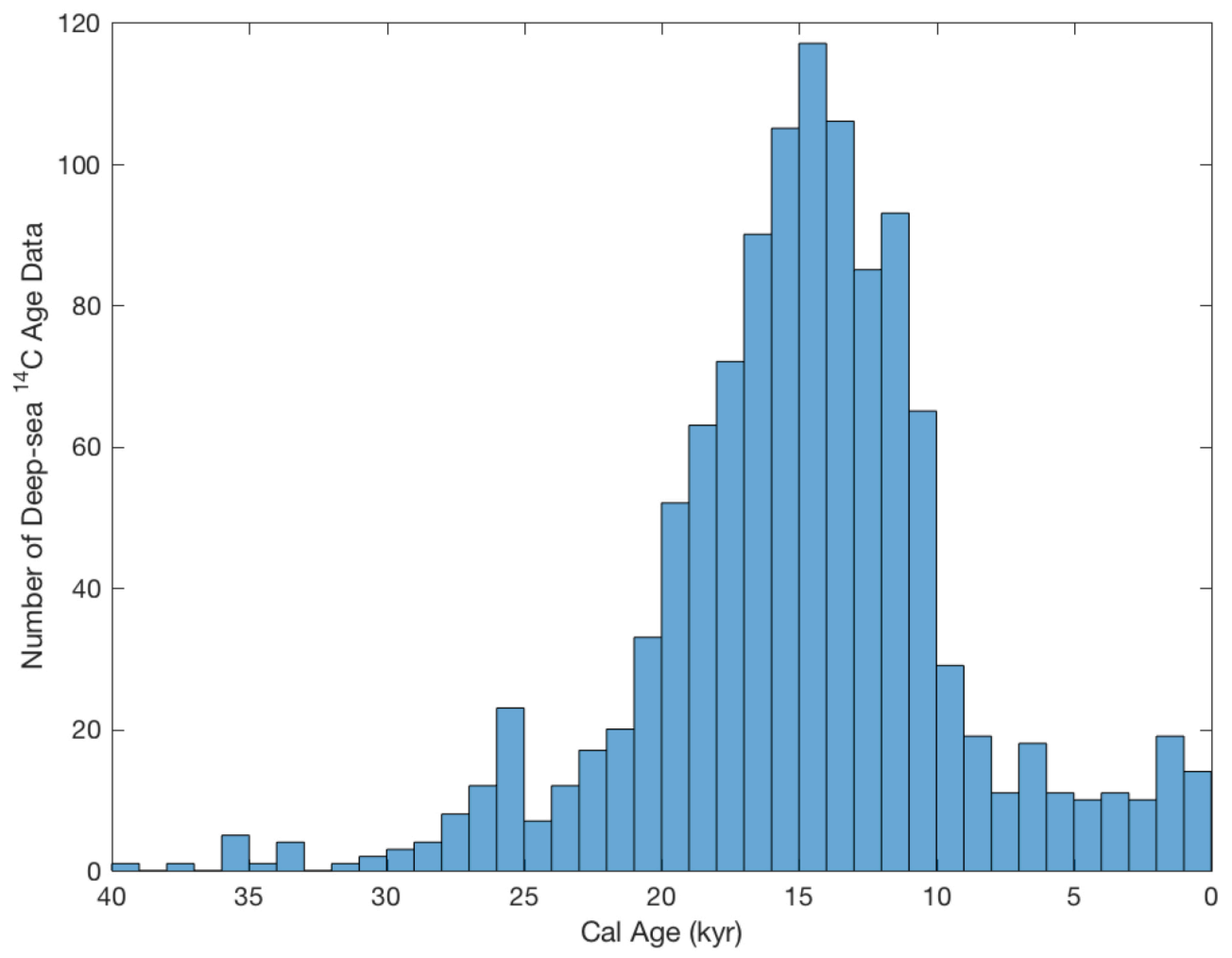

Fig. 4.3. Distribution of the calendar ages of published and new deep-sea ${ }^{14} \mathrm{C}$ age data compiled in this paper. Most of the data pertain to the time interval from 20 to 10 kyr B.P., which reflects the interest in the deglaciation in ${ }^{14} \mathrm{C}$-based palaeoventilation studies. 


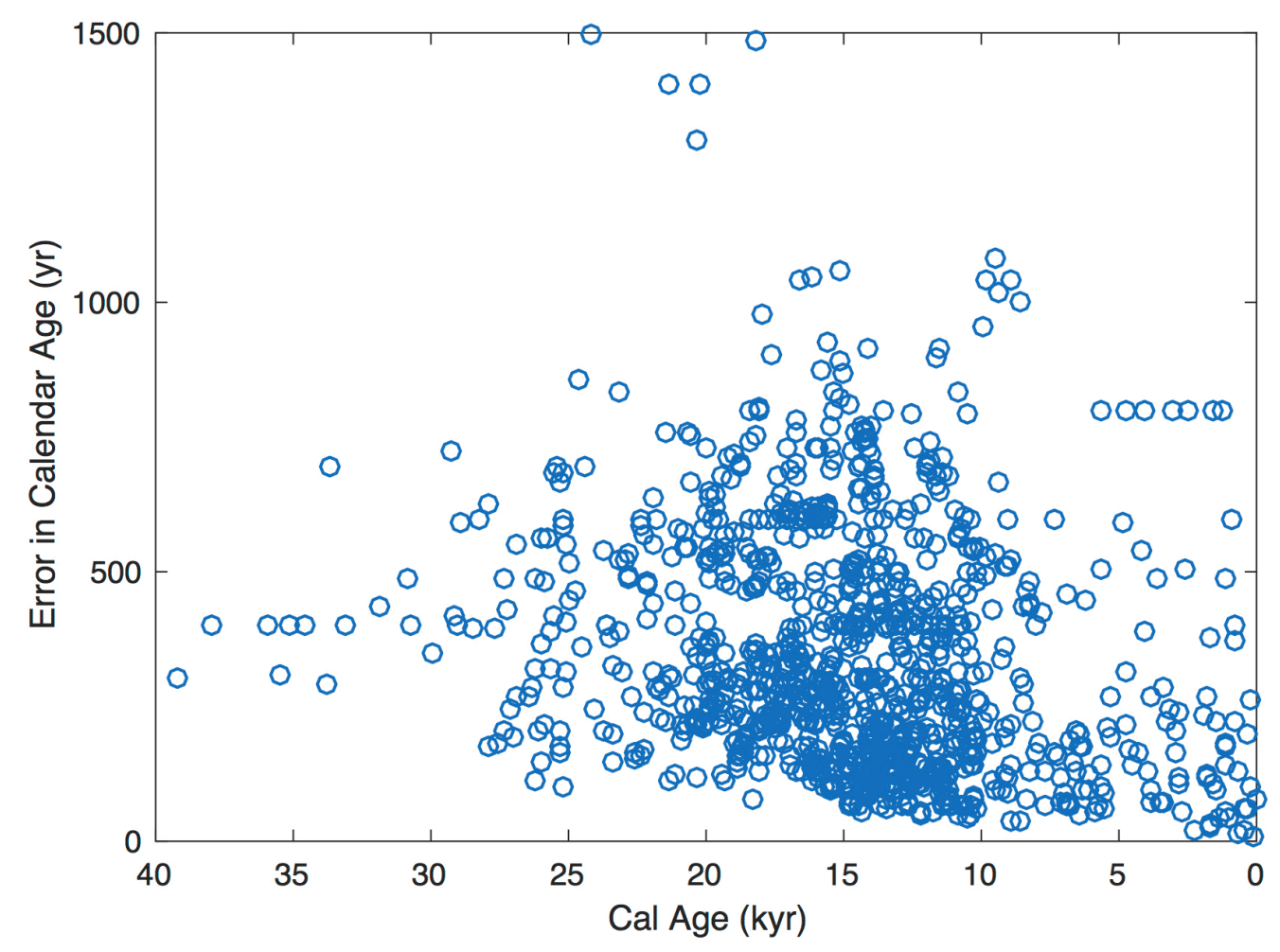

Fig. 4.4. Published errors (two standard deviations) in the calendar ages of the deepsea ${ }^{14} \mathrm{C}$ age data compiled in this study. These errors were estimated from the instrumental and (or) chronological errors. The average error (two standard deviations) between 10 and 20 kyr B.P. amounts to $336 \mathrm{yr}$. 

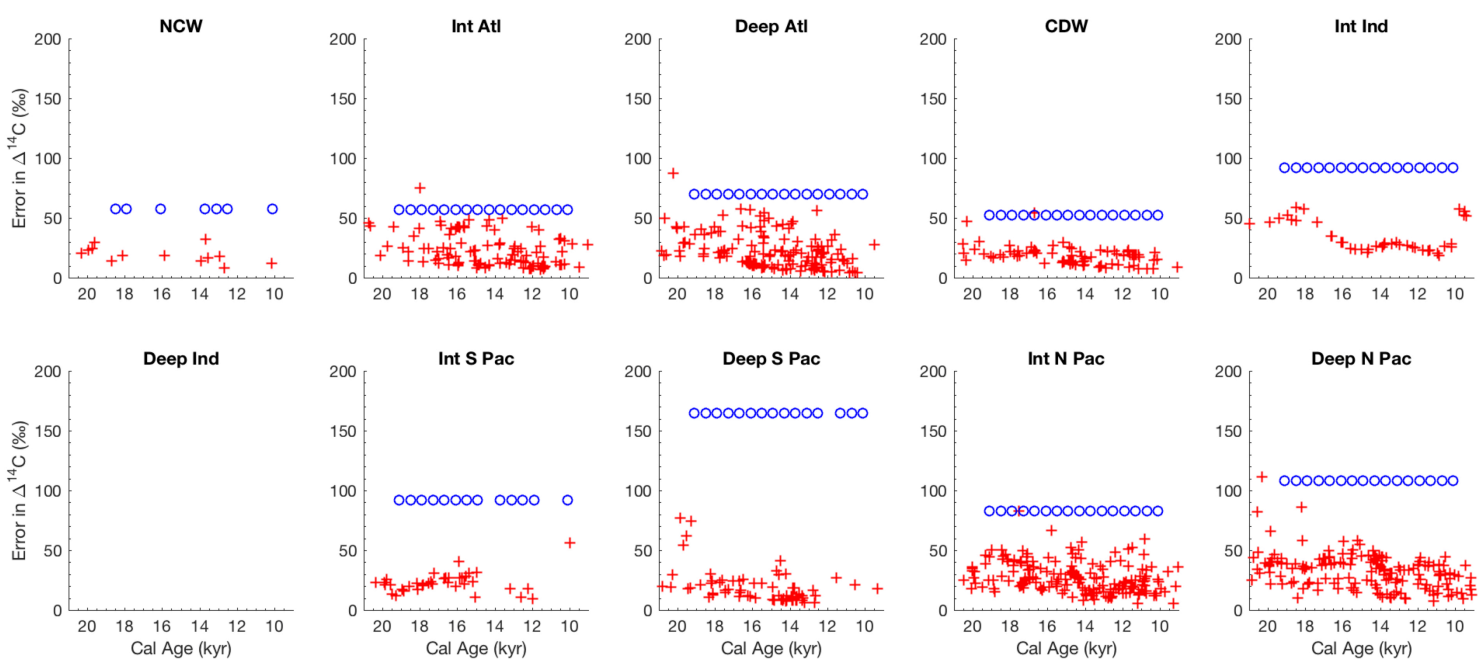

Fig. 4.5. Errors in the deep water bin $\Delta^{14} \mathrm{C}$ values as estimated from the standard deviation of the $\Delta^{14} \mathrm{C}$ values in the bin that contains the largest number of records in each box (blue circles), compared to the errors (one standard deviation) in the individual $\Delta^{14} \mathrm{C}$ values (red crosses). The errors in the individual $\Delta^{14} \mathrm{C}$ values are generally calculated by propagating the errors in the modern fractions as returned by the instruments and the errors in the sample calendar ages, assuming no error correlation. Note the absence of data for the deep Indian Ocean. 


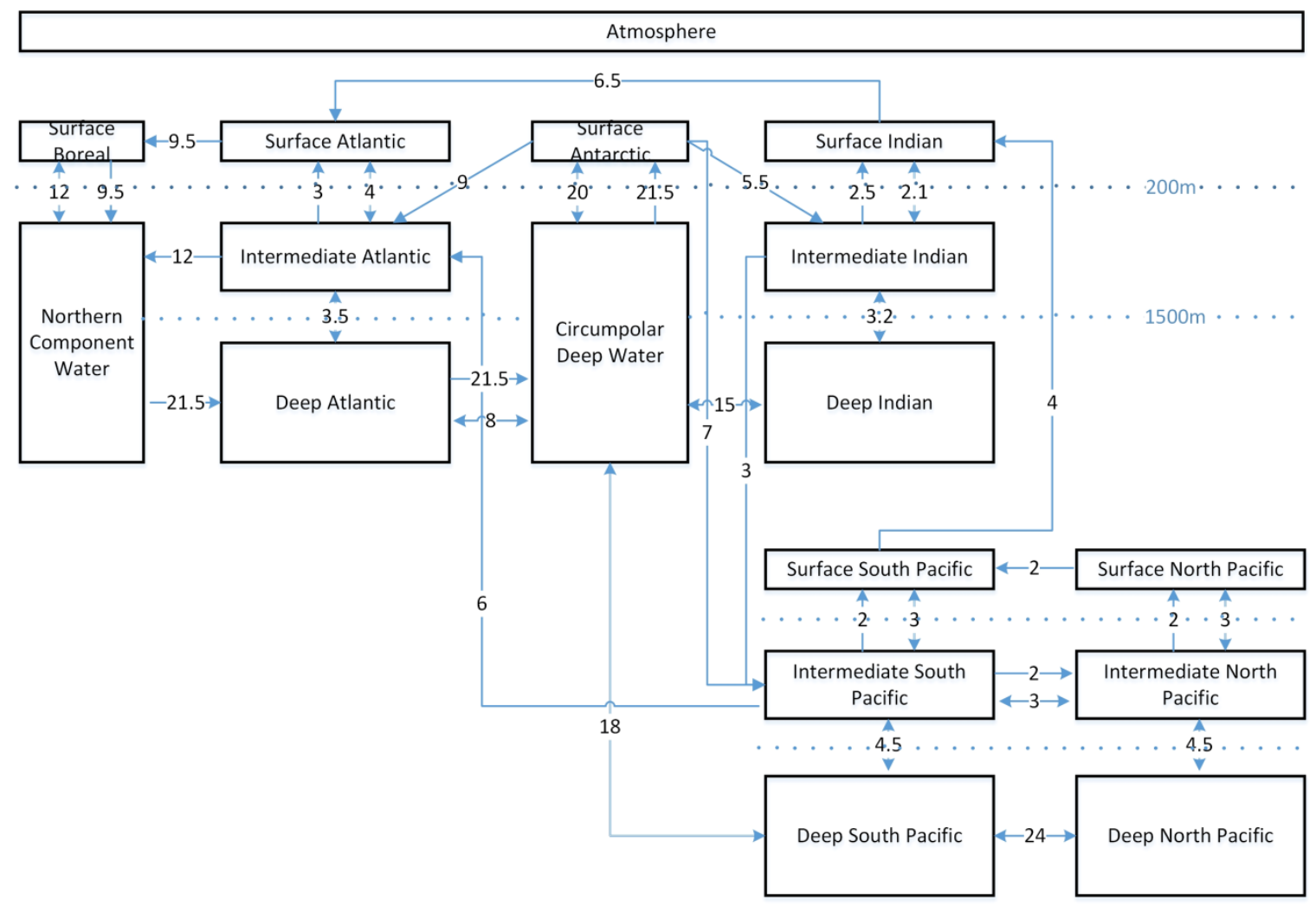

Fig. 4.6. Schematic diagram of the box model CYCLOPS. The numbers in black indicate the volume fluxes between the boxes in units of Sv $\left(1 \mathrm{~Sv}=10^{6} \mathrm{~m}^{3} \mathrm{~s}^{-1}\right)$. This figure is modified from Keir (1988) and Sigman et al. (1998). 

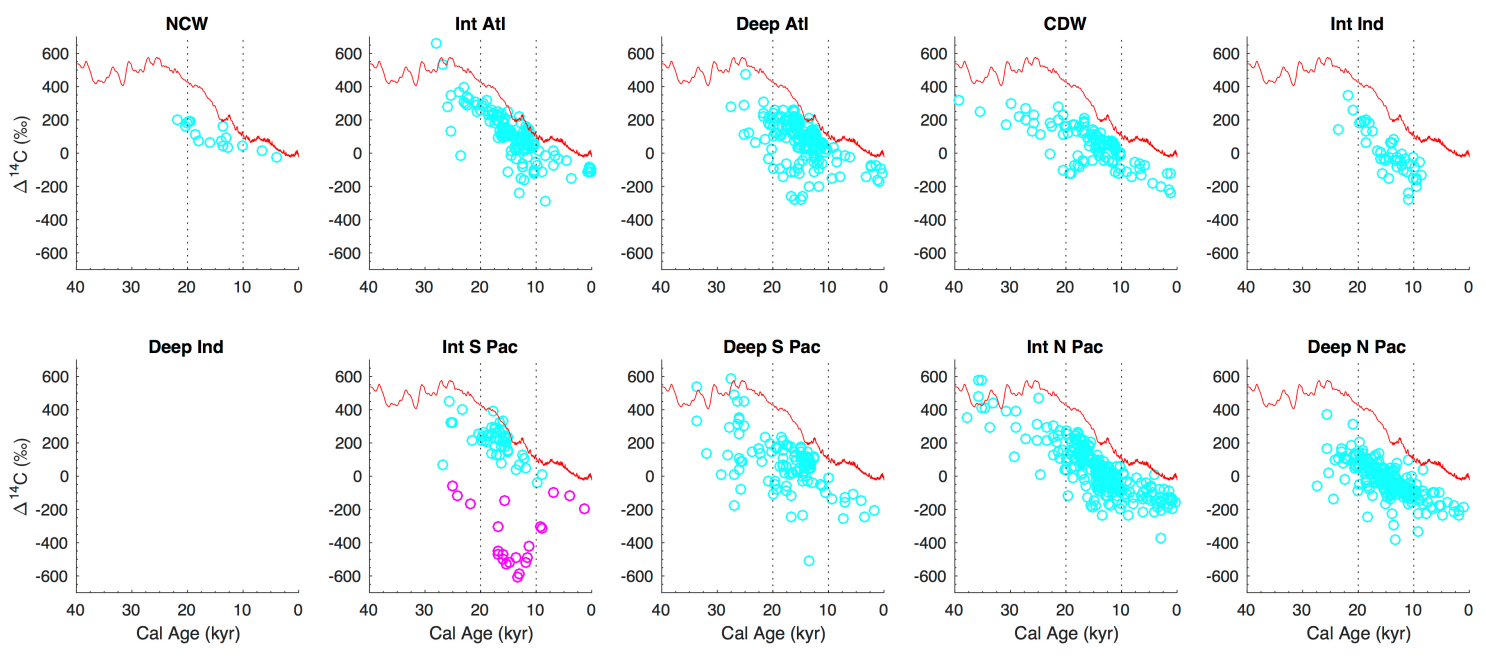

Fig. 4.7. Compiled deep-water $\Delta^{14} \mathrm{C}$ data for the ten intermediate and deep boxes of the model. Magenta circles are Galapagos data (Stott et al., 2009); the deglacial fraction of these data may reflect processes other than ocean ventilation (see text). Vertical dotted lines delineate the time interval $10-20$ kyr B.P. The atmospheric ${ }^{14} \mathrm{C}$ reconstruction is also shown in red for reference (Reimer et al., 2013). The order in which the different panels appear is arbitrary, although it is intended to broadly correspond to the sense of the estimated movement of deep waters from the northern North Atlantic (leftmost top panel) to the deep North Pacific in the modern ocean (rightmost bottom panel). 

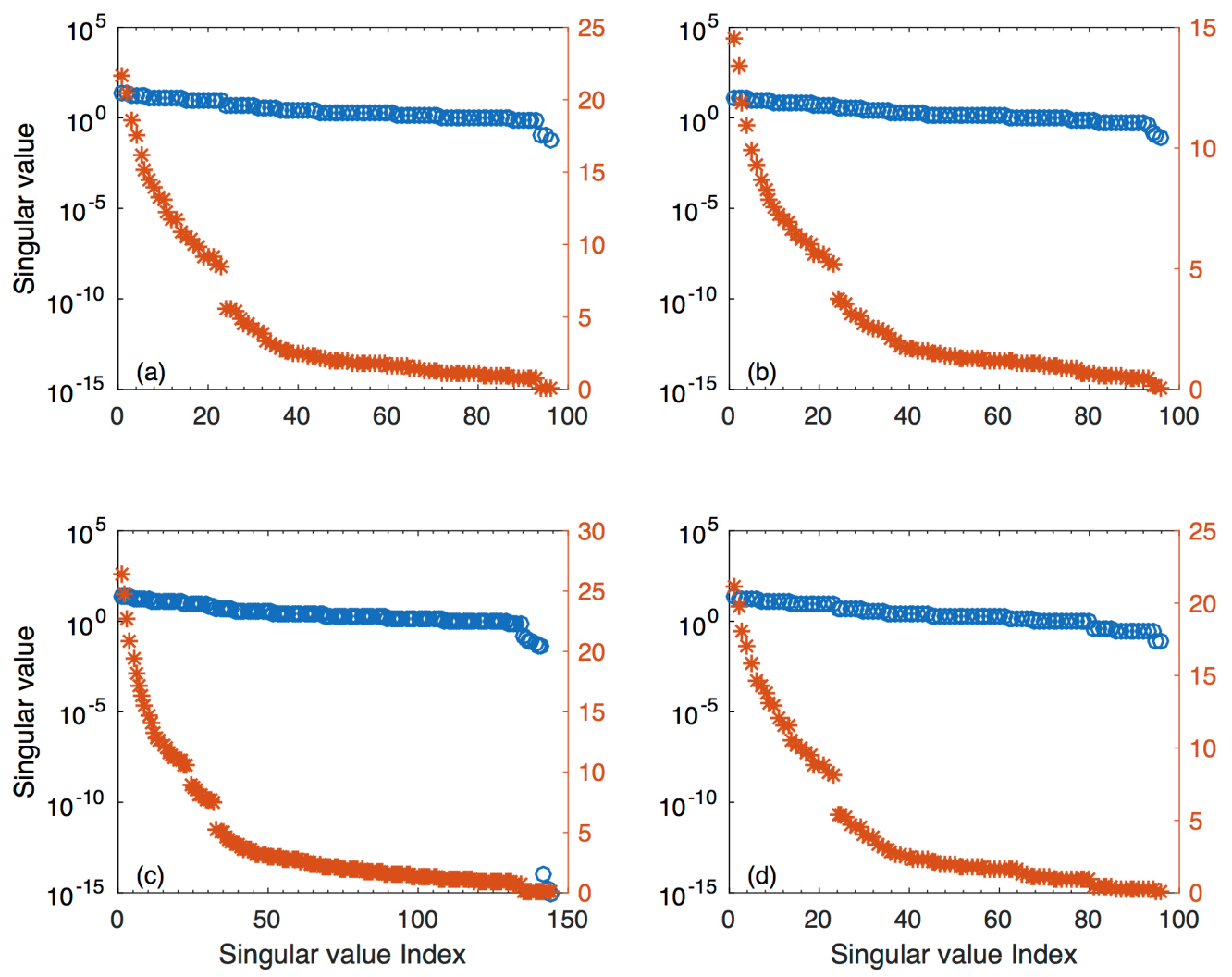

Fig. 4.8. Singular values of the coefficient matrix $\overline{\boldsymbol{G}}_{*}$ for three different cases: (a) full solution; (b) globally uniform $\Delta^{14} \mathrm{C}$ error; (c) a 400-yr bin width; and (d) the inclusion of Galapagos data (Stott et al., 2009). Notice the presence of numerically vanishing singular values for case (c). For each panel, the scale is logarithmic on the left axis and linear on the right axis. 

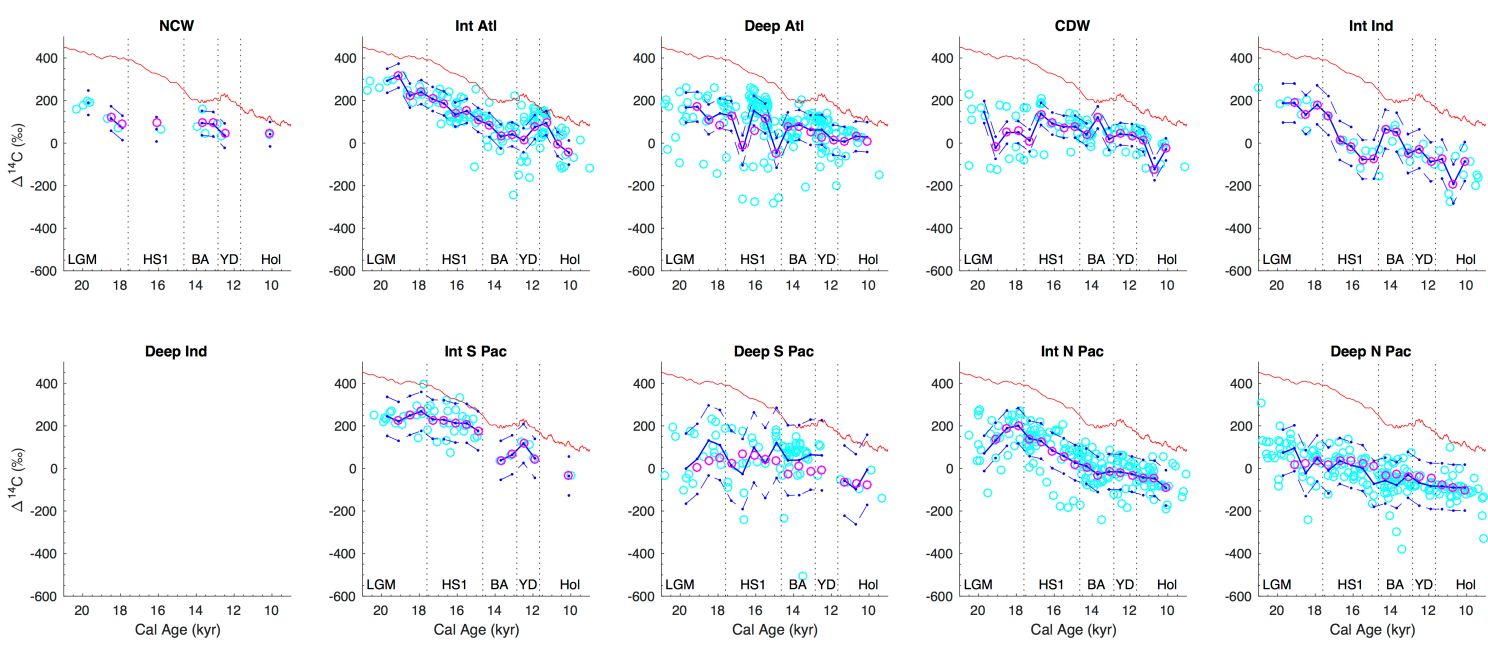

Fig. 4.9. Deep water $\Delta^{14} \mathrm{C}$ data (cyan circles), deep water bin $\Delta^{14} \mathrm{C} \pm$ one standard deviation envelope (dark blue lines), and deep water $\Delta^{14} \mathrm{C}$ resulting from the model fit for the full solution (magenta circles). The atmospheric $\Delta^{14} \mathrm{C}$ reconstruction (Reimer et al. 2013) is displayed for reference (red line). 

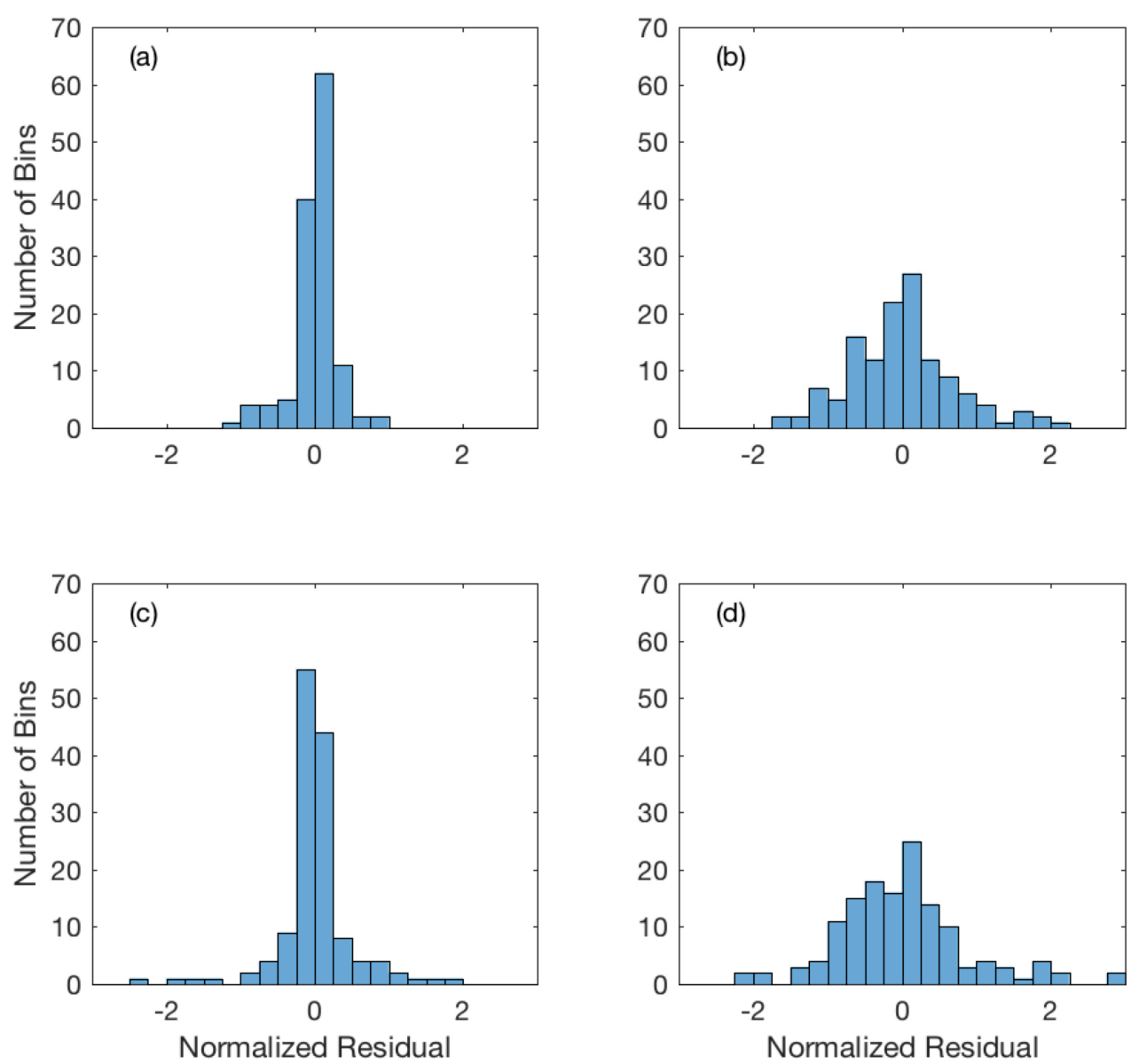

Fig. 4.10. Distribution of the difference between fitted and observed (bin) deep water $\Delta^{14} \mathrm{C}$ values, normalized to the error in the observed deep water $\Delta^{14} \mathrm{C}$ value, for different solutions. (a) Full solution (with $K=96$ singular vectors retained). (b) Truncated solution (with $K=23$ ). (c) Solution using the modified model (two boxes in the deep Atlantic) with $K=96$ singular vectors retained. (d) Solution using the modified model with $K=23$. 

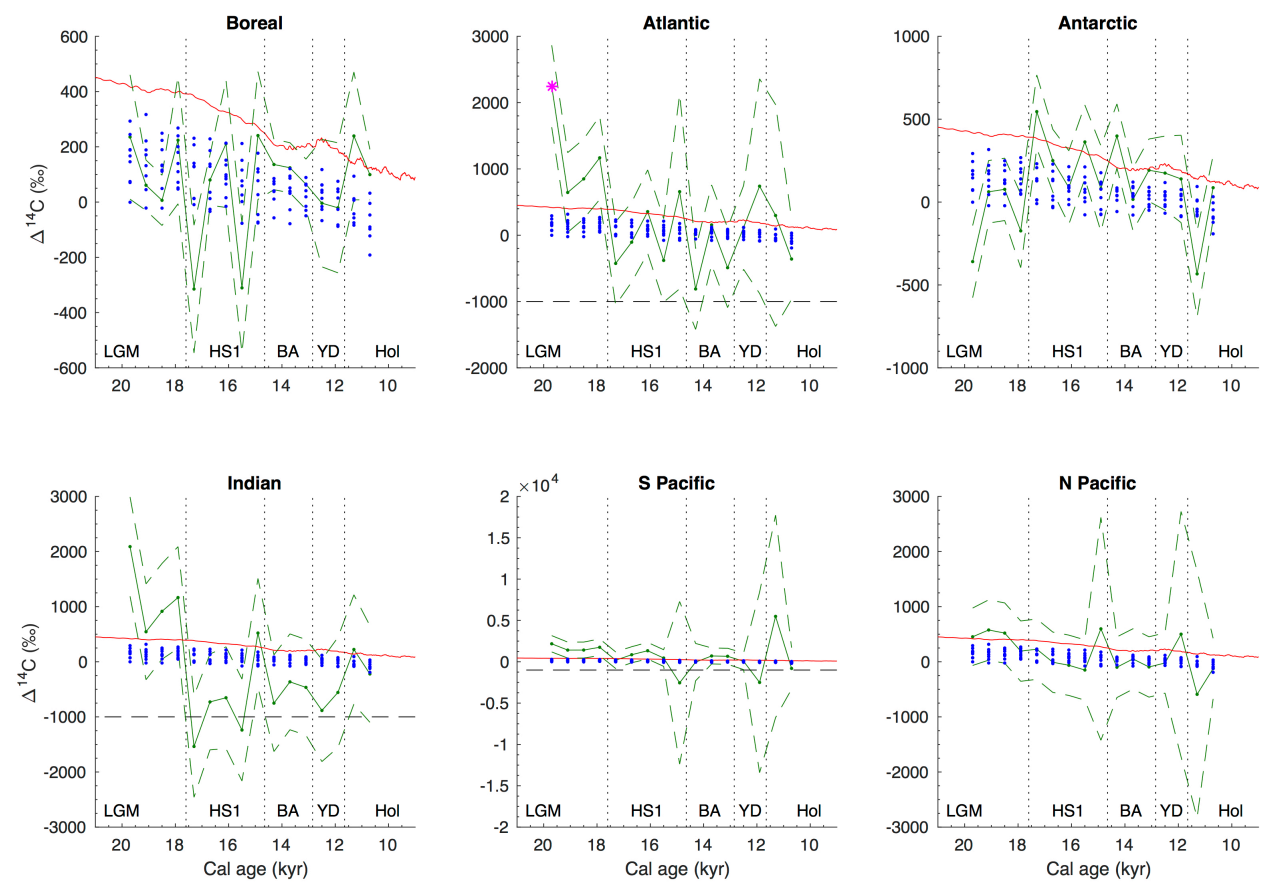

Fig. 4.11. Surface water $\Delta^{14} \mathrm{C}$ estimated for the full solution (solid green line, with dashed green lines showing the one-standard deviation envelope). The upper bound (red line) is the reconstructed atmospheric $\Delta^{14} \mathrm{C}$ (Reimer et al. 2013) and the lower bound (blue dots) is provided by bin ${ }^{14} \mathrm{C}$ values in all the subsurface boxes. The value of $\Delta^{14} \mathrm{C}=-1000 \%$ (dashed black line) corresponds to zero fraction modern. The estimated surface $\Delta^{14} \mathrm{C}$ values that violate the bounds by more than two standard deviations are shown with asterisks (magenta). 

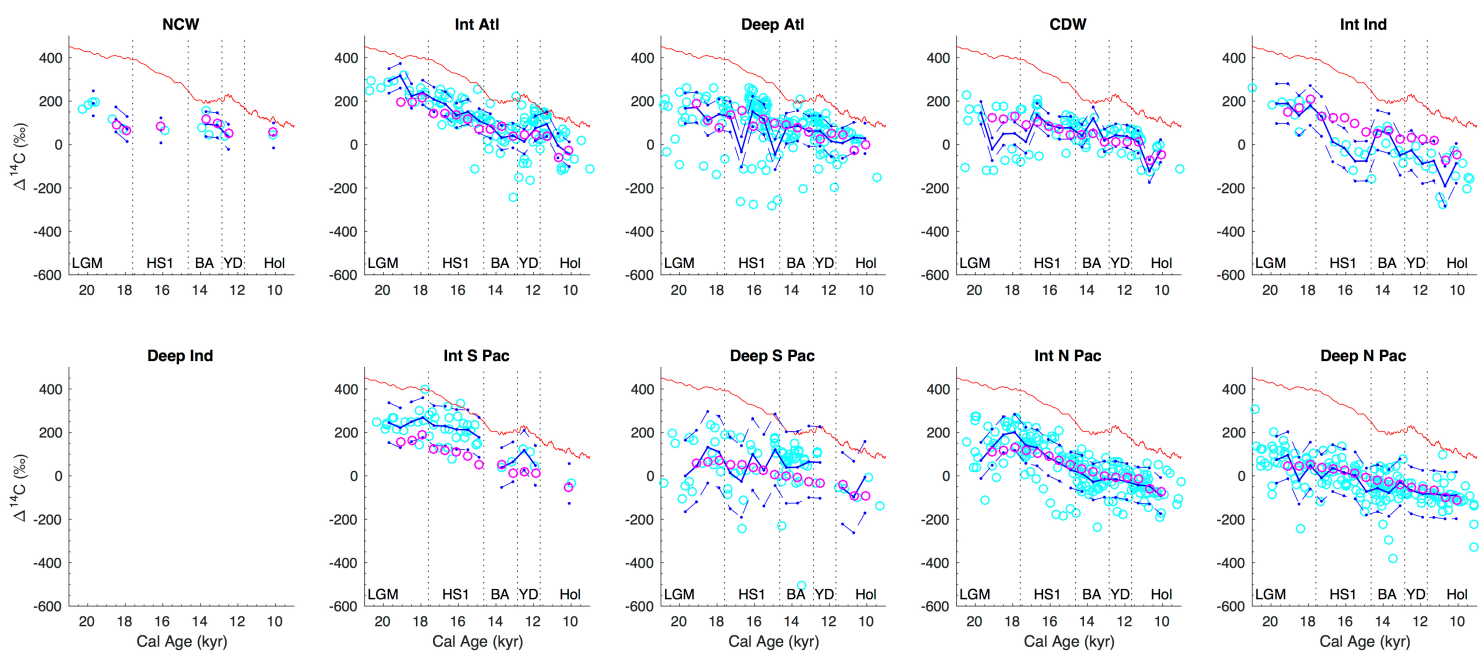

Fig. 4.12. Deep water $\Delta^{14} \mathrm{C}$ data (cyan circles), deep water bin $\Delta^{14} \mathrm{C} \pm$ one standard deviation envelope (dark blue lines), and deep water $\Delta^{14} \mathrm{C}$ resulting from the model fit for the truncated solution ( $K=23$; magenta circles). The atmospheric $\Delta^{14} \mathrm{C}$ reconstruction (Reimer et al. 2013) is shown for reference (red line). 

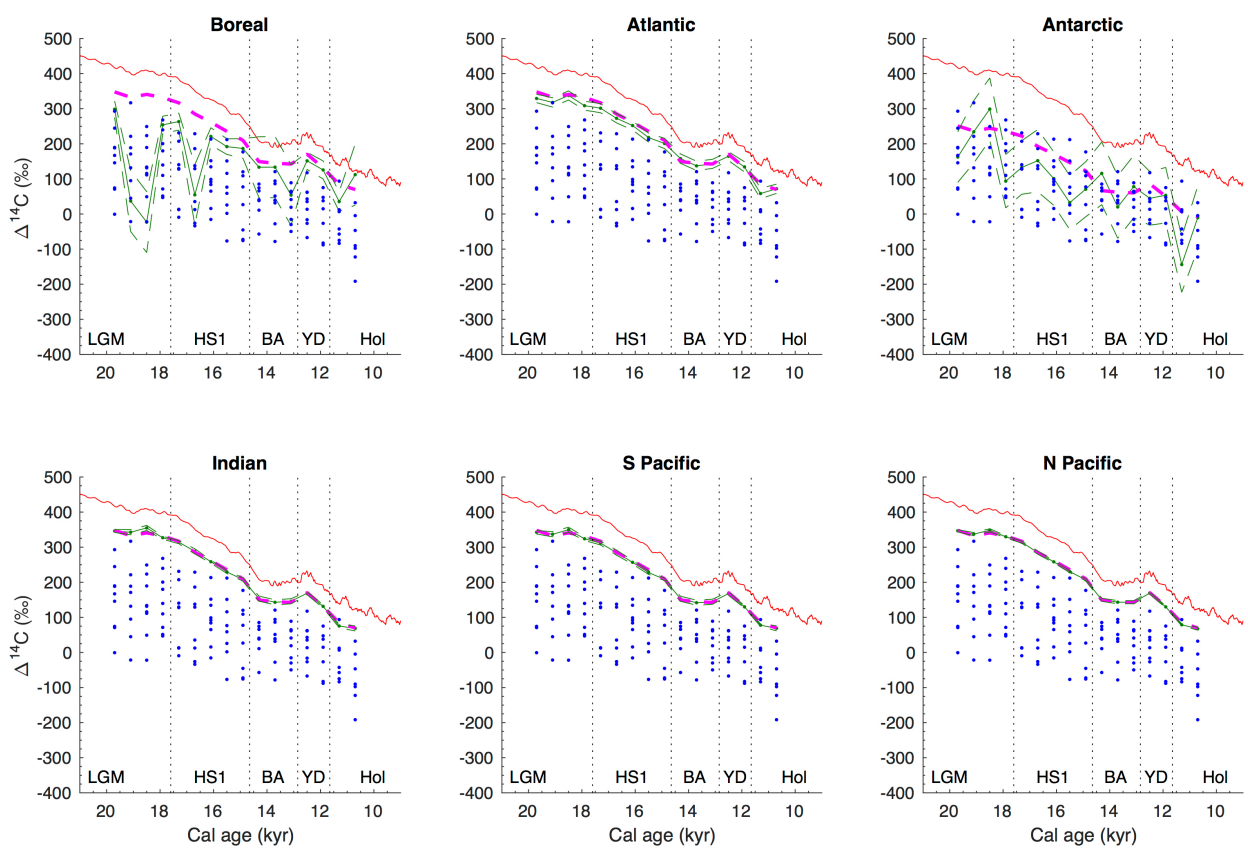

Fig. 4.13. Surface water $\Delta^{14} \mathrm{C}$ estimated for the truncated solution $(K=23$; solid green line, with dashed green lines showing the one-standard deviation envelope). The upper bound (red line) is the reconstructed atmospheric $\Delta^{14} \mathrm{C}$ (Reimer et al., 2013) and the lower bound (blue dots) is provided by bin $\Delta^{14} \mathrm{C}$ values in all the subsurface boxes. Magenta line is the surface water $\Delta^{14} \mathrm{C}$ calculated from the atmospheric $\Delta^{14} \mathrm{C}$ (Reimer et al., 2013) and estimates of pre-industrial reservoir ages (Bard, 1988). It is the first guess of the solution as defined in section 4.2.3.2. 


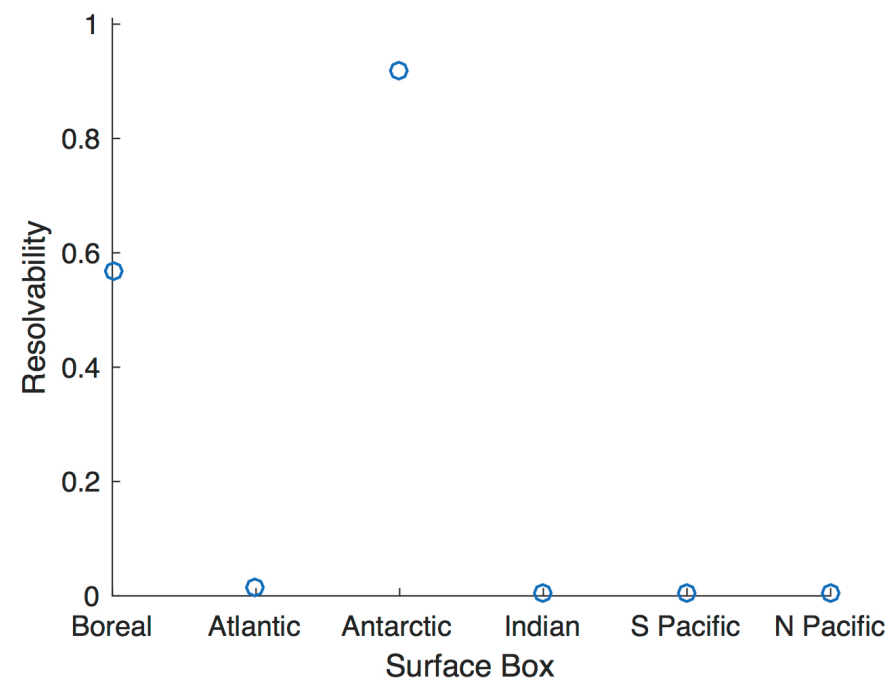

Fig. 4.14. Resolvability of $\Delta^{14} \mathrm{C}$ in the surface boxes for the truncated solution $(K=23)$. 

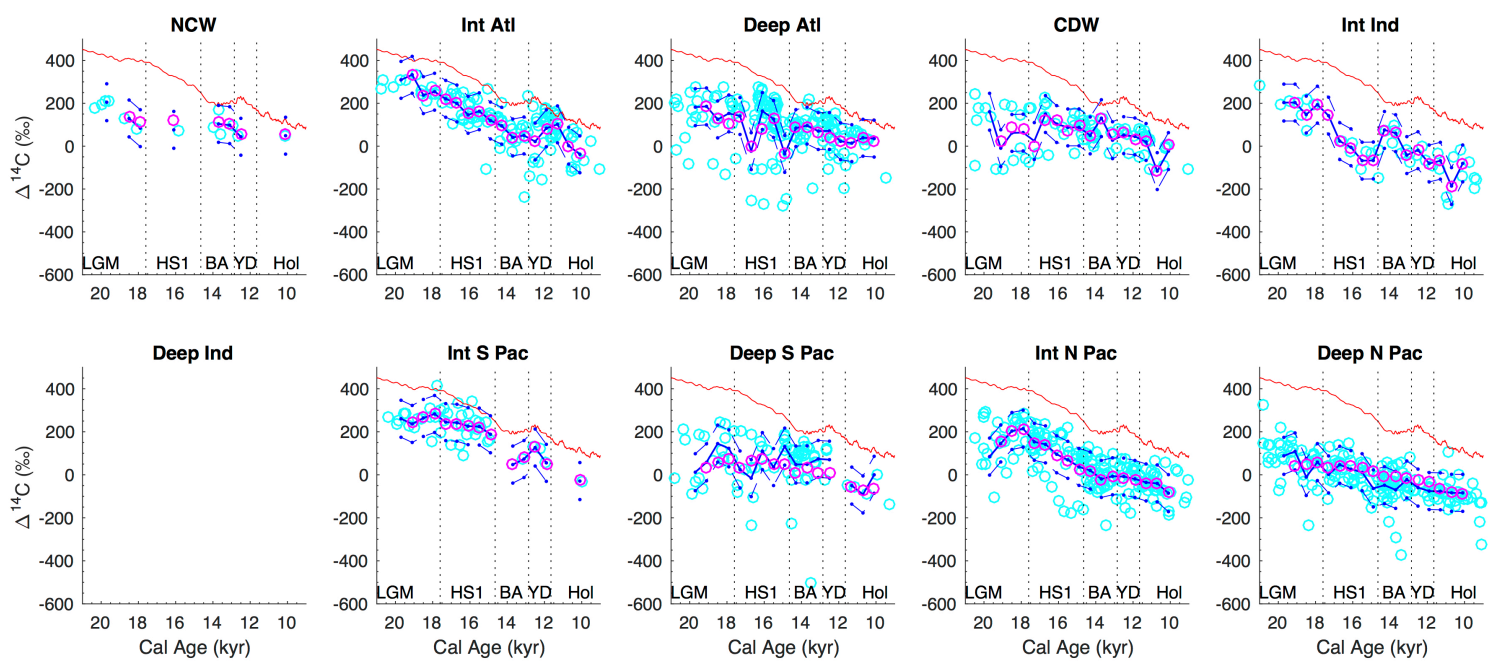

Fig. 4.15. Deep water $\Delta^{14} \mathrm{C}$ data (cyan circles), deep water bin $\Delta^{14} \mathrm{C} \pm$ one standard deviation envelope (dark blue lines), and deep water $\Delta^{14} \mathrm{C}$ resulting from the model fit for the case with globally uniform bin $\Delta^{14} \mathrm{C}$ error and $K=96$ (magenta circles). The atmospheric $\Delta^{14} \mathrm{C}$ reconstruction (Reimer et al. 2013) is shown for reference (red line). 

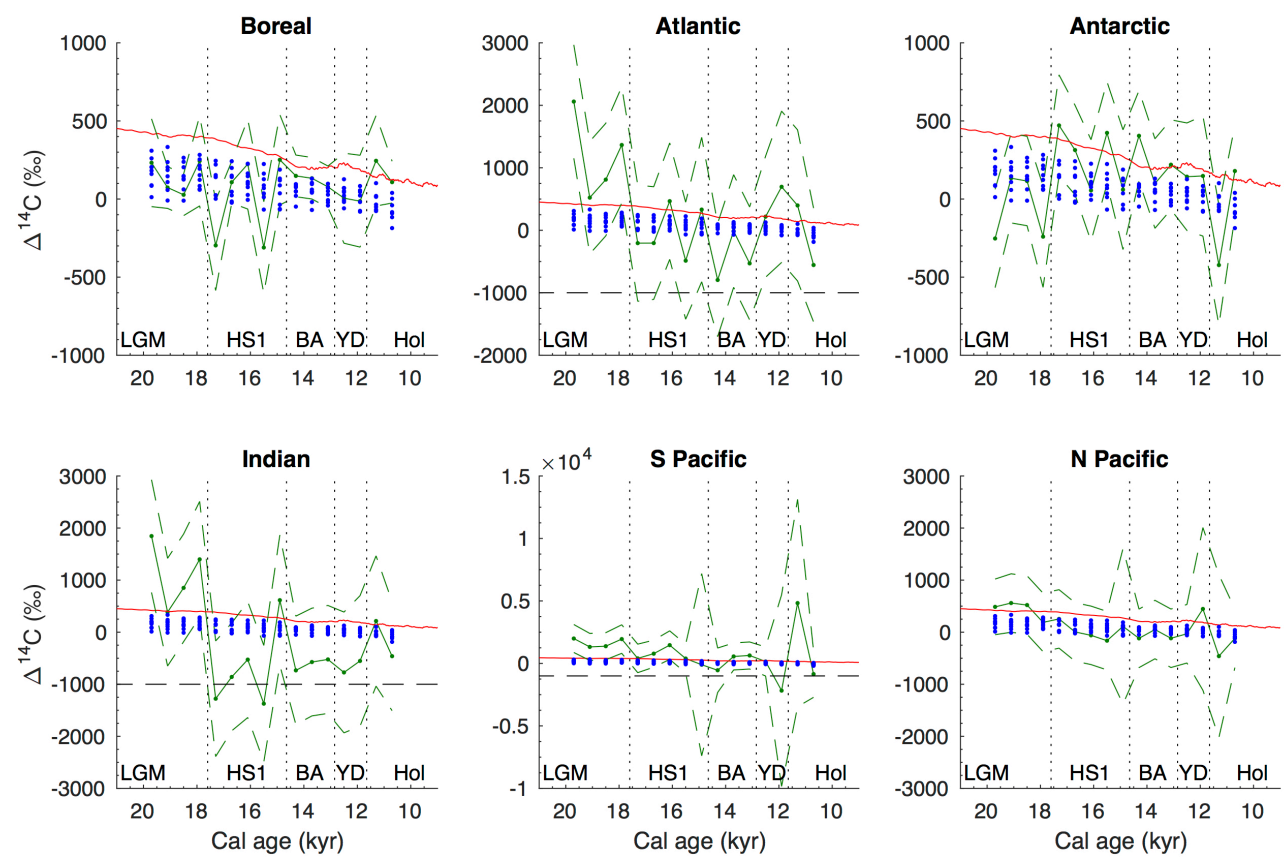

Fig. 4.16. Surface water $\Delta^{14} \mathrm{C}$ estimated for the case with a globally uniform error in the deep water bin $\Delta^{14} \mathrm{C}$ and $K=96$ (greensolid line, with dashed green lines showingone-standard deviation envelope). The upper bound (red line) is the reconstructed atmospheric $\Delta^{14} \mathrm{C}$ (Reimer et al. 2013) and the lower bound (blue dots) is provided by bin $\Delta^{14} \mathrm{C}$ values in all the subsurface boxes. The value of $\Delta^{14} \mathrm{C}=$ $1000 \%$ (dashed black line) corresponds to zero fraction modern. 

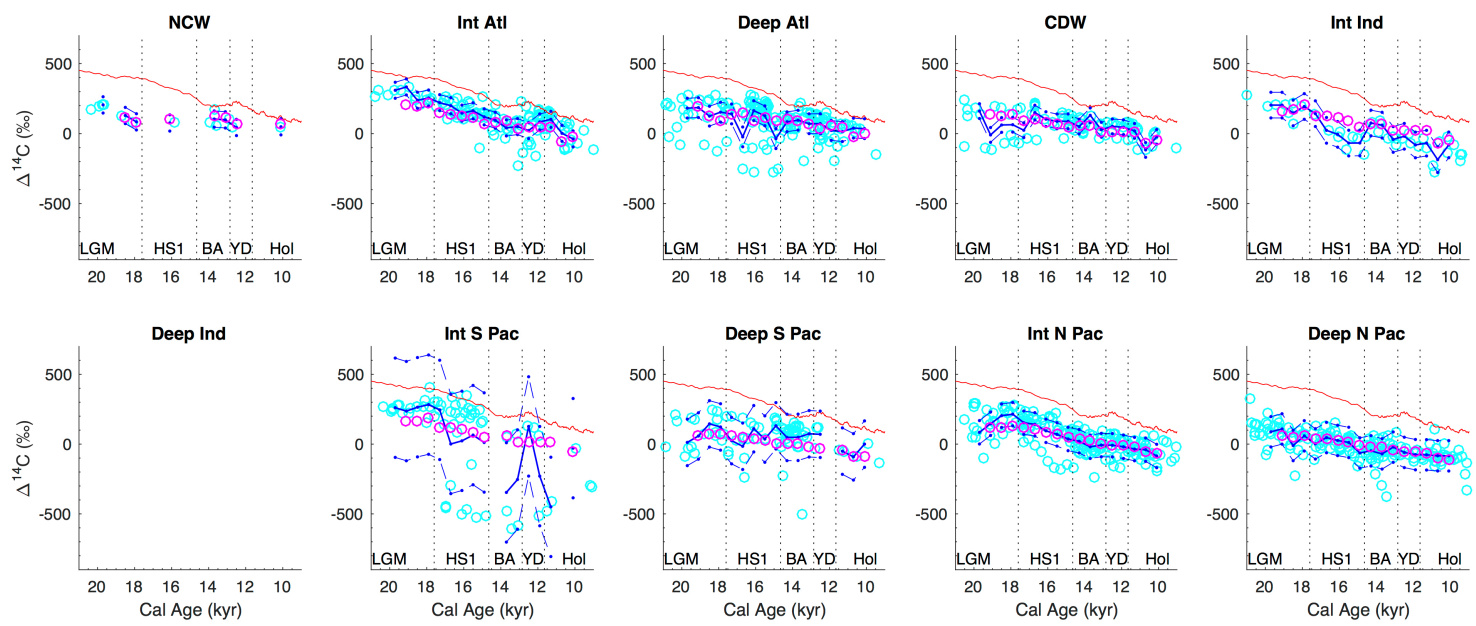

Fig. 4.17. Deep water $\Delta^{14} \mathrm{C}$ data (cyan circles), deep water bin $\Delta^{14} \mathrm{C} \pm$ one standard deviation envelope (dark blue lines), and deep water $\Delta^{14} \mathrm{C}$ resulting from the model fit (magenta circles) for the case where the Galapagos $\Delta^{14} \mathrm{C}$ data (Stott et al., 2009) are included in the analysis and $K=23$. The atmospheric $\Delta^{14} \mathrm{C}$ reconstruction (Reimer et al. 2013) is shown for reference (red line). 

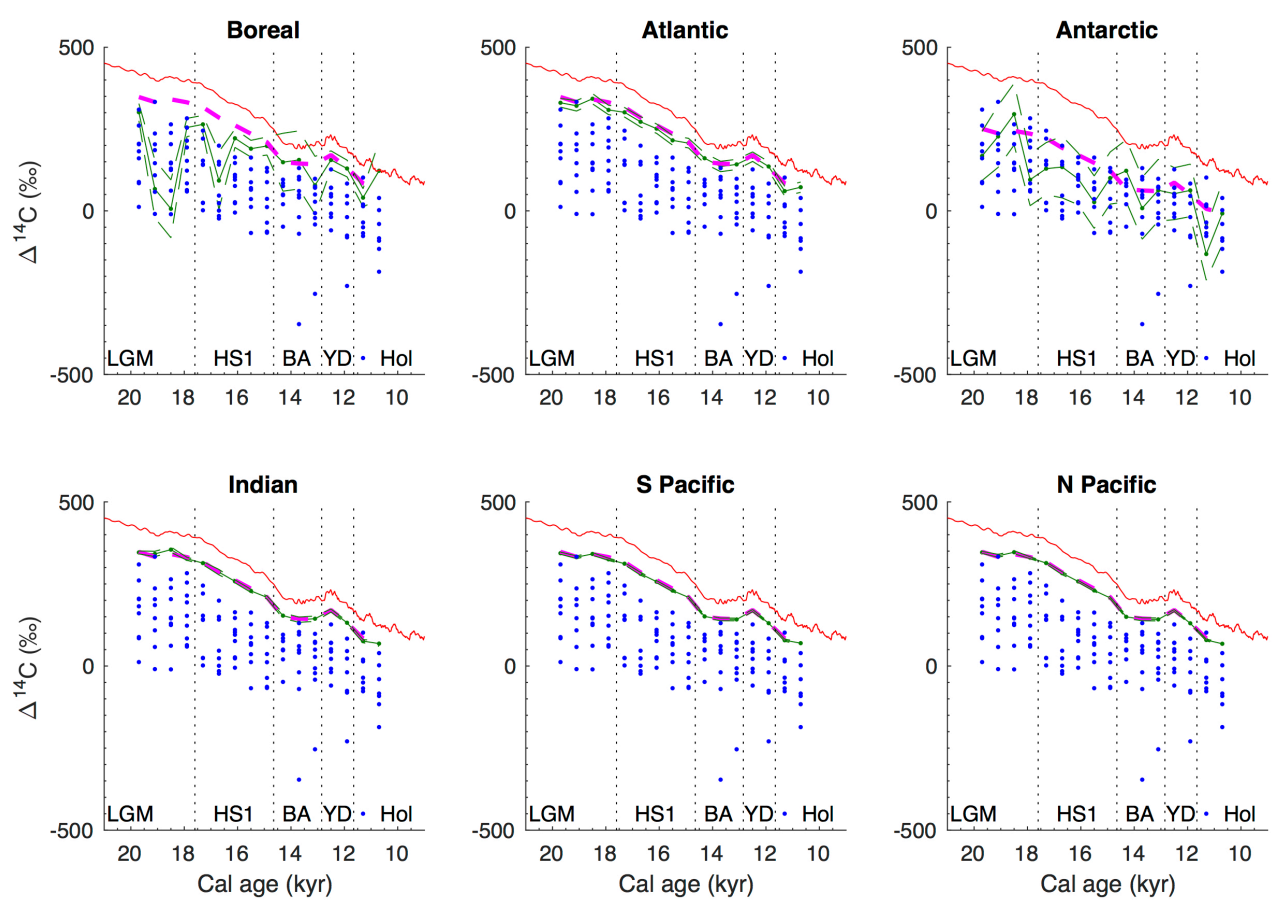

Fig. 4.18. Surface water $\Delta^{14} \mathrm{C}$ estimated for the case where the Galapagos $\Delta^{14} \mathrm{Cdata}$ are included in the analysis and $K=23$ (green solid line, with green dashed lines showing one-standard deviation envelope). The upper bound (red line) is the reconstructed atmospheric $\Delta^{14} \mathrm{C}$ (Reimer et al. 2013) and the lower bound (blue dots) is provided by $\Delta^{14} \mathrm{C}$ in all the subsurface boxes. Magenta line is the surface water $\Delta^{14} \mathrm{C}$ calculated from the atmospheric $\Delta^{14} \mathrm{C}$ (Reimer et al., 2013) and estimates of pre-industrial reservoir ages (Bard 1988). It is also the first guess of the solution as defined in section 4.2.3.2. 


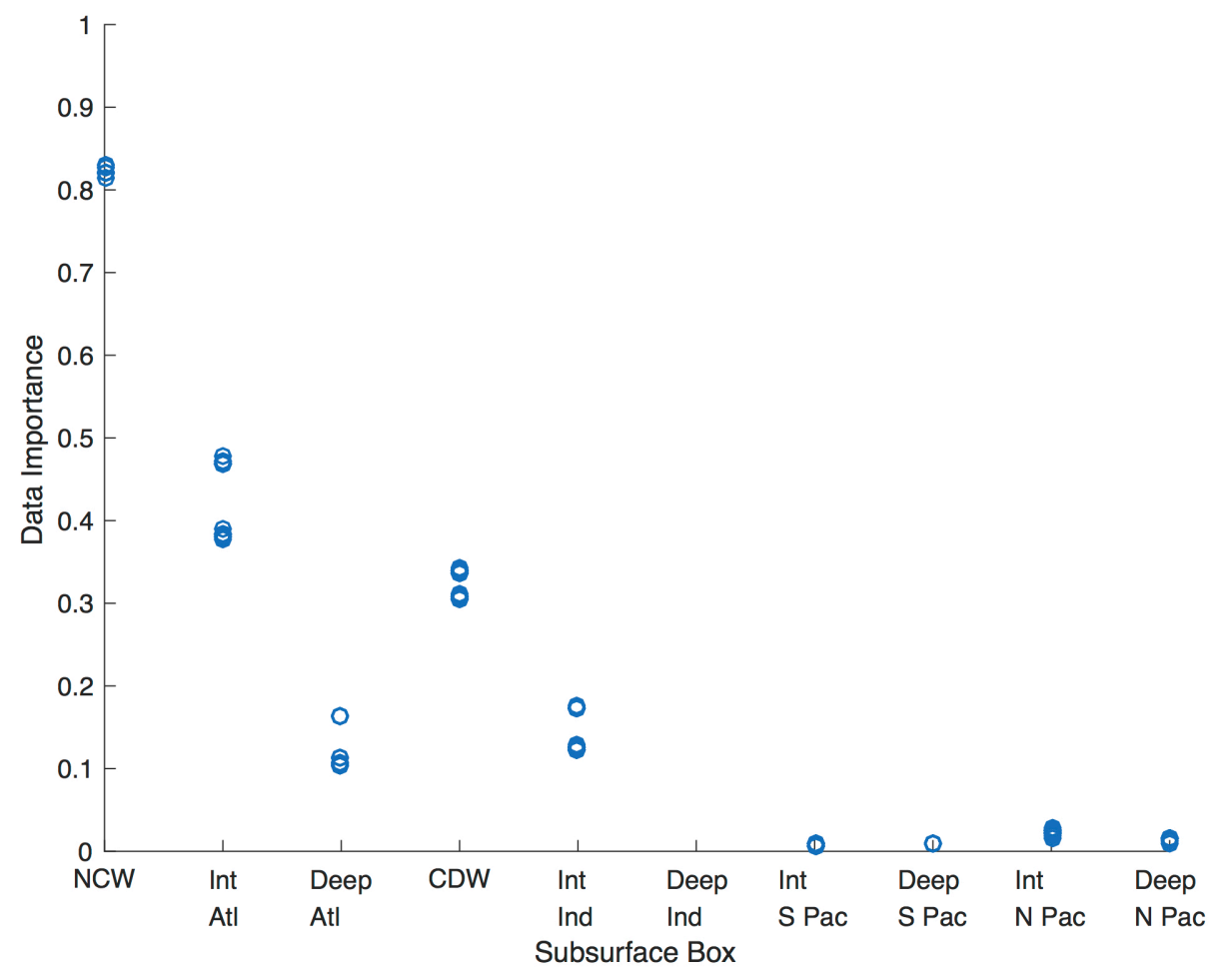

Fig. 4.19. Data importance for the subsurface boxes for the case where the Galapagos $\Delta^{14} \mathrm{C}$ data (Stott et al., 2009) are included and $K=23$. Each open circle corresponds to a bin. Note that multiple circles overlap each other in some boxes. 


\section{Supplementary Materials}

\section{Appendix: Numerical Solution of the Box Model}

Equation (5) can be approximated with finite difference as:

$$
\frac{\boldsymbol{c}(t+\Delta t)-\boldsymbol{c}(t)}{\Delta t}=\boldsymbol{A}^{\prime} \boldsymbol{c}(t+\Delta t)+\boldsymbol{B}^{\prime} \boldsymbol{c}_{\boldsymbol{s}}(t) .
$$

Notice that $\boldsymbol{A}^{\prime} \boldsymbol{c}(t+\Delta t)$ rather than $\boldsymbol{A}^{\prime} \boldsymbol{c}(t)$ is considered on the right-hand side. After rearrangement, we get

$$
\left(\boldsymbol{I}-\Delta t \boldsymbol{A}^{\prime}\right) \boldsymbol{c}(t+\Delta t)=\boldsymbol{c}(t)+\Delta t \boldsymbol{B}^{\prime} \boldsymbol{c}_{\boldsymbol{s}}(t)
$$

Multiplying each term of this equation by the matrix inverse $\left(\boldsymbol{I}-\Delta t \boldsymbol{A}^{\prime}\right)^{-1}$ yields equation (5) in the text. 


\section{Chapter 5. Summary}

This thesis explores how the ocean ventilation state during the last deglaciation compared to today, with the considerations of either reducing or better quantifying uncertainties. In order to reach this objective, I have generated marine ${ }^{14} \mathrm{C}$ records from two very distant sites: a site from the Panama Basin, in the eastern Tropical Pacific, and a site near the Tail of the Grand Banks, in the western North Atlantic. The ${ }^{14} \mathrm{C}$ records generated at these sites are less affected by some of the common but critical uncertainties in marine ${ }^{14} \mathrm{C}$ records due, e.g., to sediment core chronology, a variable mixture of water masses with different radiocarbon ages, and changes in high-latitude surface reservoir age. As a result, it is argued that the records provide significantly new insights into the deglacial ocean ventilation history. In addition to this data generation effort, I have produced a compilation of published and new deep water ${ }^{14} \mathrm{C}$ data $(>1000$ measurements obtained over the past two decades or so), and combined these data with a box model in order to test their overall consistency with modern rates of basin-scale ocean ventilation.

The main conclusions of the thesis are the following:

(1) For locations near narrow continental shelves and river mouths, it appears possible to build a chronology for deep-sea sediment cores by ${ }^{14} \mathrm{C}$ dating terrestrial plant remains in the cores. From ${ }^{14} \mathrm{C}$ dates obtained on planktonic foraminifera (PF) sampled from the layers containing the plant remains, changes in surface water ${ }^{14} \mathrm{C}$ reservoir age at the core site can then be reconstructed. Using wooden remains (twigs) found in a sediment core along the Colombian coast in the 
Panama Basin, it is shown that the glacial and deglacial surface reservoir ages at the core site were not very different from today. In addition, no old age of intermediate water is inferred at the core site during the deglaciation, in contrast with a popular inference made from a ${ }^{14} \mathrm{C}$ record generated from a similar depth near Baja California and in line with more recent results gathered off Chile. Moreover, I find that the PF $\delta^{13} \mathrm{C}$ record for the Panama Basin, now solidly anchored on an absolute chronology, shows a decrease during the Heinrich Stadial 1 (HS1), which is similar in timing and magnitude to the decrease in atmospheric $\delta^{13} \mathrm{C}$ and in $\mathrm{PF} \delta^{13} \mathrm{C}$ observed in different oceanic basins. Taken together, my results suggest that the rise in atmospheric $\mathrm{CO}_{2}$ during $\mathrm{HS} 1$ probably originated from $\mathrm{CO}_{2}$ directly released to the atmosphere from the deep ocean (a large reservoir of isotopically light carbon) at high latitudes, e.g., in the Southern Ocean, rather than first mixing through the upper ocean.

(2) Mid-depth ventilation strength in the western North Atlantic during the late deglaciation $(\sim 14-8 \mathrm{ka} \mathrm{BP})$ is reconstructed using a high-deposition rate core from the Tail of the Grand Banks. The high sedimentation rates minimize the influence of bioturbation, whereas the geographic location of the core, near potential deglacial sources of deep water, minimizes the uncertainties due to ocean mixing and pre-formed ${ }^{14} \mathrm{C}$ age. My results suggest that mid-depth ventilation was stronger than today during the Younger Dryas cold episode, probably due to the extensive sea ice formation and brine rejection over shallow shelf areas (e.g., the Grand Banks). On the other hand, intermediate water production was probably 
weaker and more intermittent than today during the Bølling-Allerød warm period and the early Holocene, but still present.

(3) A compilation of published and new deep ocean ${ }^{14} \mathrm{C}$ data for the past 40 kyrs is produced, with more than $70 \%$ of the data occurring between 10 and $20 \mathrm{ka}$ $\mathrm{BP}$. The most conspicuous feature of the compiled data is a long-term decline of $\Delta^{14} \mathrm{C}$ in different oceanic basins that mirrors the atmospheric $\Delta^{14} \mathrm{C}$ over the past 25 kyrs. This observation tends to challenge the notion that ${ }^{14} \mathrm{C}$ was subject to a sizeable redistribution between the oceanic and atmospheric reservoirs during the deglaciation. Stimulated by this observation, a 16-box model of modern ocean circulation is fit to the compiled data, and the results of the fit are analyzed. I find that the fit residuals are consistent with the estimated uncertainties in the basinscale ${ }^{14} \mathrm{C}$ values constrained from the assembled deep ocean $\Delta^{14} \mathrm{C}$ data. Surface $\Delta^{14} \mathrm{C}$ values inferred from the fit are generally realistic in the sense that they do not significantly transgress the upper and lower bounds provided by contemporaneous values of, respectively, atmospheric $\Delta^{14} \mathrm{C}$ and deep ocean $\Delta{ }^{14} \mathrm{C}$. Therefore, the compiled deep ocean ${ }^{14} \mathrm{C}$ data jointly do not provide strong evidence for basin-scale changes in deep ocean ventilation during the last deglaciation. The imbalance between cosmogenic production and radioactive decay appears as the most natural explanation for the long-term evolution of both the atmospheric and deep ocean ${ }^{14} \mathrm{C}$ activity over the last 25 kyrs.

This thesis focuses on various aspects of deep ocean ventilation during the last deglaciation. Altogether, my results suggest that deep ocean ventilation may have changed on a local or regional scale during some time intervals of the last 
deglaciation, such as in the western North Atlantic around the Younger Dryas cold spell, but that the current ${ }^{14} \mathrm{C}$ data base is still inadequate to infer basin-scale changes with high confidence. On the other hand, processes other than ocean ventilation per se might be more important than we thought in controlling the storage and transport of carbon and heat in the ocean. For example, sea ice in highlatitude oceans could be very important in producing deep water and in controlling $\mathrm{CO}_{2}$ exchange between the ocean and the atmosphere. The generation of highquality radiocarbon data (for both the surface and deep ocean) and the quantitative combination of these data to detailed ocean models are advocated in order to test with greater confidence hypotheses related to past changes in deep ocean ventilation and, more generally, a role of these changes in the deglacial variations in atmospheric $\mathrm{CO}_{2}$ concentration and climate. 


\section{References}

Adkins, J.F., Boyle, E.A., 1997. Changing atmospheric $\Delta^{14} \mathrm{C}$ and the record of deep water paleoventilation ages. Paleoceanography 12, 337-344.

Adkins, J.F., Cheng, H., Boyle, E.A., Druffel, E.R., Edwards, R.L., 1998. Deep-sea coral evidence for rapid change in ventilation of the deep North Atlantic 15,400 years ago. Science 280, 725-728.

Ahagon, N., Ohkushi, K.i., Uchida, M., Mishima, T., 2003. Mid-depth circulation in the northwest Pacific during the last deglaciation: Evidence from foraminiferal radiocarbon ages. Geophys. Res. Lett. 30, 2097.

Amrhein, D.E. (2016) Inferring ocean circulation during the Last Glacial Maximum and last deglaciation using data and models. Ph.D. thesis, Massachusetts Institute of Technology and Woods Hole Oceanographic Institution.

Amrhein, D.E., Gebbie, G., Marchal, O., Wunsch, C., 2015. Inferring surface water equilibrium calcite $\delta^{18} \mathrm{O}$ during the last deglacial period from benthic foraminiferal records: Implications for ocean circulation. Paleoceanography 30, 1470-1489.

Anderson, R.F., Ali, S., Bradtmiller, L.I., Nielsen, S.H.H., Fleisher, M.Q., Anderson, B.E., Burckle, L.H., 2009. Wind-driven upwelling in the Southern Ocean and the deglacial rise in atmospheric $\mathrm{CO}_{2}$. Science $323,1443-1448$.

Audi, G., Bersillon, O., Blachot, J., Wapstra, A.H., 2003. The NUBASE evaluation of nuclear and decay properties. Nuclear Physics A 729, 3-128.

Bakke, J., Lie, Ø., Heegaard, E., Dokken, T., Haug, G.H., Birks, H.H., Dulski, P., Nilsen, T., 2009. Rapid oceanic and atmospheric changes during the Younger Dryas cold period. Nat. Geosci. 2, 202-205.

Bard, E., 1988. Correction of accelerator mass spectrometry ${ }^{14} \mathrm{C}$ ages measured in planktonic foraminifera: paleoceanographic implications. Paleoceanography 3, 635-645.

Bard, E., Arnold, M., Mangerud, J., Paterne, M., Labeyrie, L., Duprat, J., Mélières, M.-A., Sønstegaard, E., Duplessy, J.-C., 1994. The North Atlantic atmosphere-sea surface ${ }^{14} \mathrm{C}$ gradient during the Younger Dryas climatic event. Earth Planet. Sci. Lett. 126, 275-287.

Bard, E., Hamelin, B., Arnold, M., Montaggioni, L., Cabioch, G., Faure, G., Rougerie, F., 1996. Deglacial sea-level record from Tahiti corals and the timing of global meltwater discharge. Nature 382, 241-244.

Bard, E., Hamelin, B., Delanghe-Sabatier, D., 2010. Deglacial meltwater pulse 1B and Younger Dryas sea levels revisited with boreholes at Tahiti. Science 327, 1235-1237.

Barker, S., Knorr, G., Vautravers, M.J., Diz, P., Skinner, L.C., 2010. Extreme deepening of the Atlantic overturning circulation during deglaciation. Nat. Geosci. 3, 567-571.

Bauska, T.K., Baggenstos, D., Brook, E.J., Mix, A.C., Marcott, S.A., Petrenko, V.V., Schaefer, H., Severinghaus, J.P., Lee, J.E., 2016. Carbon isotopes characterize 
rapid changes in atmospheric carbon dioxide during the last deglaciation. Proc. Nat. Acad. Sci. 113, 3465-3470.

Bondevik, S., Mangerud, J., Birks, H.H., Gulliksen, S., Reimer, P., 2006. Changes in North Atlantic radiocarbon reservoir ages during the Allerød and Younger Dryas. Science 312, 1514-1517.

Boyle, E.A., Keigwin, L., 1987. North Atlantic thermohaline circulation during the past 20,000 years linked to high-latitude surface temperature. Nature 330, $35-40$.

Broecker, W., Andree, M., Bonani, G., Wolfli, W., Oeschger, H., Klas, M., Mix, A., Curry, W., 1988a. Preliminary estimates for the radiocarbon age of deep water in the glacial ocean. Paleoceanography 3, 659-669.

Broecker, W., Barker, S., Clark, E., Hajdas, I., Bonani, G., Stott, L., 2004. Ventilation of the glacial deep Pacific Ocean. Science 306, 1169-1172.

Broecker, W., Clark, E., 2010. Search for a glacial-age ${ }^{14} \mathrm{C}$-depleted ocean reservoir. Geophys. Res. Lett. 37, L13606.

Broecker, W., Clark, E., Barker, S., 2008. Near constancy of the Pacific Ocean surface to mid-depth radiocarbon-age difference over the last $20 \mathrm{kyr}$. Earth Planet. Sci. Lett. 274, 322-326.

Broecker, W., Klas, M., Ragano-Beavan, N., Mathieu, G., Mix, A., Andree, M., Oeschger, H., Wölfli, W., Suter, M., Bonani, G., Hofmann, H.J., Nessi, M., Morenzoni, E., 1988b. Accelerator mass spectrometry radiocarbon measurements on marine carbonate samples. Radiocarbon 30, 261-295.

Broecker, W., Putnam, A.E., 2012. How did the hydrologic cycle respond to the twophase mystery interval? Quat. Sci. Rev. 57, 17-25.

Broecker, W.S., Kennett, J.P., Flower, B.P., Teller, J.T., Trumbore, S., Bonani, G., Wolfli, W., 1989. The routing of meltwater from the Laurentide ice-sheet during the Younger Dryas cold episode. Nature 341, 318-321.

Broecker, W.S., Klas, M., Clark, E., Trumbore, S.E., Bonani, G., Wölfli, W., Ivy, S., 1990. AMS Radiocarbon Measurements on Foraminifera Shells from Deep-Sea Cores. Radiocarbon 32, 119-133.

Broecker, W.S., Mix, A., Andree, M., Oeschger, H., 1984. Radiocarbon measurements on coexisting benthic andplanktic foraminfera shells: potential for reconstructing ocean ventilation times over the past 20,000 years. Nuclear Inst. and Methods in Phys. Res. section B: Beam Interactions with Materials and Atoms 5, 332-339.

Broecker, W.S., Peng, T.-H., 1982. Tracers in the Sea. Lamont-Doherty Geological Observatory, Palisades, N. Y.

Bryan, S.P., Marchitto, T.M., Lehman, S.J., 2010. The release of ${ }^{14}$ C-depleted carbon from the deep ocean during the last deglaciation: Evidence from the Arabian Sea. Earth Planet. Sci. Lett. 298, 244-254.

Buizert, C., Gkinis, V., Severinghaus, J.P., He, F., Lecavalier, B.S., Kindler, P., Leuenberger, M., Carlson, A.E., Vinther, B., Masson-Delmotte, V., 2014. Greenland temperature response to climate forcing during the last deglaciation. Science 345, 1177-1180. 
Burke, A., Marchal, O., Bradtmiller, L.I., McManus, J.F., François, R., 2011. Application of an inverse method to interpret ${ }^{231} \mathrm{~Pa} /{ }^{230} \mathrm{Th}$ observations from marine sediments. Paleoceanography 26, PA1212.

Burke, A., Robinson, L.F., 2012. The Southern Ocean's role in carbon exchange during the last deglaciation. Science 335, 557-561.

Cabedo-Sanz, P., Belt, S.T., Knies, J., Husum, K., 2013. Identification of contrasting seasonal sea ice conditions during the Younger Dryas. Quat. Sci. Rev. 79, 7486.

Chambers, J.Q., Higuchi, N., Schimel, J.P., Ferreira, L.V., Melack, J.M., 2000. Decomposition and carbon cycling of dead trees in tropical forests of the central Amazon. Oecologia 122, 380-388.

Chen, T., Robinson, L.F., Burke, A., Southon, J., Spooner, P., Morris, P.J., Ng, H.C., 2015. Synchronous centennial abrupt events in the ocean and atmosphere during the last deglaciation. Science 349, 1537-1541.

Clark, P.U., Dyke, A.S., Shakun, J.D., Carlson, A.E., Clark, J., Wohlfarth, B., Mitrovica, J.X., Hostetler, S.W., McCabe, A.M., 2009. The last glacial maximum. Science 325, 710-714.

Clarke, R., Hendry, R., Yashayaev, I., Watts, D., 1998. A western boundary current meter array in the North Atlantic near $42^{\circ} \mathrm{N}$. Int. WOCE Newsl 33, 33-34.

Cléroux, C., deMenocal, P., Guilderson, T., 2011. Deglacial radiocarbon history of tropical Atlantic thermocline waters: absence of $\mathrm{CO}_{2}$ reservoir purging signal. Quat. Sci. Rev. 30, 1875-1882.

Condron, A., Winsor, P., 2012. Meltwater routing and the Younger Dryas. Proc. Nat. Acad. Sci. 109, 19928-19933.

Cook, M.S., Keigwin, L.D., 2015. Radiocarbon profiles of the NW Pacific from the LGM and deglaciation: evaluating ventilation metrics and the effect of uncertain surface reservoir ages. Paleoceanography 30, 174-195.

Dail, H., Wunsch, C., 2014. Dynamical reconstruction of upper-ocean conditions in the Last Glacial Maximum Atlantic. J. Clim. 27, 807-823.

Dansgaard, W., White, J.W.C., Johnsen, S.J., 1989. The abrupt termination of the Younger Dryas climate event. Nature 339, 532-534.

Davies-Walczak, M., Mix, A.C., Stoner, J.S., Southon, J.R., Cheseby, M., Xuan, C., 2014. Late Glacial to Holocene radiocarbon constraints on North Pacific Intermediate Water ventilation and deglacial atmospheric $\mathrm{CO}_{2}$ sources. Earth Planet. Sci. Lett. 397, 57-66.

de la Fuente, M., Skinner, L., Calvo, E., Pelejero, C., Cacho, I., 2015. Increased reservoir ages and poorly ventilated deep waters inferred in the glacial Eastern Equatorial Pacific. Nat. Commun. 6, 7420.

De Pol-Holz, R., Keigwin, L., Southon, J., Hebbeln, D., Mohtadi, M., 2010. No signature of abyssal carbon in intermediate waters off Chile during deglaciation. Nat. Geosci. 3, 192-195.

Denton, G.H., Alley, R.B., Comer, G.C., Broecker, W.S., 2005. The role of seasonality in abrupt climate change. Quaternary Sci. Rev. 24, 1159-1182.

Dokken, T.M., Jansen, E., 1999. Rapid changes in teh mechanism of coean convection during the last glacial period. Nature 401, 458-461. 
Dokken, T.M., Nisancioglu, K.H., Li, C., Battisti, D.S., Kissel, C., 2013. Dansgaard Oeschger cycles: Interactions between ocean and sea ice intrinsic to the Nordic seas. Paleoceanography 28, 491-502.

Duplessy, J.-C., arnold, M., Bard, E., Juillet-Leclerc, A., Kallel, N., Labeyrie, L., 1989. AMS ${ }^{14} \mathrm{C}$ study of transient events and of the ventilation rte of the Pacific intermediate water during the last deglaciation. Radiocarbon 31, 493-502.

Dyke, A.S., 2004. An outline of North American deglaciation with emphasis on central and northern Canada. Developments in Quaternary Sciences 2, 373424.

Eltgroth, S.F., Adkins, J.F., Robinson, L.F., Southon, J., Kashgarian, M., 2006. A deepsea coral record of North Atlantic radiocarbon through the Younger Dryas: Evidence for intermediate water/deepwater reorganization. Paleoceanography 21, PA4207.

Eynaud, F., 2011. Planktonic foraminifera in the Arctic: potentials and issues regarding modern and quaternary populations. IOP Conference Series: Earth and Environmental Science 14, 012005.

Fairbanks, R.G., Sverdlove, M., Free, R., Wiebe, P.H., Bé, A.W.H., 1982. Vertical distribution and isotopic fractionation of living planktonic foraminifera from the Panama Basin. Nature 298, 841-844.

Fiadeiro, M.E., 1982. Three-dimensional modeling of tracers in the deep Pacific Ocean II. radiocarbon and the circulation. Jour. Mar. Res. 40, 537-550.

Fiedler, P.C., Talley, L.D., 2006. Hydrography of the eastern tropical Pacific: A review. Prog. Oceanogr. 69, 143-180.

Fischer, H., Schmitt, J., Lüthi, D., Stocker, T.F., Tschumi, T., Parekh, P., Joos, F., Köhler, P., Völker, C., Gersonde, R., 2010. The role of Southern Ocean processes in orbital and millennial CO 2 variations-A synthesis. Quat. Sci. Rev. 29, 193205.

Franke, J., Schulz, M., Paul, A., Adkins, J.F., 2008. Assessing the ability of the 14C projection - age method to constrain the circulation of the past in a 3 - D ocean model. Geochem. Geophys. Geosyst. 9, Q08003.

Freeman, E., Skinner, L.C., Tisserand, A., Dokken, T., Timmermann, A., Menviel, L., Friedrich, T., 2015. An Atlantic-Pacific ventilation seesaw across the last deglaciation. Earth Planet. Sci. Lett. 424, 237-244.

Galbraith, E.D., Jaccard, S.L., Pedersen, T.F., Sigman, D.M., Haug, G.H., Cook, M., Southon, J.R., Francois, R., 2007. Carbon dioxide release from the North Pacific abuss during the last deglaciation. Nature 449, 890-894.

Galbraith, E.D., Kwon, E.Y., Bianchi, D., Hain, M.P., Sarmiento, J.L., 2015. The impact of atmospheric $\mathrm{pCO}_{2}$ on carbon isotope ratios of the atmosphere and ocean. Global Biogeochem. Cycles 29, 307-324.

Gebbie, G., 2012. Tracer transport timescales and the observed Atlantic-Pacific lag in the timing of the Last Termination. Paleoceanography 27.

Gebbie, G., 2014. How much did Glacial North Atlantic Water shoal? Paleoceanography, doi:10.1002/2013PA002557.

Gebbie, G., Huybers, P., 2006. Meridional circulation during the Last Glacial Maximum explored through a combination of South Atlantic $\delta^{18} \mathrm{O}$ 
observations and a geostrophic inverse model. Geochem. Geophys. Geosyst. 7.

Gil, I.M., Keigwin, L.D., Abrantes, F., 2015. The deglaciation over Laurentian Fan: History of diatoms, IRD, ice and fresh water. Quat. Sci. Rev. 129, 57-67.

Goldstein, S.J., Lea, D.W., Chakraborty, S., Kashgarian, M., Murrell, M.T., 2001. Uranium-series and radiocarbon geochronology of deep-sea corals: implications for Southern Ocean ventilation rates and the oceanic carbon cycle. Earth Planet Sci. Lett. 193, 167-182.

Goodman, P.J., Hazeleger, W., de Vries, P., Cane, M., 2005. Pathways into the Pacific Equatorial Undercurrent: A trajectory analysis. J. Phys. Oceanogr. 35, 21342151.

Gorbarenko, S.A., Khusid, T.A., Basov, I.A., Oba, T., Southon, J.R., Koizumi, I., 2002. Glacial Holocene environment of the southeastern Okhotsk Sea: evidence from geochemical and palaeontological data. Palaeogeog. Palaeoclimatol. Palaeoecol. 177, 237-263.

Gorbarenko, S.A., Psheneva, O.Y., Artemova, A.V., Tiedemann, R., Nürnberg, D., 2010. Paleoenvironment changes in the NW Okhotsk Sea for the last $18 \mathrm{kyr}$ determined with micropaleontological, geochemical, and lithological data. Deep Sea Res. Part I 57, 797-811.

Gorbarenko, S.A., southon, J.R., Keigwin, L.D., Cherepanova, M.V., Gvozdeva, I.G., 2004. Late Pleistocene-Holocene oceanographic variability in the Okhotsk Sea: Geochemical, lithological and paleontological evidence. Palaeogeo., Palaeoclim., Palaeoeco. 209, 281-301.

Häggblom, A., 1982. Driftwood in Svalbard as an indicator of sea ice conditions. Geogr. Ann. A 64, 81-94.

Hain, M.P., Sigman, D.M., Haug, G.H., 2010. Carbon dioxide effects of Antarctic stratification, North Atlantic Intermediate Water formation, and subantarctic nutrient drawdown during the last ice age: Diagnosis and synthesis in a geochemical box model. Global Biogeochem. Cycles 24.

Hain, M.P., Sigman, D.M., Haug, G.H., 2011. Shortcomings of the isolated abyssal reservoir model for deglacial radiocarbon changes in the mid-depth IndoPacific Ocean. Geophys. Res. Lett. 38.

Hain, M.P., Sigman, D.M., Haug, G.H., 2014. Distinct roles of the Southern Ocean and North Atlantic in the deglacial atmospheric radiocarbon decline. Earth Planet. Sci. Lett. 394, 198-208.

Hillaire-Marcel, C., Vernal, A.d., Bilodeau, G., Weaver, A.J., 2001. Absence of deepwater formation in the Labrador Sea during the last interglacial period. Nature 410, 1073-1077.

Hines, S.K.V., Southon, J.R., Adkins, J.F., 2015. A high-resolution record of Southern Ocean intermediate water radiocarbon over the past 30,000 years. Earth Planet. Sci. Lett. 432, 46-58.

Hughen, K., Southon, J., Lehman, S., Bertrand, C., Turnbull, J., 2006. Marine-derived ${ }^{14} \mathrm{C}$ calibration and activity record for the past 50,000 years updated from the Cariaco Basin. Quat. Sci. Rev. 25, 3216-3227.

Ikehara, K., Danhara, T., Yamashita, T., Tanahashi, M., Morita, S., Ohkushi, K.i., 2011. Paleoceanographic control on a large marine reservoir effect offshore of 
Tokai, south of Japan, NW Pacific, during the last glacial maximumdeglaciation. Quat. Int. 246, 213-221.

Ikehara, K., Ohkushi, K.i., Shibahara, A., Hoshiba, M., 2006. Change of bottom water conditions at intermediate depths of the Oyashio region, NW Pacific over the past 20,000 yrs. Global Planet. Change 53, 78-91.

Ingram, B.I., Kennett, J.P., 1995. Radiocarbon chronology and planktonic-benthic foraminiferal ${ }^{14} \mathrm{C}$ age differences in Santa Barbara Basin sediments, Hole 893A. Proceedings of the Ocean Drilling Program, Scientific Results 146 (Part 2), 19-27.

Ivanov, V.V., Shapiro, G.I., Huthnance, J.M., Aleynik, D.L., Golovin, P.N., 2004. Cascades of dense water around the world ocean. Prog. Oceanogr. 60, 47-98.

Jaccard, S.L., Galbraith, E.D., Martínez-García, A., Anderson, R.F., 2016. Covariation of deep Southern Ocean oxygenation and atmospheric $\mathrm{CO}_{2}$ through the last ice age. Nature 530, 207-210.

Jonkers, L., Jiménez-Amat, P., Mortyn, P.G., Brummer, G.-J.A., 2013. Seasonal Mg/Ca variability of N. pachyderma (s) and G. bulloides: Implications for seawater temperature reconstruction. Earth Planet. Sci. Lett. 376, 137-144.

Keigwin, L., Schlegel, M., 2002. Ocean ventilation and sedimentation since the glacial maximum at $3 \mathrm{~km}$ in the western North Atlantic. Geochem. Geophys. Geosyst. $3,1-14$.

Keigwin, L.D., 2002. Late Pleistocene-Holoicene paleoceanography and ventilation of the Gulf of California. Jour. Oceanography 58, 421-432.

Keigwin, L.D., 2004. Radiocarbon and stable isotope constraints on Last Glacial Maximum and Younger Dryas ventilation in the western North Atlantic. Paleoceanography 19, PA4012, doi:4010.1029/2004PA001029.

Keigwin, L.D., Boyle, E.A., 2008. Did North Atlantic overturning halt 17,000 years ago? Paleoceanography 23, PA1101, doi:1110.1029/2007PA001500.

Keigwin, L.D., Lehman, S.J., 2015. Radiocarbon evidence for a possible abyssal front near $3.1 \mathrm{~km}$ in the glacial equatorial Pacific Ocean. Earth Planet. Sci. Lett. 425, 93-104.

Keir, R.S., 1988. On the Late Pleistocene Ocean Geochemistry and Circulation. Paleocenaography 3 413-445.

Kendall, M., Gibbons, J.D.R., 1990. Rank correlation methods. Oxford University Press, Oxford.

Key, R.M., Kozyr, A., Sabine, C.L., Lee, K., Wanninkhof, R., Bullister, J.L., Feely, R.A., Millero, F.J., Mordy, C., Peng, T.H., 2004. A global ocean carbon climatology: Results from Global Data Analysis Project (GLODAP). Global Biogeochem. Cycles 18, GB4031.

Kienast, M., Kienast, S.S., Calvert, S.E., Eglinton, T.I., Mollenhauer, G., Francois, R., Mix, A.C., 2006. Eastern Pacific cooling and Atlantic overturning circulation during the last deglaciation. Nature 443, 846-849.

Knox, F., McElroy, M.B., 1984. Changes in atmospheric $\mathrm{CO}_{2}$ : Influence of the marine biota at high latitude. Journal of Geophysical Research: Atmospheres 89, 4629-4637.

Kovanen, D.J., Easterbrook, D.J., 2002. Paleodeviations of radiocarbon marine reservoir values for the northeast Pacific. Geology 30, 243-246. 
Kozdon, R., Eisenhauer, A., Weinelt, M., Meland, M.Y., Nürnberg, D., 2009. Reassessing $\mathrm{Mg} / \mathrm{Ca}$ temperature calibrations of Neogloboquadrina pachyderma (sinistral) using paired $\delta^{44 / 40} \mathrm{Ca}$ and $\mathrm{Mg} / \mathrm{Ca}$ measurements. Geochem. Geophys. Geosyst. 10.

Lambert, F., Bigler, M., Steffensen, J.P., Hutterli, M., Fischer, H., 2012. Centennial mineral dust variability in high-resolution ice core data from Dome $\mathrm{C}$, Antarctica. Clim. Past 8, 609-623.

Lane, C.S., Brauer, A., Blockley, S.P., Dulski, P., 2013. Volcanic ash reveals timetransgressive abrupt climate change during the Younger Dryas. Geology 41, 1251-1254.

LeGrand, P., Wunsch, C., 1995. Constraints from paleotracer data on the North Atlantic circulation during the Last Glacial Maximum. Paleoceanography 10, 1011-1045.

Lindsay, C.M., Lehman, S.J., Marchitto, T.M., Ortiz, J.D., 2015. The surface expression of radiocarbon anomalies near Baja California during deglaciation. Earth Planet. Sci. Lett. 422, 67-74.

Lumpkin, R., Speer, K., 2003. Large-scale vertical and horizontal circulation in the North Atlantic Ocean. J. Phys. Oceanogr. 33, 1902-1920.

Lumpkin, R., Speer, K., 2007. Global ocean meridional overturning. J. Phys. Oceanogr. $37,2550-2562$.

Lumpkin, R., Speer, K.G., Koltermann, K.P., 2008. Transport across $48^{\circ} \mathrm{N}$ in the Atlantic Ocean. J. Phys. Oceanogr. 38, 733-752.

Lund, D.C., Asimow, P.D., 2011. Does sea level influence mid-ocean ridge magmatism on Milankovitch timescales? Geochem. Geophys. Geosyst. 12, Q12009.

Lund, D.C., Asimow, P.D., Farley, K.A., Rooney, T.O., Seeley, E., Jackson, E.W., Durham, Z.M., 2016. Enhanced East Pacific Rise hydrothermal activity during the last two glacial terminations. Science 351, 478-482.

Lund, D.C., Mix, A.C., Southon, J., 2011. Increased ventilation age of the deep northeast Pacific Ocean during the last deglaciation. Nat. Geosci. 4, 771-774.

Lund, D.C., Tessin, A.C., Hoffman, J.L., Schmittner, A., 2015. Southwest Atlantic water mass evolution during the last deglaciation. Paleoceanography 30, 477-494.

Magana, A.L., Southon, J.R., Kennett, J.P., Roark, E.B., Sarnthein, M., Stott, L.D., 2010. Resolving the cause of large differences between deglacial benthic foraminifera radiocarbon measurements in Santa Barbara Basin. Paleoceanography 25.

Mangini, A., Godoy, J.M., Godoy, M.L., Kowsmann, R., Santos, G.M., Ruckelshausen, M., Schroeder-Ritzrau, A., Wacker, L., 2010. Deep sea corals off Brazil verify a poorly ventilated Southern Pacific Ocean during H2, H1 and the Younger Dryas. Earth Planet. Sci. Lett. 293, 269-276.

Mangini, A., Lomitschka, M., Eichstädter, R., Frank, N., Vogler, S., Bonani, G., Hajdas, I., Patzold, J., 1998. Coral provides way to age deep water. Nature 392, 347-348.

Marchal, O., Curry, W.B., 2008. On the abyssal circulation in the glacial Atlantic. J. Phys. Oceanogr. 38, 2014-2037.

Marchitto, T.M., Lehman, S.J., Ortiz, J.D., Fluckiger, J., van Geen, A., 2007. Marine radiocarbon evidence for the mechanism of deglacial atmospheric $\mathrm{CO}_{2}$ rise. Science 316, 1456-1459. 
Marcott, S.A., Bauska, T.K., Buizert, C., Steig, E.J., Rosen, J.L., Cuffey, K.M., Fudge, T.J., Severinghaus, J.P., Ahn, J., Kalk, M.L., 2014. Centennial-scale changes in the global carbon cycle during the last deglaciation. Nature 514, 616-619.

Marshall, J., Schott, F., 1999. Open-ocean convection: Observations, theory, and models. Rev. Geophys. 37, 1-64.

Marshall, J., Speer, K., 2012. Closure of the meridional overturning circulation through Southern Ocean upwelling. Nat. Geosci. 5, 171-180.

Martínez-Botí, M.A., Marino, G., Foster, G.L., Ziveri, P., Henehan, M.J., Rae, J.W.B., Mortyn, P.G., Vance, D., 2015. Boron isotope evidence for oceanic carbon dioxide leakage during the last deglaciation. Nature 518, 219-222.

Martínez-García, A., Sigman, D.M., Ren, H., Anderson, R.F., Straub, M., Hodell, D.A., Jaccard, S.L., Eglinton, T.I., Haug, G.H., 2014. Iron fertilization of the Subantarctic Ocean during the last ice age. Science 343, 1347-1350.

Maser, C., Tarrant, R.F., Trappe, J.M., Franklin, J.F., 1988. From the forest to the sea: a story of fallen trees Gen. Tech. Rep. PNW-GTR-229, US Dept. of Agriculture, Forest Service.

Max, L., Lembke-Jene, L., Riethdorf, J.-R., Tiedemann, R., Nürnberg, D., Kühn, H., Mackensen, A., 2014. Pulses of enhanced North Pacific Intermediate Water ventilation from the Okhotsk Sea and Bering Sea during the last deglaciation. Clim. Past 10, 591-605.

McKay, J.L., Pedersen, T.F., Southon, J., 2005. Intensification of the oxygen minimum zone in the northeast Pacific off Vancouver Island during the last deglaciation: Ventilation and/or export production? Paleoceanography 20.

McManus, J.F., Francois, R., Gherardi, J.-M., Keigwin, L.D., Brown-Leger, S., 2004. Collapse and rapid resumption of Atlantic meridional circulation linked to deglacial climate changes. Nature 428, 834-837.

McNichol, A.P., Jull, A.J.T., Burr, G.S., 2001. Converting AMS data to radiocarbon values: considerations and conventions. Radiocarbon 43, 313-320.

Meland, M.Y., Dokken, T.M., Jansen, E., Hevrøy, K., 2008. Water mass properties and exchange between the Nordic seas and the northern North Atlantic during the period 23-6 ka: Benthic oxygen isotopic evidence. Paleoceanography 23.

Minoshima, K., Kawahata, H., Irino, T., Ikehara, K., Aoki, K., Uchida, M., Yoneda, M., Shibata, Y., 2007. Deep water ventilation in the northwestern North Pacific during the last deglaciation and the early Holocene (15-5 cal. kyr B. P.) based on AMS ${ }^{14} \mathrm{C}$ dating. Nuclear Instruments and Methods in Physics Research Section B: Beam Interactions with Materials and Atoms 259, 448-452.

Mix, A.C., Lund, D.C., Pisias, N.G., Boden, P., Bornmalm, L., Lyle, M., Pike, J., 1999. Rapid climate oscillations in the northeast Pacific during the last deglaciation reflect northern and southern hemisphere sources, In: Clark, P.U., Webb, R.S., Keigwin, L.D. (Eds.), Mechanisms of global climate change at millennial time scales. American Geophysical Union, Washington, D. C., pp. 127-148.

Monnin, E., Indermühle, A., Dällenbach, A., Flückiger, J., Stauffer, B., Stocker, T.F., Raynaud, D., Barnola, J.-M., 2001. Atmospheric $\mathrm{CO}_{2}$ concentrations over the last glacial termination. Science 291, 112-114.

Muscheler, R., Beer, J., Wagner, G., Laj, C., Kissel, C., Raisbeck, G.M., Yiou, F., Kubik, P.W., 2004. Changes in the carbon cycle during the last deglaciation as 
indicated by the comparison of ${ }^{10} \mathrm{Be}$ and ${ }^{14} \mathrm{C}$ records. Earth Planet. Sci. Lett. 219, 325-340.

Ninnemann, U.S., Charles, C.D., 1997. Regional differences in Quaternary Subantarctic nutrient cycling: Link to intermediate and deep water ventilation. Paleoceanography 12, 560-567.

Okazaki, Y., Kimoto, K., Asahi, H., Sato, M., Nakamura, Y., Harada, N., 2014. Glacial to deglacial ventilation and productivity changes in the southern Okhotsk Sea. Palaeogeog. Palaeoclimatol. Palaeoecol. 395, 53-66.

Okazaki, Y., Sagawa, T., Asahi, H., Horikawa, K., Onodera, J., 2012. Ventilation changes in the western North Pacific since the last glacial period. Clim. Past 8, 17-24.

Okazaki, Y., Timmermann, A., Menviel, L., Harada, N., Abe-Ouchi, A., Chikamoto, M.O., Mouchet, A., Asahi, H., 2010. Deepwater formation in the North Pacific during the last glacial termination. Science 329, 200-204.

Oppo, D.W., Fairbanks, R.G., 1989. Carbon isotope composition of tropical surface water during the past 22,000 years. Paleoceanography 4, 333-351.

Pahnke, K., Sachs, J.P., Keigwin, L., Timmermann, A., Xie, S.-P., 2007. Eastern tropical Pacific hydrologic changes during the past 27,000 years from $\mathrm{D} / \mathrm{H}$ ratios in alkenones. Paleoceanography 22, PA4214.

Parrenin, F., Masson-Delmotte, V., Köhler, P., Raynaud, D., Paillard, D., Schwander, J., Barbante, C., Landais, A., Wegner, A., Jouzel, J., 2013. Synchronous change of atmospheric $\mathrm{CO}_{2}$ and Antarctic temperature during the last deglacial warming. Science 339, 1060-1063.

Pearce, C., Seidenkrantz, M.-S., Kuijpers, A., Massé, G., Reynisson, N.F., Kristiansen, S.M., 2013. Ocean lead at the termination of the Younger Dryas cold spell. Nat. Commun. 4, 1664, doi:1610.1038/ncomms2686.

Pena, L.D., Cacho, I., Ferretti, P., Hall, M.A., 2008. El Niño-Southern Oscillation-like variability during glacial terminations and interlatitudinal teleconnections. Paleoceanography 23, PA3101.

Pena, L.D., Goldstein, S.L., Hemming, S.R., Jones, K.M., Calvo, E., Pelejero, C., Cacho, I., 2013. Rapid changes in meridional advection of Southern Ocean intermediate waters to the tropical Pacific during the last 30 kyr. Earth Planet. Sci. Lett. $368,20-32$.

Peterson, L.C., Haug, G.H., Hughen, K.A., Röhl, U., 2000. Rapid changes in the hydrologic cycle of the tropical Atlantic during the last glacial. Science 290, 1947-1951.

Pickart, R.S., Spall, M.A., Ribergaard, M.H., Moore, G.K., Milliff, R.F., 2003. Deep convection in the Irminger Sea forced by the Greenland tip jet. Nature 424, 152-156.

Poveda, G., Mesa, O.J., 2000. On the existence of Lloró (the rainiest locality on Earth): Enhanced ocean-land-atmosphere interaction by a low-level jet. Geophys. Res. Lett. 27, 1675-1678.

Rae, J.W.B., Sarnthein, M., Foster, G.L., Ridgwell, A., Grootes, P.M., Elliott, T., 2014. Deep water formation in the North Pacific and deglacial $\mathrm{CO}_{2}$ rise. Paleoceanography 29, 645-667.

Rasmussen, S.O., Andersen, K.K., Svensson, A., Steffensen, J.P., Vinther, B.M., Clausen, H.B., Siggaard-Andersen, M.L., Johnsen, S.J., Larsen, L.B., Dahl-Jensen, D., 
Bigler, M., Röthlisberger, R., Fischer, H., Goto-Azuma, K., Hansson, M.E., Ruth, U., 2006. A new Greenland ice core chronology for the last glacial termination. J. Geophys. Res. 111, D06102.

Rasmussen, S.O., Seierstad, I.K., Andersen, K.K., Bigler, M., Dahl-Jensen, D., Johnsen, S.J., 2008. Synchronization of the NGRIP, GRIP, and GISP2 ice cores across MIS 2 and palaeoclimatic implications. Quat. Sci. Rev. 27, 18-28.

Rayner, D., Hirschi, J.J.M., Kanzow, T., Johns, W.E., Wright, P.G., Frajka-Williams, E., Bryden, H.L., Meinen, C.S., Baringer, M.O., Marotzke, J., 2011. Monitoring the Atlantic meridional overturning circulation. Deep Sea Res. Part II 58, 17441753.

Reimer, P.J., Bard, E., Bayliss, A., Beck, J.W., Blackwell, P.G., Ramsey, C.B., Grootes, P.M., Guilderson, T.P., Haflidason, H., Hajdas, I., 2013. IntCal13 and Marine13 radiocarbon age calibration curves $0-50,000$ years cal BP. Radiocarbon 55, 1869-1887.

Rhodes, R.H., Brook, E.J., Chiang, J.C.H., Blunier, T., Maselli, O.J., McConnell, J.R., Romanini, D., Severinghaus, J.P., 2015. Enhanced tropical methane production in response to iceberg discharge in the North Atlantic. Science 348, 1016-1019.

Robinson, L.F., Adkins, J.F., Fernandez, D.P., Burnett, D.S., Wang, S.L., Gagnon, A.C., Krakauer, N., 2006. Primary U distribution in scleractinian corals and its implications for U series dating. Geochem. Geophys. Geosyst. 7.

Robinson, L.F., Adkins, J.F., Keigwin, L.D., Southon, J., Fernandez, D.P., Wang, S., Scheirer, D.S., 2005. Radiocarbon variability in the western North Atlantic during the last deglaciation. Science 310, 1469-1473.

Robinson, L.F., van de Flierdt, T., 2009. Southern Ocean evidence for reduced export of North Atlantic Deep Water during Heinrich event 1. Geology 37, 195-198.

Rose, K.A., Sikes, E.L., Guilderson, T.P., Shane, P., Hill, T.M., Zahn, R., Spero, H.J., 2010. Upper-ocean-to-atmosphere radiocarbon offsets imply fast deglacial carbon dioxide release. Nature 466, 1093-1097.

Sarmiento, J.L., Gruber, N., 2006. Ocean Biogeochemical Dynamics. Princeton University Press, Princeton, N.J., U.S.A.

Sarmiento, J.L., Gruber, N., Brzezinski, M.A., Dunne, J.P., 2004. High-latitiude controls of thermocline nutrients and low latitude biological productivity. Nature 427, 56-60.

Sarmiento, J.L., Toggweiler, J.R., 1984. A new model for the role of the oceans in determining atmospheric $\mathrm{pCO}_{2}$. Nature 308, 621-624.

Sarnthein, M., Grootes, P.M., Kennett, J.P., Nadeau, M.J., 2007. ${ }^{14} \mathrm{C}$ reservoir ages show deglacial changes in ocean currents and carbon cycle, In: Schmittner, A., Chiang, J.C.H., Hemming, S.R. (Eds.), Ocean Circulation: Mechanisms and Impacts-Past and Future Changes of Meridional Overturning. AGU Geophysical Monograph Series vol. 173, American Geophysical Union, Washington, DC, pp. 175-196.

Sarnthein, M., Kiefer, T., Grootes, P.M., Elderfield, H., Erlenkeuser, H., 2006. Warmings in the far northwestern Pacific promoted pre-Clovis immigration to America curing heinrich event 1. Geology. 
Sarnthein, M., Schneider, B., Grootes, P.M., 2013. Peak glacial ${ }^{14} \mathrm{C}$ ventilation ages suggest major draw-down of carbon into the abyssal ocean. Clim. Past 9, 2595-2614.

Schmitt, J., Schneider, R., Elsig, J., Leuenberger, D., Lourantou, A., Chappellaz, J., Köhler, P., Joos, F., Stocker, T.F., Leuenberger, M., 2012. Carbon isotope constraints on the deglacial $\mathrm{CO}_{2}$ rise from ice cores. Science 336, 711-714.

Schmittner, A., Lund, D.C., 2015. Early deglacial Atlantic overturning decline and its role in atmospheric $\mathrm{CO}_{2}$ rise inferred from carbon isotopes $\left(\delta^{13} \mathrm{C}\right)$. Clim. Past $11,135-152$.

Schott, F.A., Zantopp, R., Stramma, L., Dengler, M., Fischer, J., Wibaux, M., 2004. Circulation and deep-water export at the western exit of the subpolar North Atlantic. J. Phys. Oceanogr. 34, 817-843.

Schwabe, E., Bartsch, I., Błażewicz-Paszkowycz, M., Brenke, N., Chernyshev, A.V., Elsner, N.O., Fischer, V., Jażdżewska, A., Malyutina, M.V., Miljutin, D., 2015. Wood-associated fauna collected during the KuramBio expedition in the North West Pacific. Deep Sea Res. Part II 111, 376-388.

Shackleton, N.J., Duplessy, J.C., Arnold, M., Maurice, P., Hall, M.A., Cartlidge, J., 1988. Radiocarbon age of last glacial Pacific deep water. Nature 335, 708-711.

Shackleton, N.J., Hall, M.A., Line, J., Shuxi, C., 1983. Carbon isotope data in core V1930 confirm reduced carbon dioxide concentration in the ice age atmosphere. Nature 306, 319-322.

Shakun, J.D., Clark, P.U., He, F., Marcott, S.A., Mix, A.C., Liu, Z., Otto-Bliesner, B., Schmittner, A., Bard, E., 2012. Global warming preceded by increasing carbon dioxide concentrations during the last deglaciation. Nature 484, 49-54.

Siani, G., Michel, E., De Pol-Holz, R., DeVries, T., Lamy, F., Carel, M., Isguder, G., Dewilde, F., Lourantou, A., 2013. Carbon isotope records reveal precise timing of enhanced Southern Ocean upwelling during the last deglaciation. Nat. Commun. 4.

Siegenthaler, U., Wenk, T., 1984. Rapid atmospheric $\mathrm{CO}_{2}$ variations and ocean circulation. Nature 308, 624-626.

Sigman, D.M., Boyle, E.A., 2000. Glacial/interglacial variations in atmospheric carbon dioxide. Nature 407, 859-869.

Sigman, D.M., Hain, M.P., Haug, G.H., 2010. The polar ocean and glacial cycles in atmospheric $\mathrm{CO}_{2}$ concentration. Nature 466, 47-55.

Sigman, D.M., McCorkle, D.C., Martin, W.R., 1998. The calcite lysocline as a constraint on glacial/interglacial low-latitude production changes. Global Biogeochem. Cycles 12, 409-427.

Sikes, E.L., Guilderson, T.P., 2016. Southwest Pacific Ocean surface reservoir ages since the last glaciation: Circulation insights from multiple-core studies. Paleoceanography 31, 298-310.

Sikes, E.L., Samson, C.R., Guilderson, T.P., Howard, W.R., 2000. Old radiocarbon ages in the southwest Pacific Ocean during last glacial period and deglaciation. Nature 405.

Simstich, J., Sarnthein, M., Erlenkeuser, H., 2003. Paired $\delta^{18} 0$ signals of Neogloboquadrina pachyderma (s) and Turborotalita quinqueloba show 
thermal stratification structure in Nordic Seas. Mar. Micropaleontol. 48, 107125.

Skinner, L., McCave, I.N., Carter, L., Fallon, S., Scrivner, A.E., Primeau, F., 2015. Reduced ventilation and enhanced magnitude of the deep Pacific carbon pool during the last glacial period. Earth Planet. Sci. Lett. 411, 45-52.

Skinner, L.C., 2009. Glacial-interglacial atmospheric $\mathrm{CO}_{2}$ change: a possible" standing volume" effect on deep-ocean carbon sequestration. Clim. Past 5, 537-550.

Skinner, L.C., Fallon, S., Waelbroeck, C., Michel, E., Barker, S., 2010. Ventilation of the deep Southern Ocean and deglacial $\mathrm{CO}_{2}$ rise. Science 328, 1147-1151.

Skinner, L.C., Shackleton, N.J., 2004. Rapid transient changes in northeast Atlantic deep water ventilation age across Termination I. Paleoceanography 19.

Skinner, L.C., Waelbroeck, C., Scrivner, A.E., Fallon, S.J., 2014. Radiocarbon evidence for alternating northern and southern sources of ventilation of the deep Atlantic carbon pool during the last deglaciation. Proc. Nat. Acad. Sci. 111, 5480-5484.

Sortor, R.N., Lund, D.C., 2011. No evidence for a deglacial intermediate water $\Delta^{14} \mathrm{C}$ anomaly in the SW Atlantic. Earth Planet. Sci. Lett. 310, 65-72.

Soulet, G., Skinner, L.C., Beaupré, S.R., Galy, V., 2016. A note on reporting of reservoir ${ }^{14} \mathrm{C}$ disequilibria and age offsets. Radiocarbon 58, 205-211.

Southon, J.R., Nelson, D.E., Vogel, J.S., 1990. A record of past ocean-atmosphere radiocarbon differences from the northeast Pacific. Paleoceanography 5, 197206.

Spero, H.J., Lea, D.W., 2002. The cause of carbon isotope minimum events on glacial terminations. Science 296, 522-525.

Stephens, B.B., Keeling, R.F., 2000. The influence of Antarctic sea ice on glacialinterglacial $\mathrm{CO}_{2}$ variations. Nature 404, 171-174.

Stern, J.V., Lisiecki, L.E., 2013. North Atlantic circulation and reservoir age changes over the past 41,000 years. Geophys. Res. Lett. 40, 1-5.

Stott, L., Southon, J., Timmermann, A., Koutavas, A., 2009. Radiocarbon age anomaly at intermediate water depth in the Pacific Ocean during the last deglaciation. Paleoceanography 24, PA2223.

Stott, L., Timmermann, A., 2011. Hypothesized link between glacial/interglacial atmospheric $\mathrm{CO}_{2}$ cycles and storage/release of $\mathrm{CO}_{2}$-rich fluids from deep-sea sediments, In: Rashid, H., Polyak, L., Mosley-Thompson, E. (Eds.), Abrupt Climate Change: Mechanisms, Patterns, and Impacts. AGU Geophysical Monograph Series vol. 193, American Geophysical Union, Washington, DC, pp. 123-138.

Stuiver, M., Grootes, P.M., 2000. GISP2 oxygen isotope ratios. Quat. Res. 53, 277-284.

Tarasov, L., Peltier, W.R., 2005. Arctic freshwater forcing of the Younger Dryas cold reversal. Nature 435, 662-665.

Teller, J.T., Leverington, D.W., Mann, J.D., 2002. Freshwater outbursts to the oceans from glacial Lake Agassiz and their role in climate change during the last deglaciation. Quaternary Sci. Rev. 21, 879-887.

Thornalley, D.J., Barker, S., Broecker, W.S., Elderfield, H., McCave, I.N., 2011a. The deglacial evolution of North Atlantic deep convection. Science 331, 202-205. 
Thornalley, D.J.R., Barker, S., Broecker, W.S., Elderfield, H., McCave, I.N., 2011b. The deglacial evolution of North Atlantic deep convection. Science 331, 202-205.

Thornalley, D.J.R., Bauch, H.A., Gebbie, G., Guo, W., Ziegler, M., Bernasconi, S.M., Barker, S., Skinner, L.C., Yu, J., 2015. A warm and poorly ventilated deep Arctic Mediterranean during the last glacial period. Science 349, 706-710.

van Geen, A., Fairbanks, R. G., Dartnell, P., McGann, M., Gardner, J. V., and Kashgarian, M., 1996. Ventilation changes in the northeast Pacific during the last deglaciation. Paleoceanography 11, 519-528.

Waelbroeck, C., Skinner, L.C., Labeyrie, L., Duplessy, J.C., Michel, E., Vazquez Riveiros, N., Gherardi, J.M., Dewilde, F., 2011. The timing of deglacial circulation changes in the Atlantic. Paleoceanography 26.

Wang, X., Auler, A.S., Edwards, R.L., Cheng, H., Cristali, P.S., Smart, P.L., Richards, D.A., Shen, C.-C., 2004. Wet periods in northeastern Brazil over the past $210 \mathrm{kyr}$ linked to distant climate anomalies. Nature 432, 740-743.

Wang, Y.J., Cheng, H., Edwards, r.L., An, Z.S., Wu, J.Y., Shen, C.-C., Dorale, J.A., 2001. A high-resolution absolute-dated late Pleistocene monsoon record from Hulu Cave, China. Science 294, 2345-2348.

Weldeab, S., Friedrich, T., Timmermann, A., Schneider, R.R., 2016. Strong middepth warming and weak radiocarbon imprints in the equatorial Atlantic during Heinrich 1 and Younger Dryas. Paleoceanography 31, 1070-1082.

Winckler, G., Anderson, R.F., Jaccard, S.L., Marcantonio, F., 2016. Ocean dynamics, not dust, have controlled equatorial Pacific productivity over the past 500,000 years. Proc. Nat. Acad. Sci. 113, 6119-6124.

Wunsch, C., 2003. Determining paleoceanographic circulations, with emphasis on the Last Glacial Maximum. Quat. Sci. Rev. 22, 371-385.

Wunsch, C., 2006. Discrete inverse and state estimation problems: with geophysical fluid applications. Cambridge University Press, Cambridge, U.K. 